\title{
Gap junctions in the $C$. elegans nervous system regulate ageing and lifespan
}

Nathalie Alexandra Vladis ${ }^{1,2}$, Katharina Elisabeth Fischer ${ }^{1,2}$, Eva Digalaki ${ }^{1}$, Daniel-Cosmin Marcu ${ }^{1}$, Modestos Nakos Bimpos ${ }^{1}$, Peta Greer ${ }^{1}$, Alice Ayres ${ }^{1}$, Qiaochu Li $^{1}$ and Karl Emanuel Busch $^{1 *}$

${ }^{1}$ Centre for Discovery Brain Sciences, Edinburgh Medical School: Biomedical Sciences, The University of Edinburgh, Hugh Robson Building, George Square, Edinburgh EH16 5JB, UK

${ }^{2}$ these authors contributed equally to this work

*Correspondence should be addressed to K.E.B. (emanuel.busch@ed.ac.uk) 


\section{Abstract}

The nervous system is a central regulator of longevity, but how neuronal communication interfaces with ageing pathways is not well understood. Gap junctions are key conduits that allow voltage and metabolic signal transmission across cellular networks, yet it has remained unexplored whether they play a role in regulating ageing and longevity. We show that the innexin genes encoding gap junction subunits in Caenorhabditis elegans have extensive and diverse impacts on lifespan. Loss of the neural innexin unc-9 increases longevity by a third and also strongly benefits healthspan. Unc- 9 acts specifically in a glutamatergic circuit linked to mechanosensation. Absence of unc-9 depends on a functional touch-sensing machinery to regulate lifespan and alters the age-dependent decline of mechanosensory neurons. The life extension produced by removal of unc- 9 requires reactive oxygen species. Our work reveals for the first time that gap junctions are important regulators of ageing and lifespan. 


\section{Introduction}

The nervous system is a central regulator of ageing and lifespan ${ }^{1}$. Nerve cells need to sustain their internal homeostasis throughout life to maintain neural function and behavior. However, as their electrical activity is energetically and metabolically demanding, they become vulnerable to the resulting physiological stress ${ }^{2}$. Loss of cellular homeostasis, such as of $\mathrm{Ca}^{2+}$ levels, redox balance or energy state, contribute to neuronal dysfunction and neurodegeneration and play an essential role in ageing processes ${ }^{3}$. However, it is not well understood how cellular homeostasis processes interface with and signal to other cells and tissues to regulate ageing in a non-cell-autonomous way. The nexus of how age-dependent cellular and physiological changes impinge on and relate to the processes controlling lifespan also remains largely unexplained ${ }^{4}$.

Gap junctions are unique and ubiquitous intercellular conduits that play fundamental roles in the development and physiology of animals ${ }^{5,6}$. They are formed by channels on the plasma membrane of two adjacent cells that dock onto each other, allowing the direct transmission of voltage signals between the coupled cells ${ }^{7}$. They functionally join the cytoplasm of the two cells and thus also other small molecules such as second messengers or metabolites can passage through them, allowing biochemical or metabolic coupling ${ }^{8}$. Gap junctions are abundant in the nervous systems where they function as electrical synapses, and are critical for higher-order neural functions such as synchronicity, oscillatory activity or coincidence detection ${ }^{9}$. Conversely, gap junction coupling can also have pathogenic consequences and is responsible for the propagation of cellular injury or death signals to "bystander" cells ${ }^{10-12}$. For example, an injury-mediated increase in neuronal gap junction coupling is part of the mechanism causing excitotoxicity and neuronal death ${ }^{13}$. However, it 
is currently unknown whether gap junction coupling as a key intercellular communication channel contributes to the regulation of ageing and longevity.

Here we set out to explore if gap junctions affect ageing using the nematode Caenorhabditis elegans, an outstanding model for studies on ageing ${ }^{14,15}$. We assayed the lifespan of loss-offunction mutants of most of the 25 C. elegans innexins and discovered that innexins have a significant impact on lifespan, some leading to an extension of lifespan while others shorten it. Surprisingly, most null mutations of neural innexins extended lifespan, with loss of unc-9, the most widely expressed innexin in the nervous system, increasing longevity by a third. Its selective removal from glutamatergic neurons led to an increase in lifespan and points to a mechanosensory circuit where UNC-9 regulates ageing. Our results show that UNC-9 alters the age-dependent decline of touch-sensing neurons and depends on functional touch sensation as well as reactive oxygen species to modulate lifespan. This study gives strong evidence to suggest an important and previously unknown role for gap junction intercellular communication in shaping ageing and longevity.

\section{Results}

\section{The $C$. elegans gap junction genes regulate longevity}

As there is extensive intercellular gap junction coupling in all organs of $C$. elegans, we hypothesised that gap junction channels may play specific roles in organismal ageing and longevity. The channel subunits encoded by 25 innexin genes show diverse, highly combinatorial, plastic and dynamic expression in virtually all organs and cells of this animal. The gap junction channels these innexins form play key roles in intercellular 
communication $^{16-18}$. We asked if innexins influence longevity, which has not been known. To this end we performed lifespan assays in loss-of-function mutants of all innexins except inx3, inx-12 and inx-13; these genes are essential for embryonic development or osmoregulation and their loss confers a lethal phenotype ${ }^{18,19}$. Loss-of-function mutants are available for all remaining 22 innexins and most of them are putative null alleles (Supplementary Table 1). Lifespan assays were conducted under standard conditions at $20^{\circ} \mathrm{C}$. We found that innexins have profound and distinct impacts on lifespan (Fig. 1; Fig. 2; Supplementary Table 2; Supplementary Fig. 1). The effect of the mutants on lifespan differed widely, ranging from inx-6, which reduced lifespan by a third, to unc- 9 , which expanded it by the same length. Not only the magnitude of the effects differed, but also their shape; for example, loss of inx-2 generally shifted the survival curve to the right, while the positive effect of the inx-15 mutation on lifespan was seen predominantly in the longlived segment of the population (Fig. 1e,o). Four innexin mutants, inx-5, inx-7, inx-10 and inx-16, had no significant effect on lifespan (Fig. 1; Fig. 2). Six innexin mutants showed reduced lifespan, namely eat-5, che-7, inx-6, inx-8, inx-21 and inx-22. This indicates that the functions conferred by these innexins is necessary to achieve normal lifespan in N2 wildtype animals. To our surprise, twelve innexin mutants extended lifespan, constituting the largest group in the assay (Fig. 2). This indicates that the presence of these innexins in $C$. elegans reduces longevity.

Overall, our results demonstrate that the innexin gene family in C. elegans has extensive and diverse effects on lifespan. 


\section{The effects of innexins on lifespan correlate with their tissue expression patterns}

Given that the mutants of different innexins have distinct effects on longevity, we sought to compare these effects with the expression patterns and known functions of these genes, based on the literature (Fig. 2). C. elegans gap junctions have a plethora of functions in all organs, with different groups of innexins being expressed in each of them ${ }^{18,20}$.

Some of the most striking effects of innexin mutants were seen in those important for food intake in the pharynx. EAT-5 and INX-6 regulate synchronised muscle contractions in the pharynx and their mutations are defective in feeding ${ }^{21,22}$. We found that their mutants have the shortest lifespan observed in the assay (Fig. 2). The eat-5 mutants developed slowly and remained frail and small until their death. Similarly, inx-6 mutants had overall poor health.

Apart from the pharyngeal pumping-defective eat-5 and inx-6, mutants of innexins with expression in the alimentary canal generally had increased longevity. The absence of inx-15, which is expressed only in the intestine, strongly increased lifespan; no phenotypes had been reported for inx-15 previously. $\ln x-11$ and inx-20 are expressed in the pharynx muscles and hindgut and inx-11 additionally in the intestine; their mutations also extended lifespan. No defects in pharynx function have been reported for them. INX-16 promotes intestinal muscle contractions by propagating $\mathrm{Ca}^{2+}$ waves between cells, and its mutant has defective defecation and constipation ${ }^{23}$; we did not observe a change of lifespan in inx-16, however.

The innexins that function in the reproductive system show opposing effects on lifespan. While mutants of two innexins primarily expressed in the germline, inx-21 and inx-22, shortened lifespan, loss of inx-14 significantly increased it. Inx-8 and inx-9, which are 
expressed in the somatic gonad, also had opposing effects on lifespan, with the inx-8 mutant reducing lifespan, while inx-9 mutants lived longer.

Most remarkably, 8 out of 12 innexin mutants with a positive effect on lifespan are expressed in the nervous system, with intestinal inx-15 as the primary exception. Conversely, of the innexins with significant neural expression, only che-7 mutants had a reduced lifespan (Fig. 2). Che-7 mutants are defective in chemotaxis ${ }^{24}$. Unc-9 and unc-7 have several functional roles in the nervous system, including in regulating locomotion, and inx19 is required for cell fate determination ${ }^{16,17,25-28}$. All three mutants significantly increased longevity.

The neural innexins show a high degree of overlap with those expressed in the body wall muscles and the pharyngeal nervous system. Of the six innexins that contribute to the electrical coupling of body wall muscles ${ }^{29}$, four mutants show lifespan expansion, namely inx-1, inx-11, inx-18 and unc-9. All of them also have neural expression. Likewise, the innexins expressed in pharynx neurons are all present in the somatic nervous system as well ${ }^{20}$. This precludes assigning specific roles for innexins in either organ in regulating lifespan. The only innexin widely expressed in glia, inx-5, did not affect lifespan. Together, we conclude that despite the highly combinatorial expression of the gap junction gene family in C. elegans, the change in lifespan exerted by many innexin mutants aligns with their expression patterns and functional domains. 


\section{unc-9 regulates longevity in the same pathway as unc-7 innexin and unc-1 stomatin}

It is highly surprising that loss-function mutants of most innexins expressed in the nervous system prolonged lifespan, as it suggests that the intercellular coupling provided by the gap junctions they form has a negative impact on longevity. To explore this further, we focussed on the innexin unc-9, whose canonical putative null mutation $e 101^{30,31}$ showed the strongest increase in lifespan in our assay (Fig.1; Fig. 2; Supplementary Table 2). Unc-9 is expressed in 97 of 104 somatic neuron classes. In addition, it is expressed in pharyngeal neurons and most muscles ${ }^{18,20}$. To confirm that the long life of $e 101$ mutants is caused by the absence of unc- 9 , we tested a second allele, $f c 16$, a putative null mutation ${ }^{31}$ (Supplementary Table 1). This mutant showed significantly prolonged lifespan as well (Fig. 3a). We also created a transgenic rescue line that bears a fosmid containing the unc- 9 locus in the $e 101$ mutant background. We confirmed that this line indeed rescues unc- 9 function by placing worms in liquid medium and counting the number of lateral swimming movements (Supplementary Fig. 2). Lifespan of this strain was significantly shorter than that of the mutant and resembled that of the N2 wild-type control, indicating that it is indeed the loss of unc-9 which increases longevity (Fig. 3b).

The functions of UNC-9 in the nervous system appear to be closely linked to those of another innexin, UNC-7. UNC-7 has the highest amino acid sequence similarity to UNC-9, and unc-7 mutants phenocopy the locomotion defect of unc-9 mutants; both co-localise extensively in the nervous system. UNC-9 and UNC-7 are thought to form heterotypic gap junctions which can act as rectifying electrical synapses, especially in interneuronmotoneuron pairs to generate the undulatory wave in locomotion, and control direction of movement $25,26,32,33$. We therefore wanted to test if unc-9 and unc-7 cooperate in the 
regulation of longevity and compared the lifespan of unc-9 single and unc-9 unc-7 double mutants. As they did not show additive lifespan extension, we suggest that both innexins act in the same pathway to modulate longevity (Fig. 3c).

The stomatin-like integral membrane protein UNC-1 is specifically required for the function of gap junctions formed by UNC-934. Unc-1 loss of function mutants display the same uncoordinated locomotion phenotype as animals lacking unc- $9^{35}$. The protein colocalises with UNC-9 and is thought to regulate the gating of the gap junction channels it forms, with the channels being in a closed state when UNC-1 is absent. We therefore sought to test if the absence of unc-1 also affects ageing. We found that the putative null mutation unc1(e719) strongly extends lifespan, in a nearly identical manner as the unc-9 null mutation does (Fig. 3d). In contrast, the dominant gain-of-function unc-1(e1598) allele had the opposite effect and significantly reduced the mutant's longevity compared to N2 (Fig. 3e). If the gain-of-function form of UNC-1 shortens lifespan by acting via UNC-9, we would expect this effect to disappear in a double mutant bearing both the unc-1 gain-of-function and the unc-9 loss-of-function alleles. We observed that lifespan of this double mutant resembles that of unc-9 mutants alone and is significantly longer than that of both N2 and the unc-1 gain-of-function mutants (Fig. 3e). Therefore, unc-9(e101) is epistatic to unc-1(e1598) in the control of lifespan.

These results together support a model where functional intercellular coupling by UNC-9/ UNC-7 gap junction channels reduces the lifespan of $C$. elegans. 


\section{Lack of the unc- 9 innexin also improves healthy ageing of $C$. elegans}

Although lifespan is an excellent proxy for the rate of ageing, ageing is a broader process and encompasses also the progressive decline of the physiological functions of an organism over its lifetime ${ }^{36,37}$. This decline is conveyed by the concept of 'healthspan', which is the proportion of life spent in a healthy state ${ }^{38}$. Genetic pathways that modulate lifespan of $C$. elegans have divergent effects on healthspan, with some mutants such as daf- 2 increasing healthspan, while others reduce healthy ageing ${ }^{39,40}$. We therefore sought to measure whether the mutants of unc-9 are not only long-lived but also associated with increased healthspan. Because of the predominantly neural expression of unc-9, we measured indicators for the progressive functional decline of the nervous system with age, namely locomotion, responsiveness to touch, pharyngeal pumping and defecation.

First, we measured the change in locomotory speed with age, a well-documented indicator for the decline of physical function $38,41,42$. To separate the ageing effect of unc- 9 from the general uncoordinated locomotory defect caused by these mutants, we normalised speed relative the maximum locomotory speed observed in day 3 adults, as done previously for daf-2 mutants, which also affect locomotion ${ }^{42}$. We found that the decline of locomotory speed in ageing worms is significantly delayed in unc-9 mutants and that the animals perform consistently better than wild type until the end of their lives (Fig. 4a). We used locomotory activity to compare the healthspan (defined as the period with $>50 \%$ of maximal activity) ratio of unc-9(e101) and N2 wild-type worms, following established procedure ${ }^{40,43}$. Healthspan was extended by 6.4 days in the innexin mutant (11.7d in unc-9(e101), 5.3d in N2), a ratio of 2.2 (Fig. 4a). Our results suggest that loss of unc-9 increased healthspan more than twofold compared with wild type. As a second comparison, we integrated the areas 
under the relative locomotory speed curves as an indicator of overall behavioural performance, as done previously ${ }^{40}$; here, unc- 9 mutants showed a 1.8 -fold increase over N2 wild-type animals (10.92 vs. 6.19). Thus, according to either measure, the increased relative locomotory speed is considerably higher than the increase in median lifespan (37\%).

To gauge the qualitative decline of sensory responses with age, we then measured mechanosensory responsiveness of animals to harsh touch. Both N2 wild-type and unc-9 mutant animals remained fully responsive until day 10 . In older worms, the ability to respond to touch was greater and more persistent in the absence of unc-9, while N2 declined significantly faster than the innexin mutants (Fig. 4b). Half-maximal responses in the mutant were reached 6.8 days later than in controls, expanding healthspan of this parameter for the same length as the increase in median lifespan (26 vs. 19 days in unc9(e101) and N2).

Another key physiological process that shows age-related dysfunction is defecation. The frequency of defecation cycles, which are highly stereotypic and periodic in young $C$. elegans, reduces significantly in ageing worms ${ }^{44}$. We found that the decline in defecation cycle length is considerably and significantly slower in unc-9 mutants (Fig. 4c). In young adults, unc-9 defecate at slightly but significantly lower frequency than N2 (59s vs. 53s, $p<0.0001$ ), but at all later time points N2 defecate less frequently.

We also measured pharyngeal pumping, which indicates feeding activity and is also subject to age-dependent decline ${ }^{45}$. In young and middle-aged adults, pumping rates were virtually identical between N2 and unc-9 mutants ( $p=0.711$ for day 2 adults, n.s., using a linear mixed model with repeated measurements). unc- 9 animals therefore do not have a general defect 
in bacterial feeding. In old animals, pumping rates declined significantly less in unc-9, an effect that increased over time. (Fig. 4d).

We additionally measured changes in the locomotory responses to a tap stimulus with age in unc-9 and N2 animals but did not observe consistent differences between the mutant and wild type (Supplementary Fig. 3). Since unc-9 is expressed in the sex muscles and has an egg retention phenotype ${ }^{18,31}$, we examined if unc-9 mutants are defective in egg-laying. We found that the brood size of unc-9(e101) mutants is $258 \pm 7$ per parent $(n=18)$, which is $13 \%$ lower compared to N2, which has $295 \pm 6$ offspring per hermaphrodite $(n=20)$. This slightly reduced fertility is unlikely to affect lifespan.

Taken together, these results suggest that electrical coupling by UNC-9 regulates not only lifespan but also the decline of specific outputs of the nervous system with age, and that ageing worms lacking this innexin are more active and responsive than wild type, showing improved healthspan.

\section{unc-9 acts in the glutamatergic nervous system to regulate lifespan}

The clear effect of UNC-9 on lifespan and healthspan raises the question of where it acts to control longevity. unc-9 is widely expressed in the nervous system and muscles. To determine if unc-9 acts in muscles or the nervous system to regulate lifespan, we knocked down unc-9 in N2 wild-type animals and the RNAi-hypersensitive strain KP3948, using RNA interference by bacterial feeding. In N2 but not KP3948, the nervous system is refractory to RNAi. To avoid developmental defects of unc-9 knockdown, we started the RNAi treatment at the L4 larval stage. We found that unc-9 knockdown extends lifespan in KP3948 but not $\mathrm{N} 2$ animals, suggesting that the nervous system is the organ where UNC-9 affects lifespan 
(Fig. 5a,b). This result further corroborates our previous finding using unc-9 mutants that the absence of unc- 9 causes lifespan extension.

Unc-9 is expressed in 108 of 118 neuron classes $^{20}$. We therefore sought to determine whether the role of unc-9 in modulating ageing is widely distributed across the nervous system or can be narrowed down to a specific group of neurons. To test this, we specifically and selectively knocked down unc- 9 in four domains of the nervous system: the glutamatergic, GABAergic, dopaminergic and cholinergic neurons. To this end we used a tissue-specific RNAi approach, where only defined subsets of the nervous system are susceptible to RNAi by feeding ${ }^{46}$. We found that lifespan was significantly increased when unc-9 was selectively knocked down in the glutamate-releasing neurons (Fig. 5c); no effect was seen from unc-9 knockdown in either cholinergic, GABAergic or dopaminergic neurons (Fig. $5 d, e, f)$. This finding tantalisingly suggests that the effect of UNC-9-containing gap junctions on lifespan may be caused by its coupling of specific neurons or neural circuits.

\section{The glutamatergic unc-9-expressing neurons are predominantly mechanosensory}

To further narrow down the neurons where unc- 9 modulates ageing, we made use of the fact that the expression patterns of both unc- 9 and the vesicular glutamate transporter eat4 have been mapped to the level of individual neurons ${ }^{20,47,48}$. Their expression overlaps in 31 neuron classes of the somatic nervous system, namely the sensory neurons $A D L, A L M, A Q R$, ASE, ASH, ASK, AVM, AWC, FLP, OLL, OLQ, PHA, PHB, PHC, PLM, PQR, PVD and URY; the interneurons ADA, AIB, AIM, AIZ, AUA, DVC, LUA, PVQ, PVR, RIA and RIG; the motoneuron RIM; and the polymodal IL1 sensory/inter/motoneurons (Fig. 6a; Supplementary Fig. 5). Additionally, they overlap in three pharyngeal neuron classes. 
These neuron classes show intriguing shared features: they are dominated by sensory neurons -19 of the 31 classes are sensory neurons. Sensory perception plays a central role in regulating $C$. elegans lifespan ${ }^{49,50}$, and chemosensory ${ }^{51}$, thermosensory ${ }^{52,53}$ and oxygensensing neurons ${ }^{54,55}$ have been shown to shorten or extend the animals' lifespan in an environmental context-dependent manner. The oxygen-sensing neurons AQR and PQR signal tonically at $21 \%$ ambient oxygen but are largely inactive at reduced $\mathrm{O}_{2}$ levels $(7 \%)^{56}$. If UNC-9 acted in those neurons to limit lifespan, we would therefore expect to see a difference in lifespan between animals grown at $21 \%$ or $7 \% \mathrm{O}_{2}$. However, lifespan in both $\mathrm{N} 2$ and unc- 9 mutant animals did not significantly differ between animals grown at $21 \%$ and 7\% oxygen (Supplementary Fig. 4). Of the above neurons which are chemosensory, ablating ASE, ASK and AWC individually does not affect lifespan ${ }^{51}$.

Strikingly, most of the glutamatergic unc-9-expressing sensory neurons (13 of 19) are implicated in mechanosensation, including both gentle and harsh touch to the head or body. They constitute a majority of the 20 known mechanosensory neuron classes in $C$. elegans (Fig. 5a; Supplementary Figure 5) ${ }^{57,58}$. Moreover, several of the glutamatergic interneurons that express unc-9, namely PVR, LUA, AIB and RIG, receive direct synaptic connections from the mechanosensors ${ }^{59}$. The mechanosensory and interneurons feature considerable electrical coupling both with each other and with the command interneuron circuit, particularly AVD and PVC, which control the direction of movement and also express unc-9 (Supplementary Fig. 6).

\section{UNC-9 depends on mechanosensation to regulate lifespan}

Our observations raise the possibility that the regulation of lifespan by UNC-9 gap junctions depends on a neural circuit involving mechanosensory neurons. We hypothesised that in 
that case the increased longevity conferred by the lack of unc- 9 would be affected if worms are insensitive to touch and consequently the mechanosensory circuit less active.

Mechanosensation has not hitherto been known to affect $C$. elegans lifespan.

To test this hypothesis, we investigated if there is a genetic interaction between the unc- 9 loss-of-function mutation and mutants of genes required for touch sensation, namely of the degenerin mechanosensory channel subunit MEC-4 and of the paraoxonase-like protein MEC-6, which are expressed in the touch receptor neurons ALM, AVM, PLM and PVM. Null mutants of these genes are defective in responding to gentle touch and eliminate both mechanoreceptor currents and touch-evoked $\mathrm{Ca}^{2+}$ transients ${ }^{60,61}$. We performed lifespan assays with double mutants of mec-6; unc-9 and unc-9 mec-4 and compared them with single mutants of either gene as well as with N2 wild-type. Both double mutants were defective in touch responses in the same way as mec- 6 and mec- 4 single mutants are (Supplementary Fig. 7). We found that mec-6 null mutants live longer than N2 but expand median lifespan less than unc-9 null mutants (5 vs. 7 days) (Fig. 6b; Supplementary Table 2). Lifespan of the mec-6; unc-9 double mutants was identical to that of mec- 6 single mutants but longer than in $\mathrm{N} 2$ and shorter than in unc- 9 animals. The longevity conferred by the absence of mec- 6 therefore is epistatic to unc- 9 and does not depend on this innexin; conversely, loss of unc-9 depends on a functional mec- 6 gene to prolong life. Unc-9 also depends on mec-4 to expand lifespan. Longevity of the unc-9 mec-4 double mutant was significantly shorter than in the unc-9 mutant alone, while lifespan of mec-4 mutants was not significantly different from that of N2 animals (Fig. 6b,c). We conclude that the increase of lifespan in unc-9 mutants depends on touch sensation.

We then sought to test if unc-9 mutants themselves are defective in gentle touch sensation and found that these mutants had wild-type responses to touch, indicating that the increase 
in lifespan of unc-9 mutants is not caused by decreased mechanosensation (Fig. 6d). To further determine which neurons in the mechanosensory circuit play a role in the control of ageing by UNC-9, we knocked down unc- 9 in the touch receptor neurons by RNAi. Separately, we ablated the PVR interneuron, which is heavily synaptically connected with mechanosensory neurons, using a laser microbeam. However, these treatments did not affect lifespan (Supplementary Fig. 8), suggesting that in addition to the touch-receptor neurons, other glutamatergic neurons such as harsh touch sensors may be involved in the regulation of longevity by UNC-9.

\section{UNC-9 alters age-dependent morphological changes of the touch receptor neurons}

In both humans and $C$. elegans, healthy ageing of the nervous system is marked primarily by a decline in the structural integrity of neurons with age rather than outright neuron loss ${ }^{62}$. These age-associated morphological changes are particularly prevalent in the touch-sensing neurons of $C$. elegans and correlate with decreased response to light touch as well as decreased mobility ${ }^{63}$. Because unc- 9 mutants depend on a functional mechanosensory machinery for their positive effect on lifespan, we speculated that the absence of this innexin may alter the progressive decline of touch receptor neuron integrity with age. To test this, we imaged and assessed the morphology of the gentle touch-sensing ALM, AVM and PLM neurons in ageing worms. The cell bodies of ALM and AVM are positioned anteriorly, while those of PLM are located posteriorly (Fig. 7a). In young adults, the cell bodies are typically round or oval but develop progressively more irregular shapes with age ${ }^{64}$. All three extend a major neurite anteriorly which make synaptic contacts with other neurons. In addition, ALM and PLM form short posterior processes ${ }^{65}$. In young animals, those processes appear straight and uniform but develop various abnormalities in old 
adults, namely a wavy appearance and protrusions of different shapes (Fig. 7b) 66,67 . We found that unc-9(101) mutants altered the age-dependent decline in morphological integrity, and had a markedly different effect in different cell types. In the ALM neurite, the progressive increase in abnormalities was significantly accelerated in unc-9 mutants, while degeneration in the PLM dendrite was slower than in N2 (Fig. 7c,d). In AVM, cell bodies showed a significantly faster deterioration in the unc-9 mutants (Fig. 7e). Integrity of the ALM or PLM cell bodies was not significantly affected by genotype (Supplementary Fig. $9 a, b)$.

We conclude that unc-9 affects the progression of neuronal ageing in a markedly different way between touch neuron subtypes, where specific morphological structures age faster, are unaffected or deteriorate slower in the mutant. This finding parallels previous reports showing that age-dependent morphological degradation in the touch receptor neurons differs markedly between neuronal subtypes ${ }^{66,67}$.

Another hallmark of touch receptor neuron degeneration is the appearance of additional branches emanating from either the somata or processes in ageing worms $s^{63,67}$. In the above experiment, we observed that the touch receptor neurons in older unc- 9 mutants appeared to have longer and more abnormal branches than N2 animals (Fig. 7f). We therefore decided to quantify the morphology of neuronal branches of ageing worms, focusing on the ALM neurons where it could be observed most clearly. We found that the overall number of branches in ALM progressively increases with age, but is not affected by the unc-9 genotype (Fig. 7g). On the other hand, the fraction of long branches ( $\geq 2 \mathrm{x}$ soma diameter) was significantly increased in unc-9 (Fig. 7h,i). This was already apparent in young adults but increased further with age. The proportion of all types of abnormal branches combined - 
comprising short or long branches, loops and branching out of existing branches - increased with age in both genotypes but rose much earlier in unc-9 mutants (Fig. 7j).

Taken together, these results show that loss of unc- 9 alters the morphological ageing of the touch receptor neurons. Notably, unc-9 mutants have an accelerated appearance of ageing hallmarks in the ALM and AVM neurons.

\section{UNC-9 lifespan regulation is independent of FOXO signalling but linked to ROS}

Our results point to a novel role of gap junction coupling in mechanosensory circuits in regulating $C$. elegans ageing. This raises the question which ageing pathways are implicated in the effect of unc-9 on lifespan. Insulin/insulin-like growth factor-1 factor signalling (IIS) plays a pivotal role in the regulation of longevity ${ }^{68} . \ln$ C. elegans, activation of the insulin receptor DAF-2 stops DAF-16, the C. elegans orthologue of the FOXO transcription factor, from entering the nucleus. When DAF-2 is inhibited, DAF-16 translocates to the nucleus and activates genes involved in stress resistance and longevity. Consequently, daf-2(e1370) mutants with reduced IIS signalling live twice as long as N2 wild type, while daf-16(mu86) null mutants have shortened lifespan. To test if unc-9 acts through IIS signalling to regulate lifespan, we created double mutants of unc-9(e101) with both mutants. We found that daf16; unc-9 animals lived significantly longer than daf-16 single mutants (Fig. 7a). Median lifespan of the double mutants is $50 \%$ longer than in daf- 16 alone (18 vs. 12 days). This indicates that unc-9 null mutants increase longevity independently of daf-16/FOXO signalling. The lifespan of the daf-2; unc-9 double mutant population appeared to fall in two categories: for those dying before they reach median lifespan of the population, it was the same as in unc- 9 single mutants; in contrast, those who survived beyond this age lived considerably longer than unc-9 mutants. This suggests that unc-9 is partially required for the 
lifespan increase conferred by reduced IIS signalling. However, the analysis of the daf-2;

unc-9 double mutants was impeded by their strongly increased propensity for internal egg hatching, which eventually kills the parent, with one event observed as late as day 51 (Supplementary Fig. 10); we presume that this is caused by a combination of an increased rate of internal hatching caused by the unc- 9 mutation and the ability of daf- 2 mutants to produce progeny late in life ${ }^{69}$.

Together, we conclude that unc-9 acts independently of $d a f-16 / \mathrm{FOXO}$ to modulate ageing, while our data do not rule out an interaction with daf-2 insulin receptor signalling.

Intercellular gap junction channels enable the diffusion of small molecules from cell to cell. It is well established that this can cause a "bystander" effect where cells experiencing oxidative insults or apoptotic cell death increase the damage or death of gap junctioncoupled cells through the diffusion of as yet unknown signals ${ }^{12,70}$. We therefore aimed to explore if oxidative stress may be implicated in the life extension by unc- 9 mutants. We thus conducted a lifespan assay where animals were grown in the presence of $\mathrm{N}$-Acetyl-Cysteine (NAC), an antioxidant and scavenger of all types of reactive oxygen species (ROS) ${ }^{71}$. $\mathrm{N} 2$ worms maintained at normoxia $\left(21 \% \mathrm{O}_{2}\right)$ did not respond to NAC treatment, consistent with previous reports ${ }^{72,73}$. In contrast, $9 \mathrm{mM}$ NAC eliminated a substantial part of the life extension conferred by the loss of unc- 9 , with median lifespan increasing by only 2 days instead of 6 in untreated unc-9 mutants, relative to wild-type (Fig. 7c).

An important consideration in how ROS levels govern longevity is that the natural habitat of C. elegans contains much lower levels of oxygen than the laboratory conditions under which most experiments are conducted ${ }^{56,74}$. We therefore also maintained strains at their preferred and more physiological oxygen tension of $7 \% \mathrm{O}_{2}{ }^{56}$. At this lower oxygen tension, 
N2 wild-type animals survive significantly longer when grown with NAC (Fig. 7d). The effect of NAC on lifespan appears to be mostly affecting the survival of older animals. In contrast, NAC treatment again strongly reduced the increased lifespan of unc-9 null mutants (Fig. 7d). A higher dose of 9mM NAC had similar but weaker effects on worms maintained at $7 \% \mathrm{O}_{2}$ (Supplementary Fig. 11a,b).

Together, these results indicate that the increased longevity conferred by loss of the unc- 9 innexin substantially requires ROS and that antioxidant activity can increase longevity in wild-type but not unc-9 mutant animals.

\section{Discussion}

Gap junctions are unique and ubiquitous intercellular conduits that provide electrical, metabolic and biochemical coupling between cells $s^{5,6}$. They also play key pathological roles such as the propagation of cellular injury or death signals to "bystander" cells ${ }^{10-12}$. Despite their fundamental importance in intercellular communication, it has not been known whether gap junctions and the genes forming them contribute to the regulation of ageing and longevity.

We now show that the genes encoding gap junction subunits have diverse and widespread roles in regulating $C$. elegans ageing. A recurrent difficulty in studying gap junction genes arises from their partial redundancy, where members of this gene family have overlapping roles and thus when one gene is missing, others can compensate for its absence ${ }^{75}$. We found that despite their frequent overlap in expression, the majority of individual innexin mutants modulate lifespan, and thus have non-redundant effects. This suggest that the modulation of lifespan is specific to individual innexins acting in defined sets of cells, rather 
than a universal feature common to all of them. It does not rule out that innexins have overlapping roles and thus when one innexin gene is missing, others can compensate for its absence. Future studies may examine if double mutants of innexins with similar expression patterns, particularly in the nervous system, show a further increase in lifespan.

A major finding of this study is that loss of the unc- 9 innexin increases lifespan. Our results suggest that the presence of UNC-9 in the glutamatergic nervous system limits longevity. It acts in the same pathway as UNC-7 and requires regulation by the stomatin UNC-1 to control lifespan.

The effect of UNC-9 on lifespan could potentially be caused by a nonjunctional function of the protein. However, we found unc-1 to regulate lifespan by acting on unc-9. Unc-1 encodes a stomatin-like integral membrane protein that colocalises with UNC-9 and specifically modulates the gating of UNC-9 gap junction channels in muscle, but is not required for the expression or subcellular localisation of UNC- $9^{76}$. In the absence of UNC-1, UNC-9-containing gap junctions are thought to be mainly in the closed state ${ }^{76,77}$. Our results support the hypothesis that the role of UNC-9 in controlling longevity rests on its function as an intercellular channel and that its open state causes a shortening of $C$. elegans lifespan.

Some studies reported that lifespan-extending mutations predominantly increase the frail period, while other reports concluded that mutants such as daf-2 do increase healthy ageing ${ }^{39,40,43,78-80}$. We show here that unc-9 mutants enjoy not only an increase in lifespan but also extend the period of healthy ageing, with locomotory activity, responsiveness, defecation and pharyngeal pumping all persisting longer with age than in wild type. However, unc-9 mutants in general bear multiple phenotypic defects, especially 
uncoordinated behaviour. Our results suggest that by selectively removing unc- 9 from glutamatergic neurons, it would be possible for worms to enjoy the benefit of increased longevity without having other behavioural defects.

unc-9 is expressed in nearly all neurons, potentially creating an electrically coupled network encompassing virtually the entire nervous system, and is also expressed in most muscles. Yet we found that it controls lifespan specifically in a subset of its expression domain, namely the glutamatergic neurons. This raises the possibility that a functional circuit consisting of these neurons regulates lifespan in an UNC-9 gap junction-dependent manner. While we cannot rule out that other unc-9-expressing cells also have a role in lifespan regulation by this innexin, our evidence argues against it. Although expressed in the pharyngeal nervous system, unc-9 were not feeding deficient and had only a slight reduction in brood size. It is therefore unlikely that the increase of unc-9 mutant lifespan is caused by dietary restriction or reduced reproduction. It is also unlikely that the uncoordinated phenotype and reduced locomotory activity of unc- 9 mutants causes their lifespan extension. The unc phenotype of unc- 9 is thought to be caused by dysfunction of the locomotory nervous system, not of the largely sensory glutamatergic neurons. Moreover, previous reports ${ }^{81,82}$ have found that most unc mutants tested do not increase lifespan.

Unc-9 is expressed in glutamatergic sensory neurons that respond to chemical, temperature and oxygen cues which are known to influence lifespan. However, these neurons do so by regulating daf-16 FOXO signalling ${ }^{51,54,83}$. Our data show that unc-9 acts independently of daf-16 to regulate longevity, making it unlikely that unc- 9 regulates lifespan in these neurons. Instead, our findings point towards a very unexpected set of neurons involved, 
namely the mechanosensory neurons. These had not previously been implicated in lifespan regulation. However, studies have shown that mechanosensory neurons are particularly prone to decline of morphological integrity with age ${ }^{63,66}$. Changes in the mechanical properties of cells are hallmarks of the ageing process, which correlates with progressive decline in the structural integrity of cells and their diminished response to mechanical forces ${ }^{84}$. It is conceivable that mechanosensory cells represent a link between mechanical stress, the age-dependent decline of mechanical properties, and the mechanisms that regulate organismal ageing. In that respect, it is interesting that several mammalian connexins have been shown to be mechanosensitive ${ }^{85}$, and investigating how their properties change with age could be the focus of future studies.

We observed that loss of unc- 9 alters the structural integrity of the touch receptor neurons, and according to several measured parameters can accelerate the deterioration of their morphology. This suggests that isolation of these neurons from electrical neuronal networks worsens their state, but paradoxically improves lifespan and healthspan of the whole organism.

In that regard, it is interesting that ROS are partially required for the long life of unc-9 null mutants. This suggests that the mechanism of how gap junctions impinge on ageing is linked to either redox regulation or oxidative stress, key factors in both cellular ageing and longevity ${ }^{86}$. The nature of this mechanism remains to be uncovered by future studies. In any electrically coupled neuronal circuit, cells will be in different activity states, resulting in a current flow from more active to less active neurons. It has been shown that such shunting can regulate the function of a mechanosensory circuit in C. elegans, where chronically inactive electrically coupled neurons inhibited sensory responses in the whole 
circuit ${ }^{87}$. Our observations could potentially be explained by a model where, similarly to neuronal injury models, noxious or ageing-promoting signals might be spreading across unc9-containing gap junction channels to connected neurons, for example reactive byproducts originating from neurons or neural circuits with strong, persistent neural activity to "bystander" neurons with lower activity, who thereby are damaged or functionally impaired after long-term exposure. Alternatively, the absence of unc-9 gap junctions may alter cellular metabolism and thus their redox state as a result of glutamatergic cells being isolated from other neurons.

Of the other innexin mutants we found to increase lifespan, inx-15 is particularly interesting as it had the second strongest effect. It is only expressed in the intestinal epithelial cells and has not been characterised previously. The intestine is a key player in the control of lifespan and develops multiple pathologies with age ${ }^{88}$. Old C. elegans have reduced immunity and diminished capacity to control their intestinal bacterial accumulation ${ }^{89}$. Bacteria, the worms' exclusive food, can colonise their guts and invade their tissues. In mammals, connexins in the gut can play a disease-promoting role and spread bacterial infections and inflammation across cellular networks. It will be interesting to see if inx-15 plays a role in the interaction between intestinal cells and gut bacteria.

The innexins expressed in the germline had opposing effects - inx-14 mutants extended lifespan, while inx-21 and inx-22 reduced it. $\ln x-14$ is required for both germ cell proliferation and negatively regulates oocyte meiotic maturation, while inx-21 contributes only to germ cell proliferation and inx-22 only to inhibiting meiotic maturation ${ }^{90}$. It may be that removal of both functions resembles removal of the germline, which prolongs lifespan, but that inhibiting each process individually reduces longevity. 
While cellular mechanisms of ageing have been the focus of intense investigation, it remains much less well understood how non-cell-autonomous mechanisms provide a systemic control of ageing and longevity. The nervous system acts via diverse pathways to modulate organismal ageing and lifespan and itself undergoes age-dependent deterioration of its function and structure ${ }^{91,92}$. A full understanding of the causative relationships between agedependent decline of cells in the brain, organismal aging and longevity remains elusive. Our study offers the tantalising prospect that gap junction intercellular communication underpins a previously unknown non-cell autonomous mechanism that modulates ageing.

\section{Methods}

\section{Nematode strains}

C. elegans strains used are listed in Supplementary Table 3. All strains were maintained under standard conditions ${ }^{93}$ in $5 \mathrm{~cm}$ Petri dishes on NGM (nematode growth medium) agar seeded with E. coli OP50. Except for unc-1(e1598), which is a gain-of-function mutation, all other mutants used are assumed to be loss-of-function mutants. The precise molecular lesion in the inx-5(ok1053) and the inx-18(ok2454) mutants had not been previously determined; both were sequenced and found to bear a 1221 bp deletion in inx-5 (nt 5058-6278 in R09F10) and a 1704 bp deletion in inx-18 (nt 30705-32408 in C18H7), that in both cases remove more than one exon and are therefore putative null mutants (Supplementary Table 1). The inx-6(rr5) loss of function allele is temperature-sensitive and is fully restrictive at $25^{\circ} \mathrm{C}^{1}$; it was tested at $20^{\circ} \mathrm{C}$ to allow cross-comparison with other innexin mutant strains in the assay.

Unc-9 rescue lines were generated by microinjection ${ }^{94}$ of a DNA Mix containing $1 \mathrm{ng} / \mu \mathrm{l}$ of unc9 encoding fosmid WRM0611aH10 and $1.5 \mathrm{ng} / \mu \mathrm{l}$ of pCFJ90 (pmyo-2::mCherry) into unc- 
9(e101). After 2 days F1 animals were singled by co-injection marker selection. Stable arrays were identified in the transgenic F2 generation.

\section{Lifespan assays}

For lifespan assays, established protocols were followed, with some adaptations ${ }^{49,95,96}$. Strains were first cultured under standard growth conditions for two generations to minimise non-genetic effects on lifespan. Then, 30 third-generation 2-day old adult hermaphrodites were allowed 4-8 hours for timed egg-laying and progeny laid during this time was grown for approximately two days at $20^{\circ} \mathrm{C}$ to late L4 larval stage, before being transferred to fresh plates at 12-15 animals per plate. For each strain, animals were split across ten plates. Animals were passaged to fresh plates every second day during the reproductively active stage (10 days) and then passaged every three days until the end of the experiment, or when a contamination occurred. Each plate was scored every day for live animals, dead animals and censored animals: Lifespan was measured from day 1 of adulthood and all lifespan assays were conducted at $20^{\circ} \mathrm{C}$. To establish if an older worm in stationary state was dead or alive, a worm pick or a human eyelash mounted on a pick was used to gently brush the animal on different parts of the body, namely, the tail, the ventral area and the nose. If the animal did not react after several attempts, then it was considered dead and was removed. Worms were censored when they escaped from the plate, if they became contaminated by bacteria or fungi, displayed internal egg hatching, vulva rupture or vulva protrusion, or were mishandled $^{95,96}$. 


\section{Lifespan analysis}

Analyses of lifespan data were conducted using a Kaplan-Meier survival analysis on GraphPad Prism versions 6 and 7. For statistical comparisons two-tailed Log-rank tests were performed. Median Survival represents the time at which half the animals in a given experiment have died. Along with median survival, which represents the central tendency of survival scores, 25th and 75th percentiles and the inter-quartile range (IQR) were reported as a measure of dispersion. Most survival score distributions observed were multimodal, which means that the arithmetic mean is not informative. Also, in contrast to the 25th and 75th percentiles, minimum and maximum lifespan are very vulnerable to outliers and therefore not reported. Median survival and IQR are also represented by a white dot and a black box, respectively, in the Violin plots (Supplementary Fig. 1) along with the probability density of the data at different values, smoothed by a kernel density estimator (KDE). Violin plots are a combination of box and density plots and allow a better understanding of how the scores are distributed, which is especially useful for asymmetric distributions. All Violin Plots were generated with Seaborn's violin plot function in Python 3.7.

\section{RNAi by feeding}

RNAi by feeding was performed as described previously ${ }^{46,97}$ with a few adaptations for the lifespan assays. Standard NGM plates were supplemented with $25 \mu \mathrm{g} / \mathrm{ml}$ carbenicillin and 1 $\mathrm{mM}$ isopropyl b-D-1-thiogalactopyranoside (IPTG). The plates were allowed to dry in a dark environment at room temperature for five days before use. The RNAi clones containing the oac-47 pseudogene (T22H2.2) and unc-9 (R12H7.7) are from the Ahringer RNAi feeding library and were initially streaked on LB plates containing $25 \mu \mathrm{g} / \mathrm{ml}$ carbenicillin and $10 \mu \mathrm{g} / \mathrm{ml}$ tetracycline and grown overnight at $37^{\circ} \mathrm{C}$. The next day, cultures were inoculated in $2 \mathrm{x} Y \mathrm{~T}$ 
bioRxiv preprint doi: https://doi.org/10.1101/657817; this version posted June 2, 2019. The copyright holder for this preprint (which was not certified by peer review) is the author/funder, who has granted bioRxiv a license to display the preprint in perpetuity. It is made available under aCC-BY-NC-ND 4.0 International license.

medium containing $25 \mu \mathrm{g} / \mathrm{ml}$ carbenicillin overnight at $37^{\circ} \mathrm{C}$ in a shaking incubator. Two drops from the inoculated culture were seeded onto each plate. Animals were transferred to the RNAi bacteria in L4 stage. oac-47, a pseudogene, served as negative control. Identity of the clones was confirmed by sequencing prior to use. Lifespan assays were conducted as described above except that animals were scored every other day.

\section{Locomotion assay}

Measurement of locomotory speed decline was performed as described in ${ }^{98}$ with some adaptations. 45 synchronised hermaphrodites from each strain (N2, CB101) where recorded for 5 min from day 1 of adulthood and every other day until death. Worms were transferred to fresh plates, seeded the day before, 15 min before the recording and the lid was removed for the last 2 minutes before recording, allowing adaptation to the air flow. The function Video Capture of the Wormlab setup (MBF Bioscience) and a Basler acA2440 camera were used. The selected frame rate was $14 \mathrm{fps}$, the video mode was $1600 * 1200$ and the rest of the settings were used as pre-set from manufacturer. Analysis was performed using the tracking function of the software and moving average speed $(\mu \mathrm{m} / \mathrm{s})$, averaged across 7 frames, was extracted for each video. The values provided were further analysed in Excel. The absolute values of the results provided by the software were used for averaging one single value per video. Due to the lower initial locomotory speed of unc-9 mutants, speed was normalised relative to the maximum locomotory speed observed in day 3 adults.

\section{Responsiveness assay}

To assess responsiveness to light touch with a worm pick, we performed a lifespan assay as described above and evaluated touch responses every other day. To score response to touch 
we used an index where a score of 4 indicated that upon plate tap, animals initiated an escape response, typically a reversal, changed their direction of movement, or moved their nose; 3 if they responded in the same way to light touch to their tail; 2 if they responded to light touch along the body; and 1 if they responded to light touch to the nose. Animals that did not respond at all were considered dead and therefore not scored. Each worm was given a score which were then averaged across 12 animals to give a plate score for each of the 10 plates per strain.

\section{Defecation assay}

The protocol to measure defecation cycle length was adapted from ${ }^{44,99}$. Hermaphrodites were synchronised by timed egg laying and maintained at $20^{\circ} \mathrm{C}$, on standard NGM plates, in the same as for lifespan assays. The defecation cycle length was measured on day 1 of adulthood and every third day onwards until expulsions were no longer visible. Animals were transferred to fresh plates and were allowed to adapt for at least $15 \mathrm{~min}$ before observing. Measurements were obtained from feeding, non-roaming animals and the duration of the cycle was defined as the time from one expulsion to the next. Three defecation cycles were measured for each animal.

\section{Pharyngeal pumping assay}

Worms were examined in situ on NGM agar plates using a Leica S6D Greenough stereomicroscope with a Leica KL300 LED light source and a Point Grey Grasshopper3 USB3 camera, attached via a Leica $0.63 x$ relay lens. Films were captured for $60 \mathrm{~s}$ at $25 \mathrm{fps}$ and 2448x2048 resolution using FlyCapture 2.13.3.31 (Point Grey) at maximum zoom and encoded using M-JPEG compression with a quality ratio of 100 (maximum). When necessary, 
plates were moved gently to keep the head of the animal in focus and within the field of view.

The number of pharyngeal pumps was scored manually by two independent observers for each worm by playing back the videos with VLC Media Player at $0.12 x$ (day 2) to $1.00 x$ (day 18+) speed and using a clicker counter.

\section{Brood size analysis}

Brood size was measured by transferring single L4 worms to an NGM plate and kept at $20^{\circ} \mathrm{C}$. Each adult worm was transferred to a fresh plate every day and the previous plate was kept at $20{ }^{\circ} \mathrm{C}$ for another 2 days, when the number of alive progeny was scored. This procedure was repeated until no alive progeny were found anymore.

\section{Gentle touch sensation assay}

Experiments were performed on day 1 adults. Animals were placed on fresh $5 \mathrm{~cm}$ NGM plates seeded two days before with a layer of OP50 that did not touch the edges of the plate. After 10 min of acclimatisation, touch sensation was tested by streaking animals gently at the side with an eyelash pick ${ }^{100}$. In particular, a total of 10 stimuli per animal were given by alternating anterior ( $2^{\text {nd }}$ sixth of body) and posterior ( $5^{\text {th }}$ sixth of body) strokes every 3-4 sec. Positive reactions were defined as movement in the opposite direction of stimulus or stop of present movement ${ }^{101,102}$. Average gentle touch responses of strains were compared. For statistical analysis unpaired Student's t-test was used.

\section{Scoring of mechanosensory neuron morphology}

To record neurodegeneration from the mechanosensory neurons, we followed published protocols $^{66,67}$. Briefly, for synchronisation, 600 L4 larvae per strain were picked. After reaching 
day 2 adulthood they were used for egg-laying. 30 animals per $50 \mathrm{~mm}$ NGM plate, seeded with OP50 bacteria, were allowed to lay eggs for 4-6 hours. Afterwards adults were removed and plates were kept at $20^{\circ} \mathrm{C}$ until the progeny reached L4 larval state. $60 \mathrm{~L} 4 \mathrm{~s}$ per strain were transferred to 25 NGM plates, seeded with OP50 bacteria, to reach a total of 1500 animals per strain. Animals were transferred to fresh plates every second day to remove progeny. Scoring was performed on days 1, 5, 10, 15, 17, 19, 21 and 25 on 50 animals per strain and day. For scoring, 10 animals were placed on a pad with $2 \%$ agarose in $\mathrm{M} 9$, immobilised with $50 \mathrm{mM}$ levamisole, covered with a coverslip and mounted on a Zeiss Axio Imager.M2 upright fluorescence microscope. Neurons were scored by eye at 40x magnification. In each animal, one ALM neuron (cell body and dendrite), AVM (cell body), and PLM (one dendrite, left and right cell body), were scored and classified as intact, defective or degenerated. Afterwards example images were taken with ZEN pro imaging software. For analysis, the average of classifications per strain, neuron, neuron-part and day was compared.

The scoring of ALM branching was performed in the same way by collecting data and branch categories were defined as follows: $1-2 \mathrm{x}$ diameter soma $=$ normal branch, less than $1 \mathrm{x}$ diameter soma $=$ short branch, $2 x$ or more diameter soma $=$ long branch, secondary branch emanating from an existing branch out of the soma = branch in branch, branch grows in a loop $=$ loop. From this information the number of branches out of cell body, number of branches in total, normal vs. abnormal branching and the respective branch types per strain and day were compared.

\section{Statistical analysis}

Data were analysed using SPSS 24 Statistics software (IBM). Normality was assessed using the Shapiro-Wilk test. Unbalanced data with normal distributions were analysed using linear 
mixed models with type III test of fixed effects. Non-normal data showing heteroscedasticity under Levene's test were analysed using a generalised estimating equations generalisation with Wald's test for linear models. Binomially distributed data were analysed using a binomial logistic regression model. Multinomially distributed data were analysed with a multinomial logistic regression model. Data where the response variable was a count were analysed using Poisson regression.

\section{Acknowledgements}

We thank the Caenorhabditis Genetics Center and the National Bioresource Project for the nematode for strains and Maria Doitsidou and Sebastian Greiss for helpful suggestions. We also thank Simon Warburton-Pitt for help with genotyping, Kanyarat Benjasupawan for contributing to healthspan measurements, Vishaka Kulkarni for help with lifespan assays, and Eugenia Goya for advice on scoring neurodegeneration. We gratefully acknowledge financial support by the Wellcome Trust (109614/Z/15/Z), the Medical Research Council (MR/N004574/1), the Muir Maxwell Epilepsy Centre and the University of Edinburgh (PhD studentship to NAV).

\section{Author contributions}

K.E.B., N.A.V. and K.E.F. conceived and planned the study. N.A.V., M.N. and K.E.B designed the lifespan experiments which were performed by all authors and analysed by N.A.V., K.E.B. and K.E.F. Healthspan assays were planned, performed and analysed by N.A.V., E.D., D.C.M. and K.E.B. with help from A.A. Touch receptor experiments were designed, performed and analysed by K.E.F., D.C.M. and E.D. Crosses, genotyping and creating transgenic strains were 
done by K.E.F. with help from P.G. All authors discussed the data; and K.E.B. wrote the manuscript with input from N.A.V., K.E.F., E.D., D.C.M. and Q.L.

\section{References}

1 Alcedo, J., Flatt, T. \& Pasyukova, E. G. Neuronal inputs and outputs of aging and longevity. Front Genet 4, 71, doi:10.3389/fgene.2013.00071 (2013).

2 Kagias, K., Nehammer, C. \& Pocock, R. Neuronal responses to physiological stress. Front Genet 3, 222, doi:10.3389/fgene.2012.00222 (2012).

3 Riera, C. E., Merkwirth, C., De Magalhaes Filho, C. D. \& Dillin, A. Signaling Networks Determining Life Span. Annu Rev Biochem 85, 35-64, doi:10.1146/annurev-biochem060815-014451 (2016).

4 Gladyshev, V. N. On the cause of aging and control of lifespan: heterogeneity leads to inevitable damage accumulation, causing aging; control of damage composition and rate of accumulation define lifespan. Bioessays 34, 925-929, doi:10.1002/bies.201200092 (2012).

5 Evans, W. H. \& Martin, P. E. Gap junctions: structure and function (Review). Mol Membr Biol 19, 121-136, doi:10.1080/09687680210139839 (2002).

6 Goodenough, D. A. \& Paul, D. L. Gap junctions. Cold Spring Harb Perspect Biol 1, a002576, doi:10.1101/cshperspect.a002576 (2009).

7 Curti, S. \& O'Brien, J. Characteristics and plasticity of electrical synaptic transmission. BMC Cell Biol 17 Suppl 1, 13, doi:10.1186/s12860-016-0091-y (2016).

8 Goldberg, G. S., Lampe, P. D. \& Nicholson, B. J. Selective transfer of endogenous metabolites through gap junctions composed of different connexins. Nat Cell Biol 1, 457-459, doi:10.1038/15693 (1999).

9 Connors, B. W. \& Long, M. A. Electrical synapses in the mammalian brain. Annual review of neuroscience 27, 393-418 (2004).

10 Belousov, A. B., Fontes, J. D., Freitas-Andrade, M. \& Naus, C. C. Gap junctions and hemichannels: communicating cell death in neurodevelopment and disease. $B M C$ Cell Biol 18, 4, doi:10.1186/s12860-016-0120-x (2017).

11 Frantseva, M. V. et al. Specific gap junctions enhance the neuronal vulnerability to brain traumatic injury. J Neurosci 22, 644-653 (2002).

12 Spray, D. C. et al. Gap junctions and Bystander Effects: Good Samaritans and executioners. Wiley Interdiscip Rev Membr Transp Signal 2, 1-15, doi:10.1002/wmts.72 (2013).

13 Belousov, A. B. \& Fontes, J. D. Neuronal gap junctions: making and breaking connections during development and injury. Trends Neurosci 36, 227-236, doi:10.1016/j.tins.2012.11.001 (2013).

14 Antebi, A. Genetics of aging in Caenorhabditis elegans. PLoS Genet 3, 1565-1571, doi:10.1371/journal.pgen.0030129 (2007). 
15 Kenyon, C. J. The genetics of ageing. Nature 464, 504-512, doi:10.1038/nature08980 (2010).

16 Simonsen, K. T., Moerman, D. G. \& Naus, C. C. Gap junctions in C. elegans. Front Physiol 5, 40, doi:10.3389/fphys.2014.00040 (2014).

17 Phelan, P. et al. Innexins: a family of invertebrate gap-junction proteins. Trends Genet 14, 348-349 (1998).

18 Altun, Z. F., Chen, B., Wang, Z. W. \& Hall, D. H. High resolution map of Caenorhabditis elegans gap junction proteins. Dev Dyn 238, 1936-1950 (2009).

19 Starich, T. A., Miller, A., Nguyen, R. L., Hall, D. H. \& Shaw, J. E. The Caenorhabditis elegans innexin INX-3 is localized to gap junctions and is essential for embryonic development. Developmental biology 256, 403-417 (2003).

20 Bhattacharya, A., Aghayeva, U., Berghoff, E. G. \& Hobert, O. Plasticity of the Electrical Connectome of C. elegans. Cell 176, 1174-1189 e1116, doi:10.1016/j.cell.2018.12.024 (2019).

21 Starich, T. A., Lee, R. Y., Panzarella, C., Avery, L. \& Shaw, J. E. eat-5 and unc-7 represent a multigene family in Caenorhabditis elegans involved in cell-cell coupling. The Journal of cell biology 134, 537-548 (1996).

22 Li, S., Dent, J. A. \& Roy, R. Regulation of intermuscular electrical coupling by the Caenorhabditis elegans innexin inx-6. Mol Biol Cell 14, 2630-2644, doi:10.1091/mbc.e02-11-0716 (2003).

23 Peters, M. A., Teramoto, T., White, J. Q., Iwasaki, K. \& Jorgensen, E. M. A calcium wave mediated by gap junctions coordinates a rhythmic behavior in C. elegans. Curr Biol 17, 1601-1608, doi:10.1016/j.cub.2007.08.031 (2007).

24 Smith, H. K. et al. Defining specificity determinants of cGMP mediated gustatory sensory transduction in Caenorhabditis elegans. Genetics 194, 885-901, doi:10.1534/genetics.113.152660 (2013).

25 Kawano, T. et al. An imbalancing act: gap junctions reduce the backward motor circuit activity to bias C. elegans for forward locomotion. Neuron 72, 572-586, doi:10.1016/j.neuron.2011.09.005 (2011).

26 Starich, T. A., Xu, J., Skerrett, I. M., Nicholson, B. J. \& Shaw, J. E. Interactions between innexins UNC-7 and UNC-9 mediate electrical synapse specificity in the Caenorhabditis elegans locomotory nervous system. Neural Dev 4, 16, doi:10.1186/1749-8104-4-16 (2009).

27 Chuang, C. F., Vanhoven, M. K., Fetter, R. D., Verselis, V. K. \& Bargmann, C. I. An innexin-dependent cell network establishes left-right neuronal asymmetry in C. elegans. Cell 129, 787-799, doi:10.1016/j.cell.2007.02.052 (2007).

28 Phelan, P. Innexins: members of an evolutionarily conserved family of gap-junction proteins. Biochimica et biophysica acta 1711, 225-245, doi:10.1016/j.bbamem.2004.10.004 (2005).

29 Liu, P. et al. Six innexins contribute to electrical coupling of C. elegans body-wall muscle. PLoS One 8, e76877, doi:10.1371/journal.pone.0076877 (2013).

30 Dent, J. A., Smith, M. M., Vassilatis, D. K. \& Avery, L. The genetics of ivermectin resistance in Caenorhabditis elegans. Proceedings of the National Academy of Sciences of the United States of America 97, 2674-2679, doi:10.1073/pnas.97.6.2674 (2000). 
31 Barnes, T. M. \& Hekimi, S. The Caenorhabditis elegans avermectin resistance and anesthetic response gene unc- 9 encodes a member of a protein family implicated in electrical coupling of excitable cells. Journal of neurochemistry 69, 2251-2260 (1997).

32 Liu, P., Chen, B., Mailler, R. \& Wang, Z. W. Antidromic-rectifying gap junctions amplify chemical transmission at functionally mixed electrical-chemical synapses. Nat Commun 8, 14818, doi:10.1038/ncomms14818 (2017).

$33 \mathrm{Xu}, \mathrm{T}$. et al. Descending pathway facilitates undulatory wave propagation in Caenorhabditis elegans through gap junctions. Proceedings of the National Academy of Sciences of the United States of America 115, E4493-E4502, doi:10.1073/pnas.1717022115 (2018).

34 Chen, B. J., Liu, Q., Ge, Q., Xie, J. \& Wang, Z. W. UNC-1 regulates gap junctions important to locomotion in C. elegans. Current Biology 17, 1334-1339, doi:10.1016/j.cub.2007.06.060 (2007).

35 Park, E. C. \& Horvitz, H. R. Mutations with dominant effects on the behavior and morphology of the nematode Caenorhabditis elegans. Genetics 113, 821-852 (1986). Young, A. Ageing and physiological functions. Philos TR Soc B 352, 1837-1843, doi:DOI 10.1098/rstb.1997.0169 (1997).

37 Collins, J. J., Huang, C., Hughes, S. \& Kornfeld, K. The measurement and analysis of age-related changes in Caenorhabditis elegans. WormBook, 1-21, doi:10.1895/wormbook.1.137.1 (2008).

38 Keith, S. A., Amrit, F. R., Ratnappan, R. \& Ghazi, A. The C. elegans healthspan and stress-resistance assay toolkit. Methods 68, 476-486, doi:10.1016/j.ymeth.2014.04.003 (2014).

39 Rollins, J. A., Howard, A. C., Dobbins, S. K., Washburn, E. H. \& Rogers, A. N. Assessing Health Span in Caenorhabditis elegans: Lessons From Short-Lived Mutants. J Gerontol A Biol Sci Med Sci 72, 473-480, doi:10.1093/gerona/glw248 (2017).

$40 \mathrm{Hahm}, \mathrm{J} . \mathrm{H}$. et al. C. elegans maximum velocity correlates with healthspan and is maintained in worms with an insulin receptor mutation. Nature Communications 6, doi:10.1038/ncomms9919 (2015).

41 Hsu, A. L., Feng, Z., Hsieh, M. Y. \& Xu, X. Z. Identification by machine vision of the rate of motor activity decline as a lifespan predictor in C. elegans. Neurobiol Aging 30, 1498-1503, doi:10.1016/j.neurobiolaging.2007.12.007 (2009).

42 Liu, J. et al. Functional Aging in the Nervous System Contributes to Age-Dependent Motor Activity Decline in C. elegans. Cell Metabolism 18, 392-402, doi:10.1016/j.cmet.2013.08.007 (2013).

43 Bansal, A., Zhu, L. J., Yen, K. \& Tissenbaum, H. A. Uncoupling lifespan and healthspan in Caenorhabditis elegans longevity mutants. Proceedings of the National Academy of Sciences of the United States of America 112, E277-286, doi:10.1073/pnas.1412192112 (2015).

44 Bolanowski, M. A., Russell, R. L. \& Jacobson, L. A. Quantitative measures of aging in the nematode Caenorhabditis elegans. I. Population and longitudinal studies of two behavioral parameters. Mech Ageing Dev 15, 279-295 (1981).

45 Huang, C., Xiong, C. \& Kornfeld, K. Measurements of age-related changes of physiological processes that predict lifespan of Caenorhabditis elegans. Proceedings of the National Academy of Sciences of the United States of America 101, 8084-8089, doi:10.1073/pnas.0400848101 (2004). 
46 Firnhaber, C. \& Hammarlund, M. Neuron-Specific Feeding RNAi in C. elegans and Its Use in a Screen for Essential Genes Required for GABA Neuron Function. Plos Genetics 9, doi:10.1371/journal.pgen.1003921 (2013).

47 Serrano-Saiz, E. et al. A Neurotransmitter Atlas of the Caenorhabditis elegans Male Nervous System Reveals Sexually Dimorphic Neurotransmitter Usage. Genetics 206, 1251-1269, doi:10.1534/genetics.117.202127 (2017).

48 Serrano-Saiz, E. et al. Modular control of glutamatergic neuronal identity in C. elegans by distinct homeodomain proteins. Cell 155, 659-673, doi:10.1016/j.cell.2013.09.052 (2013).

49 Apfeld, J. \& Kenyon, C. Regulation of lifespan by sensory perception in Caenorhabditis elegans. Nature 402, 804-809, doi:10.1038/45544 (1999).

50 Alcedo, J., Maier, W. \& Ch'ng, Q. Sensory influence on homeostasis and lifespan: molecules and circuits. Adv Exp Med Biol 694, 197-210 (2010).

51 Alcedo, J. \& Kenyon, C. Regulation of C-elegans longevity by specific gustatory and olfactory neurons. Neuron 41, 45-55, doi:Doi 10.1016/S0896-6273(03)00816-X (2004).

52 Lee, S. J. \& Kenyon, C. Regulation of the Longevity Response to Temperature by Thermosensory Neurons in Caenorhabditis elegans. Current Biology 19, 715-722, doi:10.1016/j.cub.2009.03.041 (2009).

53 Xiao, R. et al. A genetic program promotes C. elegans longevity at cold temperatures via a thermosensitive TRP channel. Cell 152, 806-817, doi:10.1016/j.cell.2013.01.020 (2013).

54 Abergel, R., Livshits, L., Shaked, M., Chatterjee, A. K. \& Gross, E. Synergism between soluble guanylate cyclase signaling and neuropeptides extends lifespan in the nematode Caenorhabditis elegans. Aging Cell 16, 401-413, doi:10.1111/acel.12569 (2017).

55 Liu, T. \& Cai, D. Counterbalance between BAG and URX neurons via guanylate cyclases controls lifespan homeostasis in C. elegans. EMBO J 32, 1529-1542, doi:10.1038/emboj.2013.75 (2013).

56 Busch, K. E. et al. Tonic signaling from $\mathrm{O}_{2}$ sensors sets neural circuit activity and behavioral state. Nature neuroscience 15, 581-591, doi:10.1038/nn.3061 (2012).

57 Goodman, M. B. Mechanosensation. WormBook, 1-14, doi:10.1895/wormbook.1.62.1 (2006).

58 Goodman, M. B. \& Sengupta, P. How Caenorhabditis elegans Senses Mechanical Stress, Temperature, and Other Physical Stimuli. Genetics 212, 25-51, doi:10.1534/genetics.118.300241 (2019).

59 White, J. G., Southgate, E., Thomson, J. N. \& Brenner, S. The structure of the nervous system of the nematode Caenorhabditis elegans. Phil. Transact. R. Soc. Lond. B. 314, 1-340 (1986).

60 O'Hagan, R., Chalfie, M. \& Goodman, M. B. The MEC-4 DEG/ENaC channel of Caenorhabditis elegans touch receptor neurons transduces mechanical signals. Nature neuroscience 8, 43-50, doi:10.1038/nn1362 (2005).

61 Suzuki, H. et al. In vivo imaging of C. elegans mechanosensory neurons demonstrates a specific role for the MEC-4 channel in the process of gentle touch sensation. Neuron 39, 1005-1017 (2003).

62 Herndon, L. A. et al. Stochastic and genetic factors influence tissue-specific decline in ageing C. elegans. Nature 419, 808-814, doi:10.1038/nature01135 (2002). 
63 Tank, E. M., Rodgers, K. E. \& Kenyon, C. Spontaneous age-related neurite branching in Caenorhabditis elegans. J Neurosci 31, 9279-9288, doi:10.1523/JNEUROSCI.660610.2011 (2011).

64 Pan, C. L., Peng, C. Y., Chen, C. H. \& McIntire, S. Genetic analysis of age-dependent defects of the Caenorhabditis elegans touch receptor neurons. Proceedings of the National Academy of Sciences of the United States of America 108, 9274-9279, doi:10.1073/pnas.1011711108 (2011).

65 Hall, D. H. \& Altun, Z. F. C. elegans atlas. (Cold Spring Harbor Laboratory Press, 2008).

66 Pan, C. L., Peng, C. Y., Chen, C. H. \& McIntire, S. Genetic analysis of age-dependent defects of the Caenorhabditis elegans touch receptor neurons. Proceedings of the National Academy of Sciences of the United States of America 108, 9274-9279, doi:10.1073/pnas.1011711108 (2011).

67 Toth, M. L. et al. Neurite Sprouting and Synapse Deterioration in the Aging Caenorhabditis elegans Nervous System. Journal of Neuroscience 32, 8778-8790, doi:10.1523/Jneurosci.1494-11.2012 (2012).

68 Murphy, C. T. \& Hu, P. J. Insulin/insulin-like growth factor signaling in C. elegans. WormBook, 1-43, doi:10.1895/wormbook.1.164.1 (2013).

69 Gems, D. et al. Two pleiotropic classes of daf-2 mutation affect larval arrest, adult behavior, reproduction and longevity in Caenorhabditis elegans. Genetics 150, 129155 (1998).

70 Feine, I., Pinkas, I., Salomon, Y. \& Scherz, A. Local oxidative stress expansion through endothelial cells--a key role for gap junction intercellular communication. PLoS One 7, e41633, doi:10.1371/journal.pone.0041633 (2012).

71 Aruoma, O. I., Halliwell, B., Hoey, B. M. \& Butler, J. The antioxidant action of Nacetylcysteine: its reaction with hydrogen peroxide, hydroxyl radical, superoxide, and hypochlorous acid. Free Radic Biol Med 6, 593-597 (1989).

72 Yang, W. \& Hekimi, S. A mitochondrial superoxide signal triggers increased longevity in Caenorhabditis elegans. PLoS Biol 8, e1000556, doi:10.1371/journal.pbio.1000556 (2010).

73 Wei, Y. \& Kenyon, C. Roles for ROS and hydrogen sulfide in the longevity response to germline loss in Caenorhabditis elegans. Proceedings of the National Academy of Sciences of the United States of America 113, E2832-2841, doi:10.1073/pnas.1524727113 (2016).

74 Miranda-Vizuete, A. \& Veal, E. A. Caenorhabditis elegans as a model for understanding ROS function in physiology and disease. Redox Biol 11, 708-714, doi:10.1016/j.redox.2016.12.020 (2017).

75 Bedner, P., Steinhauser, C. \& Theis, M. Functional redundancy and compensation among members of gap junction protein families? Biochimica et biophysica acta, doi:10.1016/j.bbamem.2011.10.016 (2011).

76 Chen, B., Liu, Q., Ge, Q., Xie, J. \& Wang, Z. W. UNC-1 regulates gap junctions important to locomotion in C. elegans. Curr Biol 17, 1334-1339, doi:10.1016/j.cub.2007.06.060 (2007).

77 Jang, H. et al. Dissection of neuronal gap junction circuits that regulate social behavior in Caenorhabditis elegans. Proceedings of the National Academy of Sciences of the United States of America 114, E1263-E1272, doi:10.1073/pnas.1621274114 (2017). 
78 Zhang, W. B. et al. Extended Twilight among Isogenic C. elegans Causes a Disproportionate Scaling between Lifespan and Health. Cell Syst 3, 333-345 e334, doi:10.1016/j.cels.2016.09.003 (2016).

79 Newell Stamper, B. L. et al. Movement decline across lifespan of Caenorhabditis elegans mutants in the insulin/insulin-like signaling pathway. Aging Cell 17, doi:10.1111/acel.12704 (2018).

80 Podshivalova, K., Kerr, R. A. \& Kenyon, C. How a Mutation that Slows Aging Can Also Disproportionately Extend End-of-Life Decrepitude. Cell Rep 19, 441-450, doi:10.1016/j.celrep.2017.03.062 (2017).

81 Lakowski, B. \& Hekimi, S. The genetics of caloric restriction in Caenorhabditis elegans. Proceedings of the National Academy of Sciences of the United States of America 95, 13091-13096, doi:DOI 10.1073/pnas.95.22.13091 (1998).

82 Gems, D. \& Riddle, D. L. Genetic, behavioral and environmental determinants of male longevity in Caenorhabditis elegans. Genetics 154, 1597-1610 (2000).

83 Zhang, B. et al. Brain-gut communications via distinct neuroendocrine signals bidirectionally regulate longevity in C. elegans. Genes \& development 32, 258-270, doi:10.1101/gad.309625.117 (2018).

84 Phillip, J. M., Aifuwa, I., Walston, J. \& Wirtz, D. The Mechanobiology of Aging. Annu Rev Biomed Eng 17, 113-141, doi:10.1146/annurev-bioeng-071114-040829 (2015).

85 Bao, L., Sachs, F. \& Dahl, G. Connexins are mechanosensitive. Am J Physiol Cell Physiol 287, C1389-1395, doi:10.1152/ajpcell.00220.2004 (2004).

86 Sohal, R. S. \& Orr, W. C. The redox stress hypothesis of aging. Free Radic Biol Med 52, 539-555, doi:10.1016/j.freeradbiomed.2011.10.445 (2012).

87 Rabinowitch, I., Chatzigeorgiou, M. \& Schafer, W. R. A Gap Junction Circuit Enhances Processing of Coincident Mechanosensory Inputs. Current Biology 23, 963-967, doi:10.1016/j.cub.2013.04.030 (2013).

88 Ezcurra, M. et al. C. elegans Eats Its Own Intestine to Make Yolk Leading to Multiple Senescent Pathologies. Curr Biol 28, 2544-2556 e2545, doi:10.1016/j.cub.2018.06.035 (2018).

89 Portal-Celhay, C., Bradley, E. R. \& Blaser, M. J. Control of intestinal bacterial proliferation in regulation of lifespan in Caenorhabditis elegans. BMC Microbiol 12, 49, doi:10.1186/1471-2180-12-49 (2012).

90 Starich, T. A., Hall, D. H. \& Greenstein, D. Two classes of gap junction channels mediate soma-germline interactions essential for germline proliferation and gametogenesis in Caenorhabditis elegans. Genetics 198, 1127-1153, doi:10.1534/genetics.114.168815 (2014).

91 Benard, C. \& Doitsidou, M. Nervous System Ageing. Healthy Ageing Long 5, 163-189, doi:10.1007/978-3-319-44703-2_8 (2017).

92 Bishop, N. A., Lu, T. \& Yankner, B. A. Neural mechanisms of ageing and cognitive decline. Nature 464, 529-535, doi:10.1038/nature08983 (2010).

93 Sulston, J. E. \& Brenner, S. The DNA of Caenorhabditis elegans. Genetics 77, 95-104 (1974).

94 Mello, C. C., Kramer, J. M., Stinchcomb, D. \& Ambros, V. Efficient gene transfer in C.elegans: extrachromosomal maintenance and integration of transforming sequences. EMBO J 10, 3959-3970 (1991). 
95 Lionaki, E. \& Tavernarakis, N. Assessing aging and senescent decline in Caenorhabditis elegans: cohort survival analysis. Methods in molecular biology (Clifton, N.J 965, 473-484, doi:10.1007/978-1-62703-239-1_31 (2013).

96 Amrit, F. R., Ratnappan, R., Keith, S. A. \& Ghazi, A. The C. elegans lifespan assay toolkit. Methods 68, 465-475, doi:10.1016/j.ymeth.2014.04.002 (2014).

97 Timmons, L., Court, D. L. \& Fire, A. Ingestion of bacterially expressed dsRNAs can produce specific and potent genetic interference in Caenorhabditis elegans. Gene 263, 103-112 (2001).

98 Liu, J. et al. Functional aging in the nervous system contributes to age-dependent motor activity decline in C. elegans. Cell Metab 18, 392-402, doi:10.1016/j.cmet.2013.08.007 (2013).

99 Wong, A., Boutis, P. \& Hekimi, S. Mutations in the clk-1 gene of Caenorhabditis elegans affect developmental and behavioral timing. Genetics 139, 1247-1259 (1995).

100 Chen, X. \& Chalfie, M. Modulation of C. elegans touch sensitivity is integrated at multiple levels. J Neurosci 34, 6522-6536, doi:10.1523/JNEUROSCI.0022-14.2014 (2014).

101 Zhang, Y. \& Chalfie, M. MTD-1, a touch-cell-specific membrane protein with a subtle effect on touch sensitivity. Mech Dev 119, 3-7 (2002).

102 Hobert, O., Moerman, D. G., Clark, K. A., Beckerle, M. C. \& Ruvkun, G. A conserved LIM protein that affects muscular adherens junction integrity and mechanosensory function in Caenorhabditis elegans. The Journal of cell biology 144, 45-57, doi:10.1083/jcb.144.1.45 (1999).

\section{Figure Legends}

Fig. 1 The $C$. elegans gap junction genes regulate longevity. Numbers in non-italicised brackets show number of animals per group for the respective experiment. a Lifespan of N2 worms and unc-7(e5) (120), (b) unc-9(e101) (150), (c) eat-5(ad1402) (130), (d) inx-1(tm3524) (120), (e) inx-2(ok376) (120 for N2, 121 for inx-2), (f) che-7(ok2373) (130), (g) inx-5(ok1053) (130 for N2, 128 for inx-5), (h) inx-6(rr5) (130), (i) inx-7(ok2319) (120), (j) inx-8(gk42) (120), (k) inx-9(ok1502) (120), (I) inx-10(ok2714) (130), (m) inx-11(ok2783) (130), (n) inx-14(ag17) (130), (o) inx-15(tm3394) (120), (p) inx-16(ox144) (120), (q) inx-17(tm3292) (120), (r) inx18(ok2454) (130), (s) inx-19(ky634) (130 for N2, 131 for inx-19), (t) inx-20(ok681) (120), (u) 
inx-21(ok2524) (120 for N2, 130 for inx-20), (v) inx-22(tm1661) (120 for N2, 130 for inx-22)

mutants. For $p$ values see Fig. 2.

Fig. 2 The effects of innexins on lifespan correlate with their tissue expression patterns. Percentage change in lifespan (left) relative to N2 control animals produced by innexin mutations along with normal expression patterns in major C. elegans tissues (right). ${ }^{*} \mathrm{P}<0.05 ;{ }^{* * *} \mathrm{p}<0.001 ; * * * * \mathrm{p}<0.0001 ;$ NS not significant, using Log-rank test.

Fig. 3 unc-9 regulates longevity in the same pathway as unc-7 innexin and unc- 1 stomatin. a unc-9(fc16) and unc-9(e101) mutants increase lifespan relative to $\mathrm{N} 2$ controls ( $\mathrm{N}=130$ animals per group). $\mathbf{b}$ Fosmid rescue of unc-9(e101) reduces lifespan to N2 control levels ( $N=150$ animals per group). c unc-9(fc16) unc-7(e5) double mutants have the same lifespan as unc-9(fc16) mutants ( $\mathrm{N}=150$ animals per group). $\mathbf{d}$ unc-1(e719 LOF) mutants have similarly extended lifespan as unc-9(e101) mutants ( $\mathrm{N}=120$ animals per group). e unc9(e1598 GOF) mutants ( $\mathrm{N}=120$ animals) have significantly reduced lifespan compared to $\mathrm{N} 2$ controls ( $\mathrm{N}=120$ animals). unc-1(e1598) unc-9(e101) mutants ( $\mathrm{N}=130$ animals) have similar lifespans as unc-9(e101) mutants ( $\mathrm{N}=120$ animals). ${ }^{* *} \mathrm{P}<0.01 ; * * * * \mathrm{p}<0.0001$; ns not significant, using Log-rank test.

Fig. 4 Lacking the unc- 9 innexin also improves healthy ageing of C. elegans. a Relative locomotory speed declines more slowly with age in unc-9(e101) mutants than in N2 controls ( $\mathrm{N}=9$ plates per group). The arrow indicates the delay of unc-9 mutant worms in reaching $50 \%$ of maximal functional capacity, which defines healthspan, relative to N2 wild type. $\mathbf{b}$ Touch responsiveness declines more slowly in ageing unc-9(e101) mutants than in N2 
( $N=120$ animals per group). The arrow indicates the delay of unc- 9 mutant worms in reaching $50 \%$ of maximal functional capacity relative to N2. c Change in defecation cycle duration with age in unc-9(e101) mutants and N2 controls ( $\mathrm{N}=26$ animals per group). $\mathrm{d}$ Change in pharyngeal pumping rate in ageing unc-9(e101) mutants and $\mathrm{N} 2$ controls ( $\mathrm{N}=15$ animals per group). ${ }^{*} \mathrm{P}<0.05 ;{ }^{* *} \mathrm{p}<0.001$; ns not significant; (a), (c), (d) mixed effects model; (b) generalised estimating equations.

Fig. 5 unc- 9 acts in the glutamatergic nervous system to regulate lifespan. a RNAi knockdown of unc-9 does not affect lifespan in N2 animals ( $n=139$ animals per group), but (b) increases it significantly in the RNAi hypersensitive KP3948 strain ( $N=130$ animals per group). c Lifespan is significantly increased by RNAi knockdown of unc- 9 in glutamatergic neurons ( $\mathrm{N}=130$ animals control; 129 unc-9 RNAi), but not in (d) cholinergic ( $N=130$ animals per group), (e) GABAergic ( $\mathrm{N}=136$ animals control; 140 unc-9 RNAi) or (f) dopaminergic neurons ( $\mathrm{N}=134$ animals control; 136 unc-9 RNAi). ${ }^{* * * *} \mathrm{P}<0.0001$; ns not significant, using Log-rank test.

Fig. 6 UNC-9 depends on mechanosensation to regulate lifespan. a Class, type and mechanosensory function of glutamatergic neurons expressing unc-9. See also Supplementary Fig. 5. b Lifespan of mec-6(e1342); unc-9(e101) mutants is identical to that of mec-6(e1342) mutants, significantly shorter than in unc-9(e101) mutants, but longer than in $\mathrm{N} 2$ controls ( $\mathrm{N}=150$ animals per group). c Lifespan of unc-9(e101) mec-4(u253) mutants is significantly shorter than in unc-9(e101) mutants, whereas mec-4(u253) mutants have similar lifespan to $\mathrm{N} 2$ controls ( $\mathrm{N}=120$ animals per group). $\mathbf{d}$ Touch responses of N2, unc- 
9(e101), mec-3(e1338) and mec-4(e1611d) animals ( $\mathrm{N}=15$ animals per group). ${ }^{* *} \mathrm{P}<0.01$;

$* * * p<0.001 ; * * * * p<0.0001 ;$ ns not significant; (b), (c) Log-rank test; (d) Student's t-test.

Fig. 7 UNC-9 alters age-dependent morphological changes of the touch receptor neurons. a Schematic representation of ALM, AVM and PLM morphology. b Representative GFP images of mechanosensory neurons in day 1 , day 5 and day 17 unc-9(e101) adults; arrows showcase ageing-related defects; scale bar: $20 \mu \mathrm{m}$. c Age-related degeneration of ALM and (d) PLM neurites, and of (e) AVM cell body in unc-9(e101) mutants and N2 controls. f Example GFP images of normal branching and age-related morphological defects arising in ALM neurites; scale bar: $20 \mu \mathrm{m} . \mathbf{g}$ The overall number of ALM branches increases similarly with age in unc9(e101) mutants and $\mathrm{N} 2$ controls. $\mathbf{h}$ The increase in proportion of long branches with age, relative to short and normal branches combined, is significantly lower in N2 (i) than in unc9(e101) animals $\left(p<0.001,{ }^{* *}\right)$. j Abnormal branching rises earlier in unc-9(e101) mutants than $\mathrm{N} 2$ controls. ${ }^{* *} \mathrm{P}<0.01 ;{ }^{* * *} \mathrm{P}<0.001$; ns not significant; (c-e), (j) binomial regression model; (g) Poisson generalised linear model; $(\mathbf{h}, \mathbf{i})$ multinomial regression model. $\mathrm{N}=50$ animals per group for (c-e); $\mathrm{N}=30$ animals per group for (g-j).

Fig. 8 UNC-9 lifespan regulation is independent of FOXO signalling but linked to reactive oxygen species. a Lifespan of daf-16(mu86), daf-16(mu86); unc-9(e101) and unc-9(e101) mutants. b Lifespan of daf-2(e1370), daf-2(e1370); unc-9(e101) and unc-9(e101) mutants. c Lifespan of unc-9(e101) mutants and N2 animals with or without treatment with 9mM NAcetyl-Cysteine (NAC) maintained at normoxia $\left(21 \% \mathrm{O}_{2}\right)$. d Lifespan of unc-9(e101) mutants and $\mathrm{N} 2$ animals maintained at hypoxia $\left(7 \% \mathrm{O}_{2}\right)$ with or without treatment with $5 \mathrm{mM} \mathrm{NAC.}$ 
bioRxiv preprint doi: https://doi.org/10.1101/657817; this version posted June 2, 2019. The copyright holder for this preprint (which was

not certified by peer review) is the author/funder, who has granted bioRxiv a license to display the preprint in perpetuity. It is made available under aCC-BY-NC-ND 4.0 International license.

${ }^{*} \mathrm{P}<0.05 ;{ }^{* *} \mathrm{p}<0.01 ;{ }^{* *} \mathrm{p}<0.001 ;{ }^{* * *} \mathrm{p}<0.0001 ;$ ns not significant, using Log-rank test.

$\mathrm{N}=150$ animals per group (a),(b); $\mathrm{N}=120$ animals per group (c),(d). 
bioRxiv preprint doi: https://doi.org/10.1101/657817; this version posted June 2, 2019. The copyright holder for this preprint (which was

not certified by peer review) is the author/funder, who has granted bioRxiv a license to display the preprint in perpetuity. It is made IOU $\mathbf{I r e} \mathbf{I}$

a

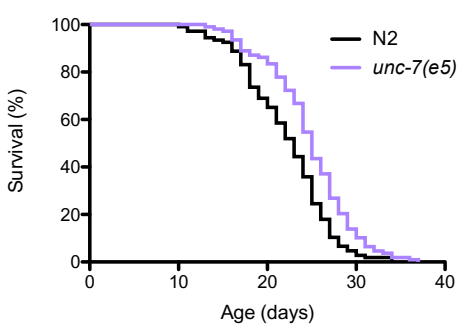

e

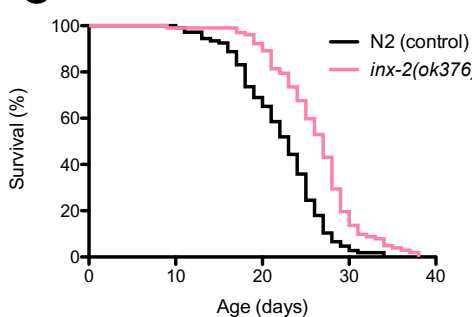

i

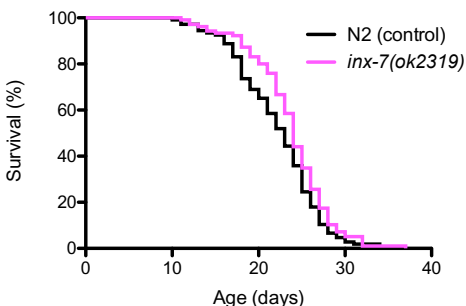

m

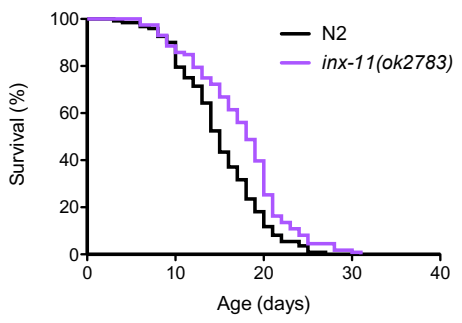

c

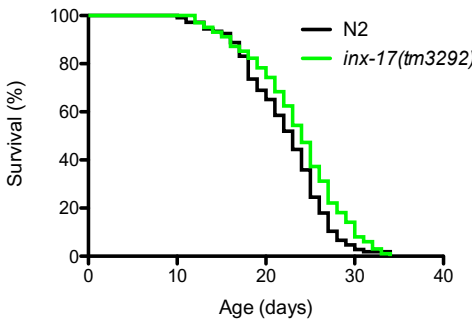

u

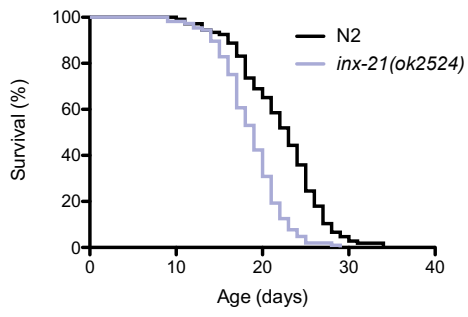

b

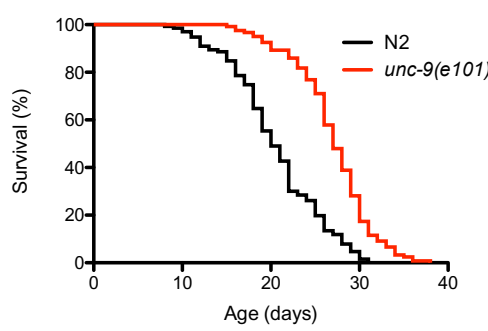

f

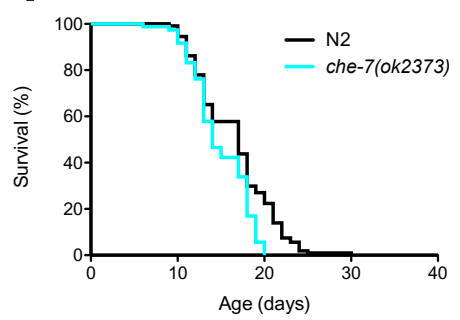

j

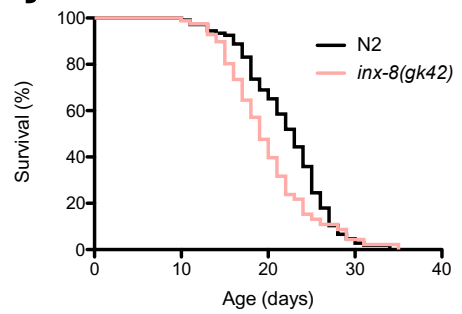

n

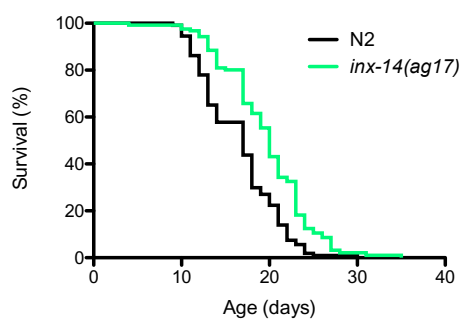

$r$
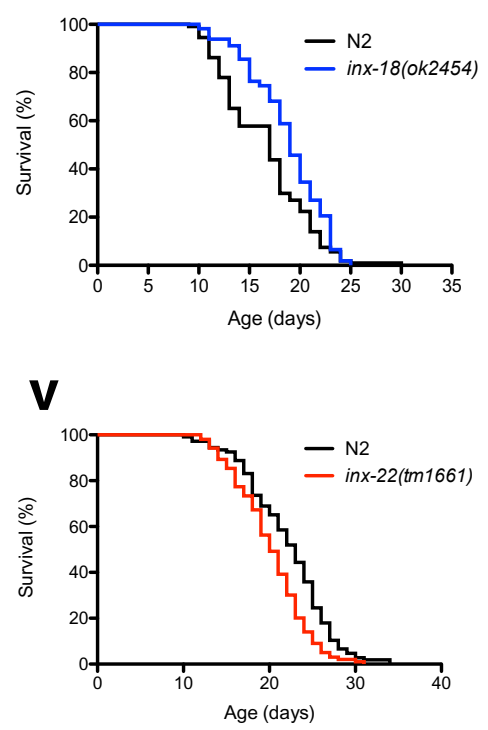

C

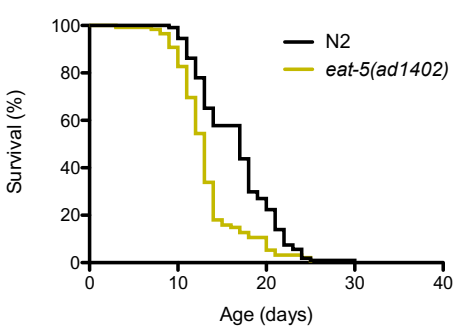

g

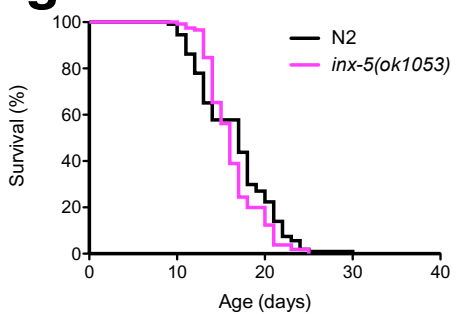

k

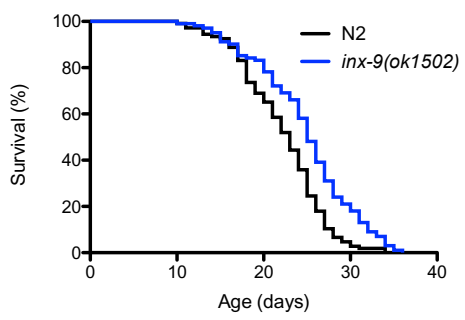

0

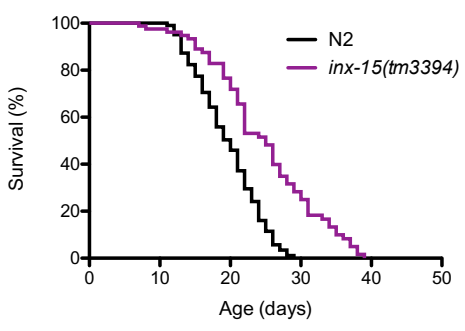

s

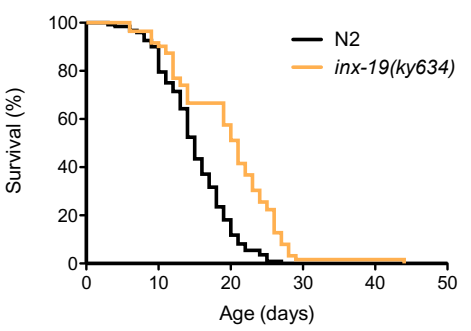

d

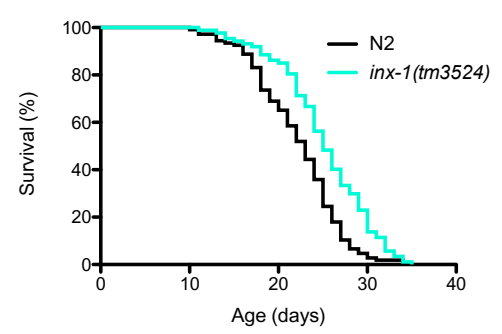

h

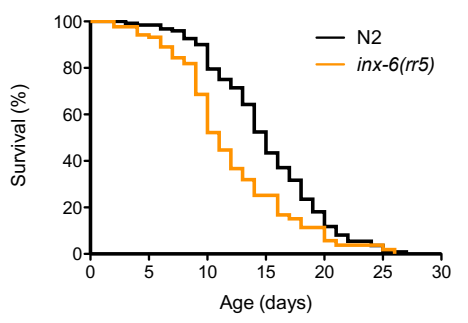

I

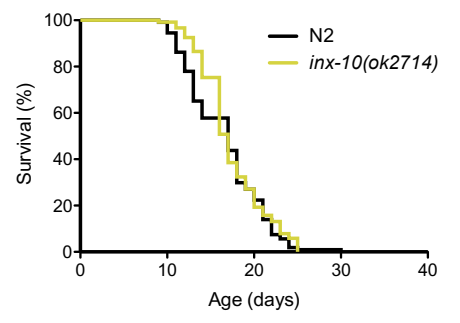

p

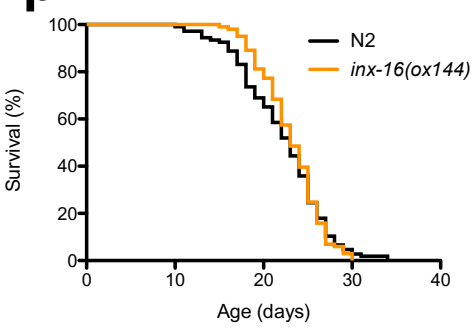

t

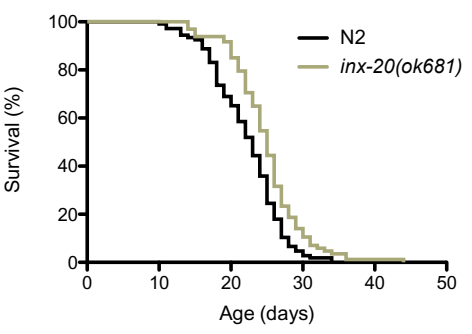




\section{Figure 2}

$\%$ change in median lifespan relative to N2

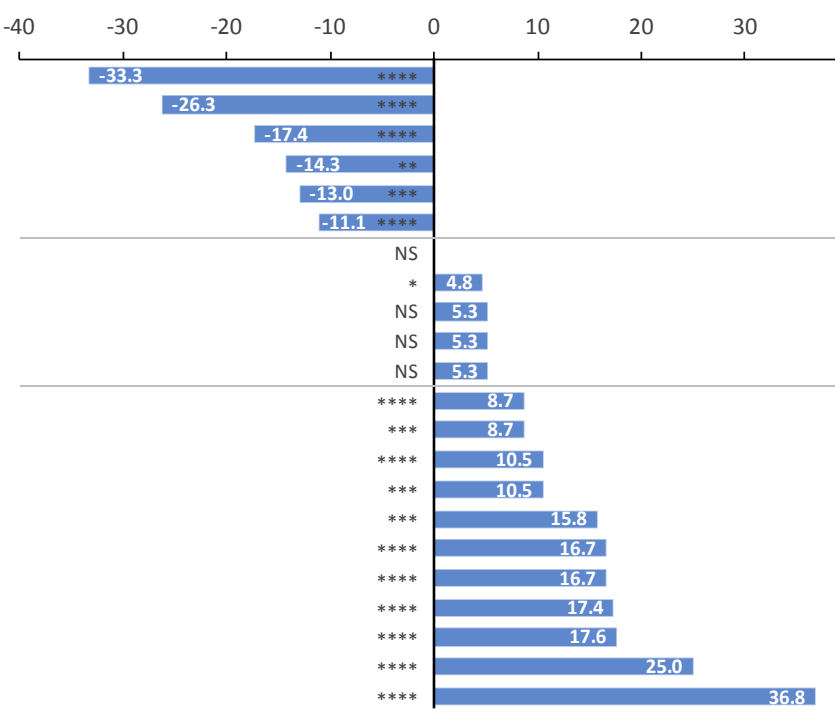

P-value

vs. control Gen

$<0.0001$ in $x-6$

$<0.0001$ eat-5 $\quad$ ad 1402

$<0.0001$ inx-21 ok2524

0.0042 in $x-8 \quad g k 42$

0.0003 in $x-22 \quad \operatorname{tm} 1661$

$<0.0001$ che-7 ok2373

$\begin{array}{lll}0.8698 & \text { in } x-16 & \text { ox144 } \\ 0.0112 & \text { in } x-17 & \text { tm } 3292\end{array}$

\begin{tabular}{lll}
0.0112 & in $x-17$ & $\operatorname{tm} 3292$ \\
\hline 0.129 & in $x-5$ & $0 k 1053$
\end{tabular}

\begin{tabular}{l|l|l|}
\hline 0.129 & inx -5 & ok1053 \\
\hline 0.0601 & inx-7 & ok2319 \\
\hline 0.0784 & in $x-10$ & ok2714
\end{tabular}

\begin{tabular}{l|l|l|}
0.0601 & inx -7 & ok2319 \\
\hline 0.0784 & inx-10 & ok2714 \\
\hline$<0.0001$ & ix -9 & ok 1502 \\
\hline
\end{tabular}

\begin{tabular}{l|l|l|}
0.0784 & in $x-10$ & ok2714 \\
\hline$<0.0001$ & inx -9 & ok1502
\end{tabular}

0.0004 in $x-20$ ok68

$<0.0001$ unc-7 e5

0.0004 in $x-1 \quad$ tm3524

0.001 in $x-18 \quad$ ok2454

$<0.0001$ in $x-11 \quad$ ok2783

$<0.0001$ inx $-19 \quad k y 634$

$<0.0001$ inx-2 ok376

\begin{tabular}{l|l|l}
$<0.0001$ & in $x-14$ & ag17 \\
\hline$<0.0001$ & in $x-15$ & tm3394
\end{tabular}

$<0.0001$ unc-9 e101

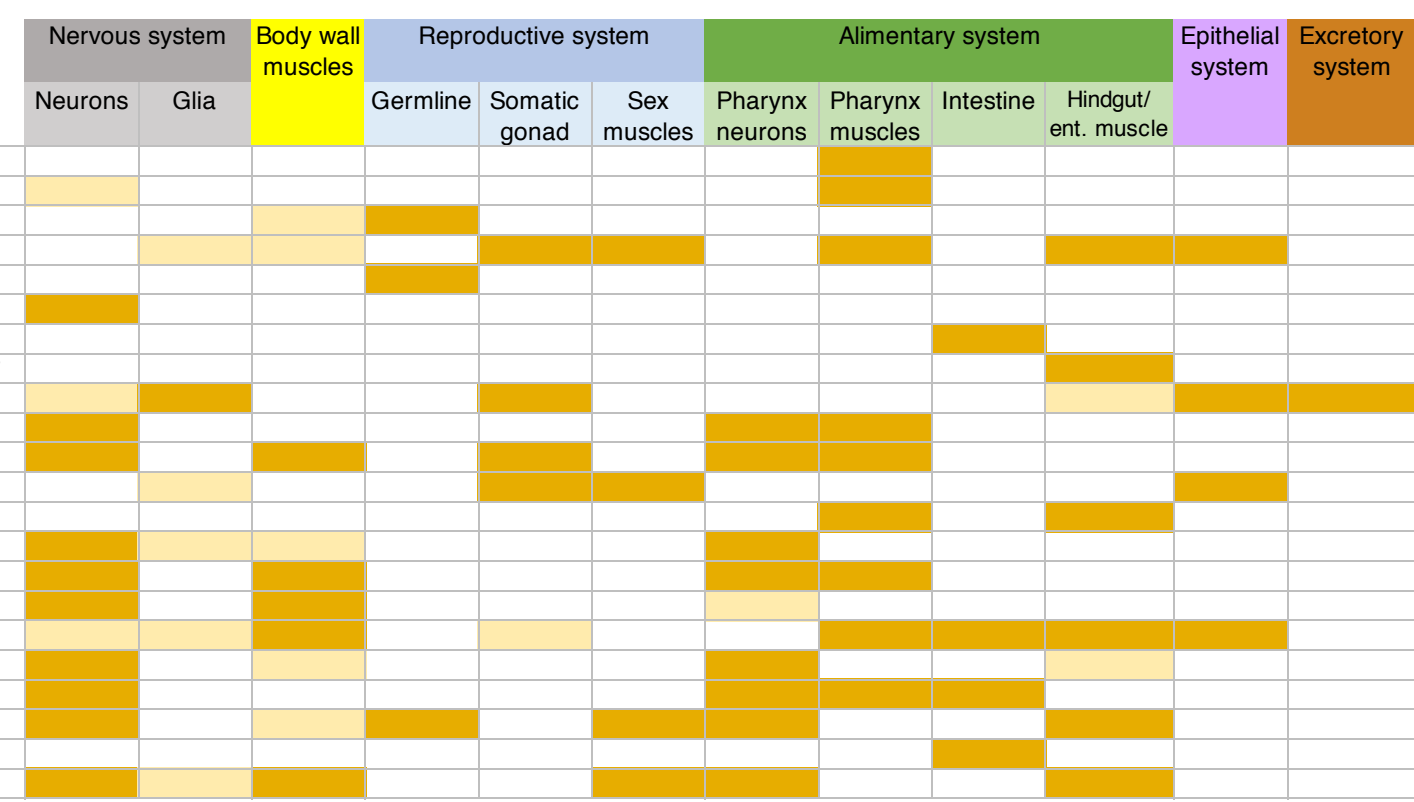

major expression minor expression 
bioRxiv preprint doi: https://doi.org/10.1101/657817; this version posted June 2, 2019. The copyright holder for this preprint (which was

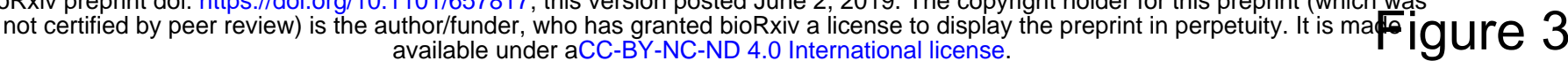

a

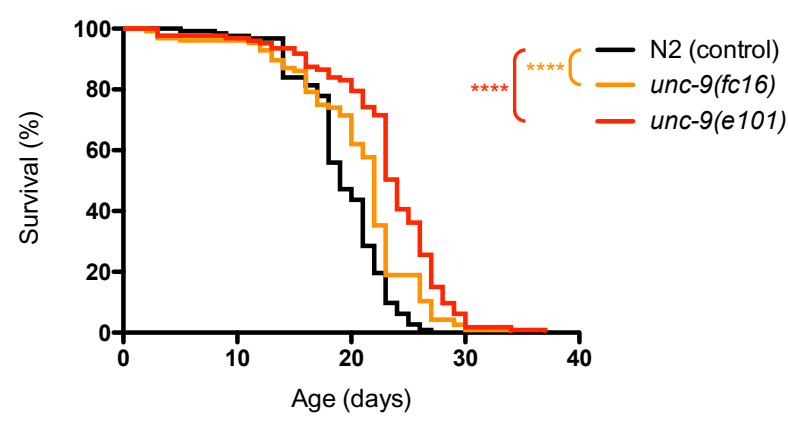

C

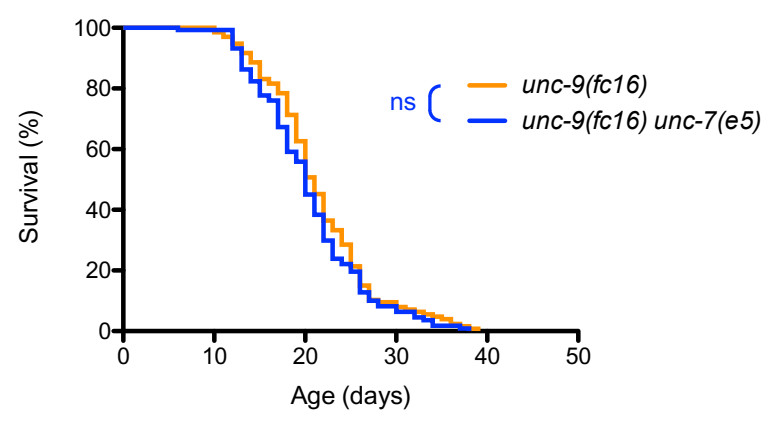

e

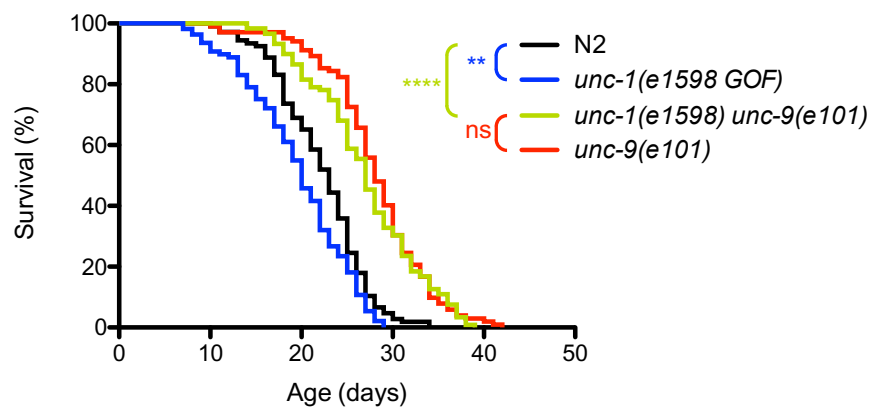

b

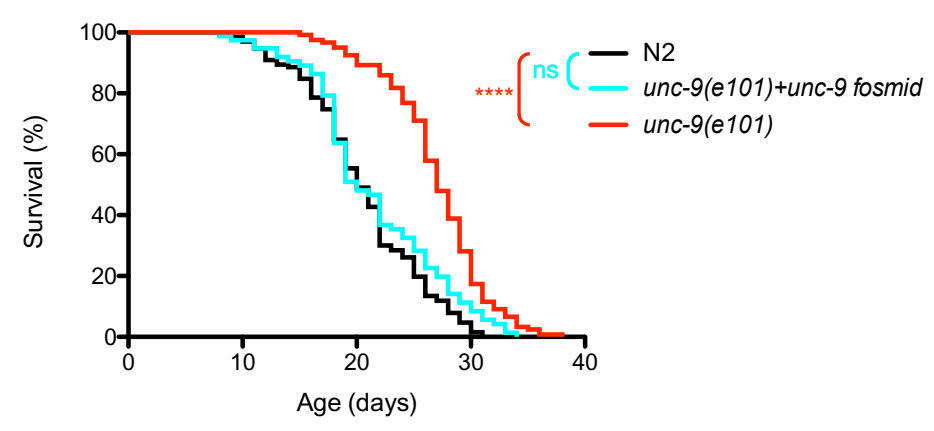

d

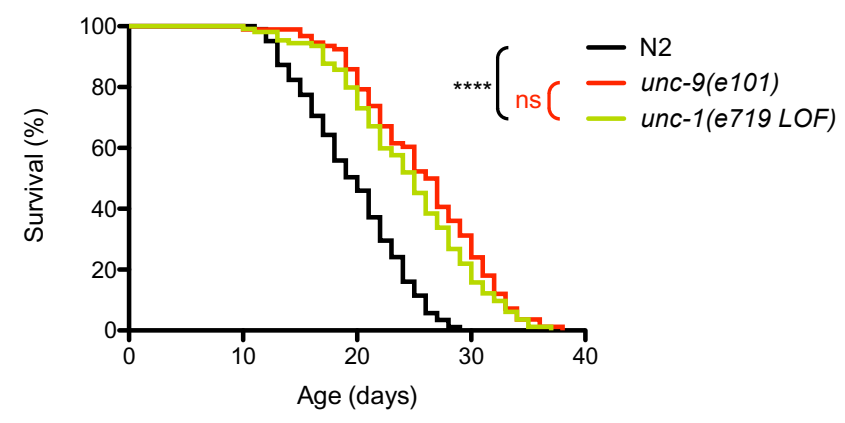


bioRxiv preprint doi: https://doi.org/10.1101/657817; this version posted June 2, 2019. The copyright holder for this preprint (which wạs

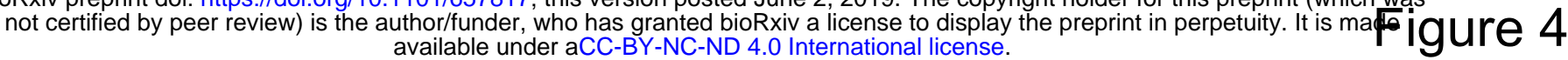

\section{a}
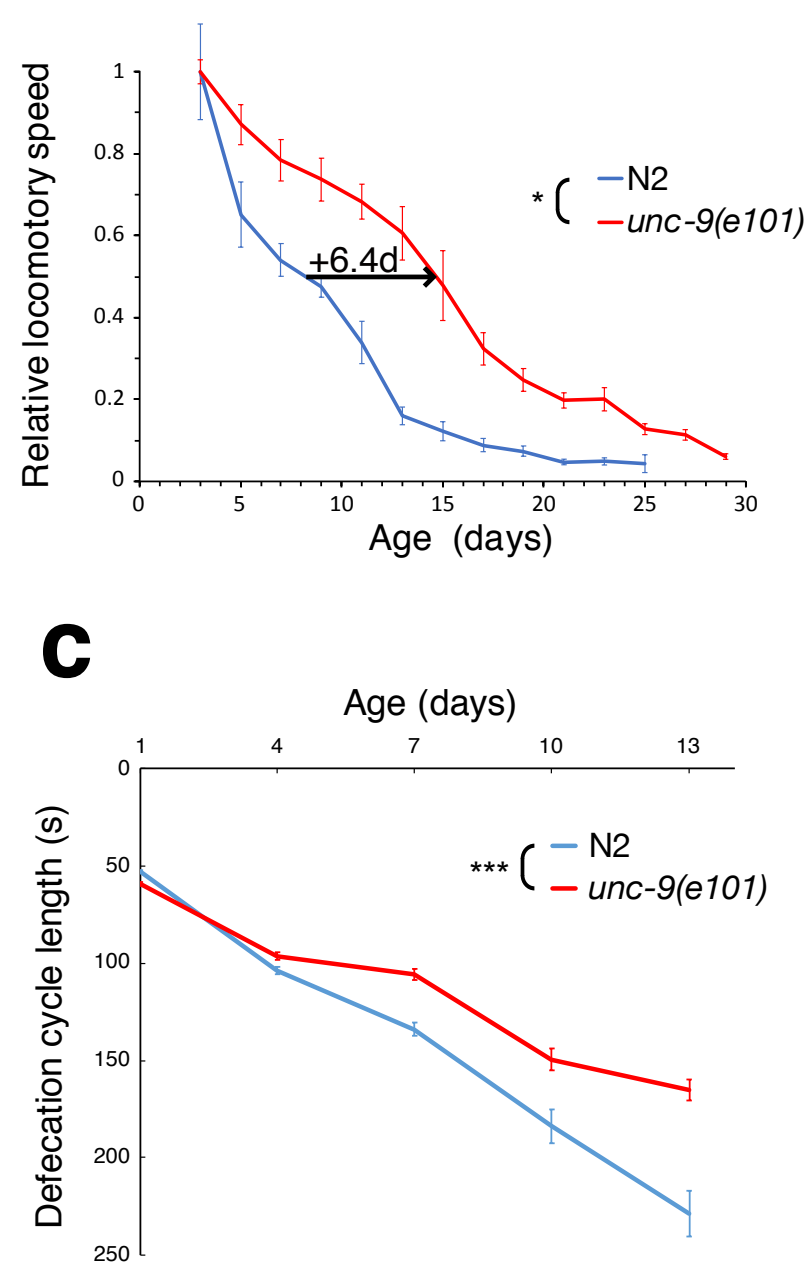

b

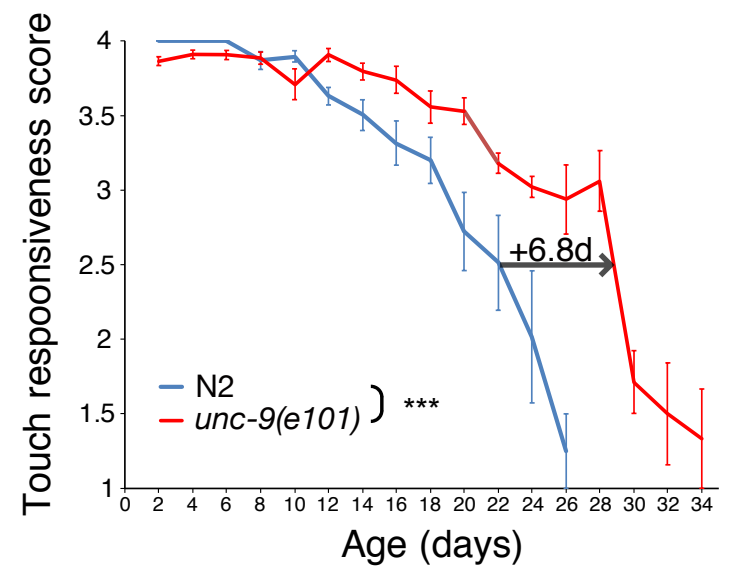

d

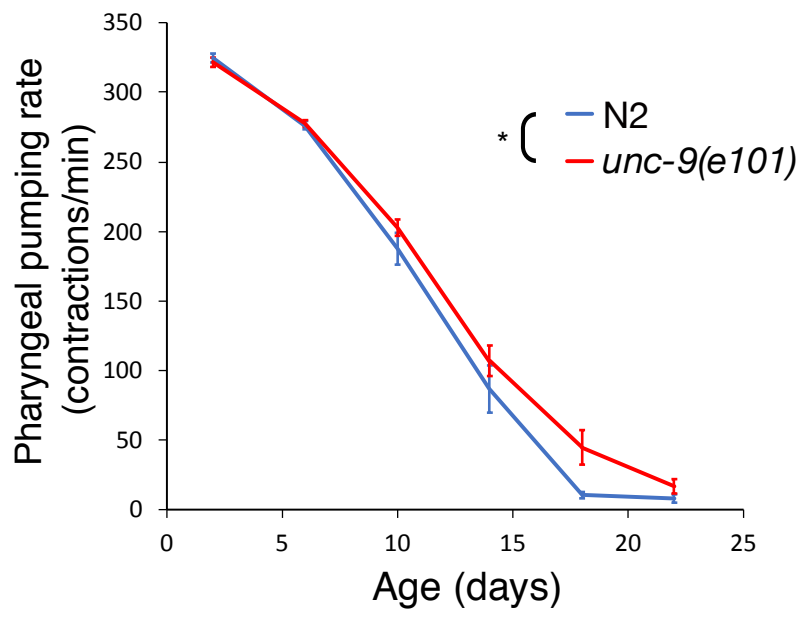


bioRxiv preprint doi: https://doi.org/10.1101/657817; this version posted June 2, 2019. The copyright holder for this preprint (which wąs

not certified by peer review) is the author/funder, who has granted bioRxiv a license to display the preprint in perpetuity. It is mafe I
available under aCC-BY-NC-ND 4.0 International license.

a

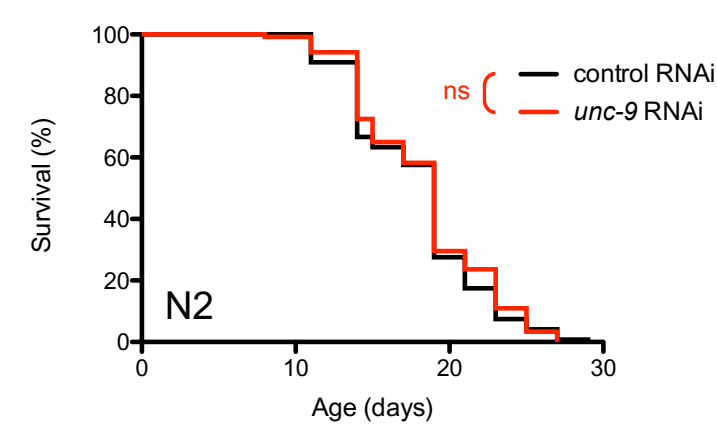

C

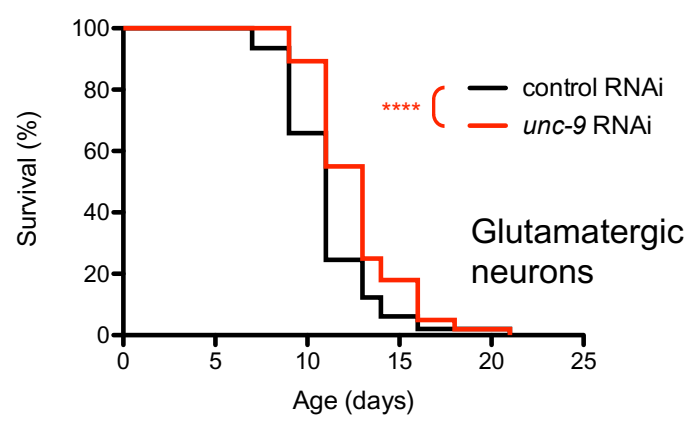

e

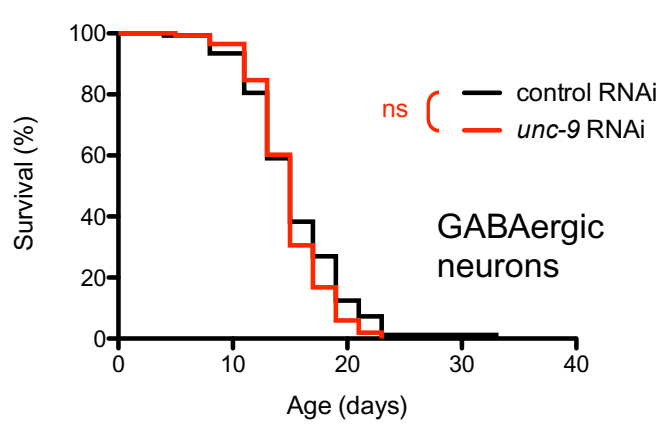

b

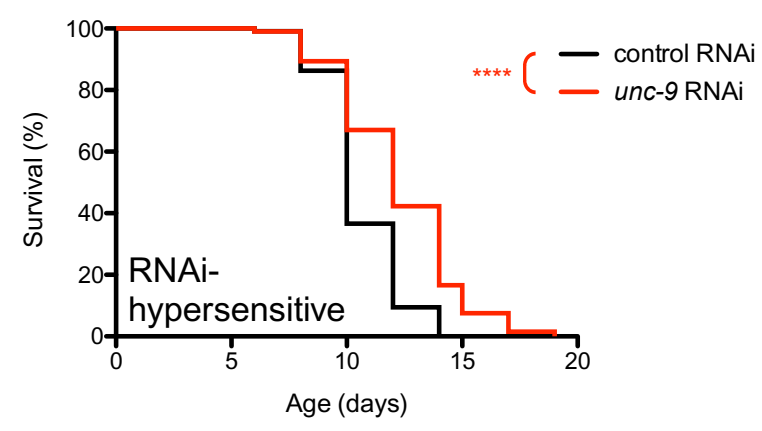

d

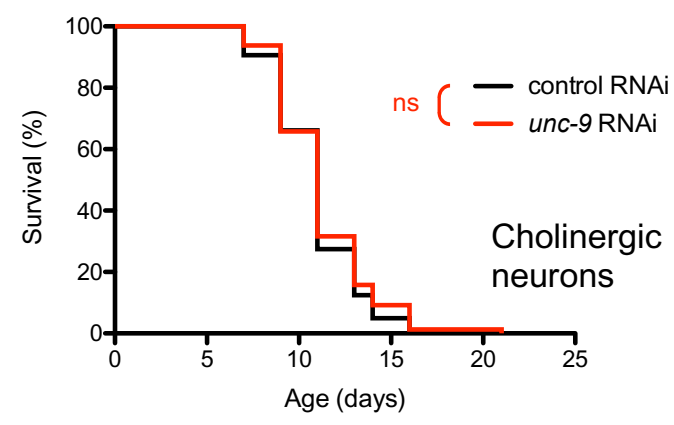

f

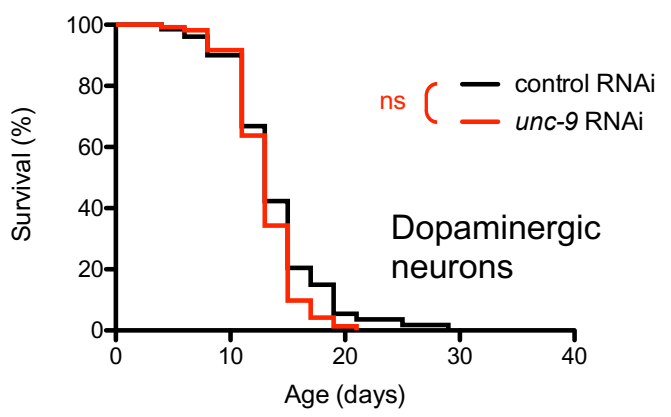


bioRxiv preprint doi: https://doi.org/10.1101/657817; this version posted June 2, 2019. The copyright holder for this preprint (which was

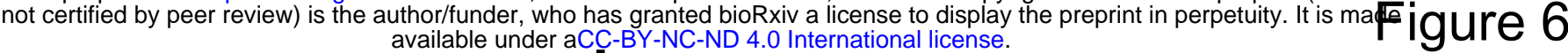

a

\begin{tabular}{|l|l|l|}
\hline $\begin{array}{l}\text { Neuron } \\
\text { class }\end{array}$ & Type & $\begin{array}{l}\text { Mechanosensory } \\
\text { function? }\end{array}$ \\
\hline ADA & Interneuron & \\
\hline ADL & Sensory & Harsh touch \\
\hline AIB & Interneuron & \\
\hline AIM & Interneuron & \\
\hline AIZ & Interneuron & \\
\hline ALM & Sensory & Gentle touch \\
\hline AQR & Sensory & Anterior harsh touch \\
\hline ASE & Sensory & \\
\hline ASH & Sensory & Harsh nose touch \\
\hline ASK & Sensory & \\
\hline AUA & Interneuron & \\
\hline AVM & Sensory & Gentle touch \\
\hline AWC & Sensory & \\
\hline DVC & Interneuron & \\
\hline FLP & Sensory & Harsh nose touch \\
\hline IL1 & Sensory & Nose touch \\
\hline LUA & Interneuron & \\
\hline OLL & Sensory & Nose touch \\
\hline OLQ & Sensory & Nose touch \\
\hline PHA & Sensory & Harsh touch to anus \\
\hline PHB & Sensory & Harsh touch to anus \\
\hline PHC & Sensory & \\
\hline PLM & Sensory & Gentle touch \\
\hline PQR & Sensory & \\
\hline PVD & Sensory & Posterior harsh touch \\
\hline PVQ & Interneuron & \\
\hline PVR & Interneuron & \\
\hline RIA & Interneuron & \\
\hline RIG & Interneuron & \\
\hline RIM & Motoneuron & \\
\hline URY & Sensory & \\
\hline & & \\
\hline
\end{tabular}

b
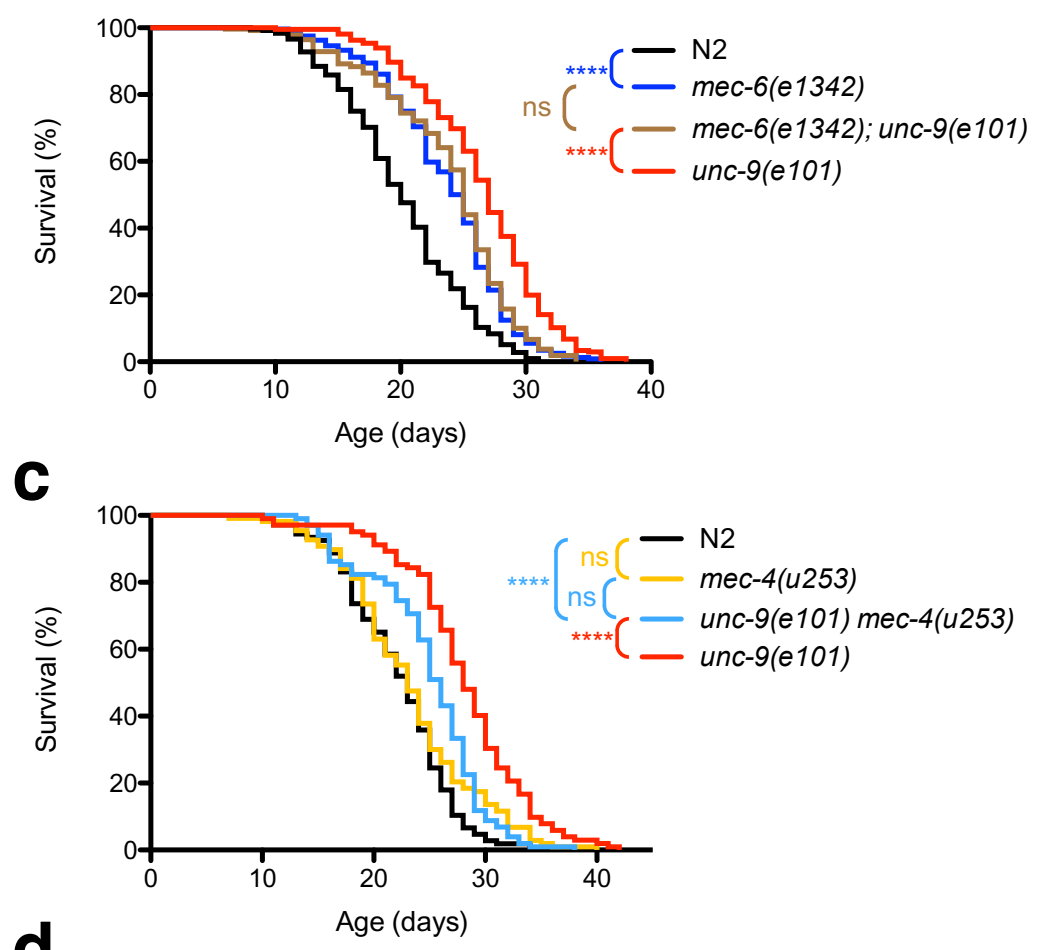

d

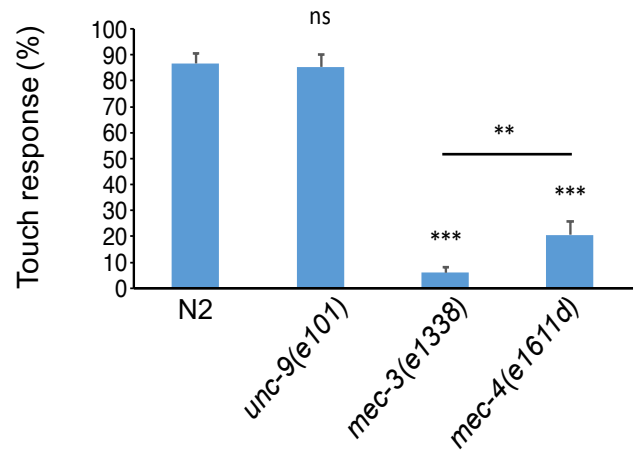


a

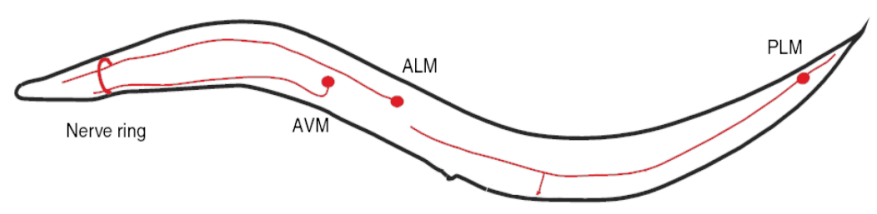

C

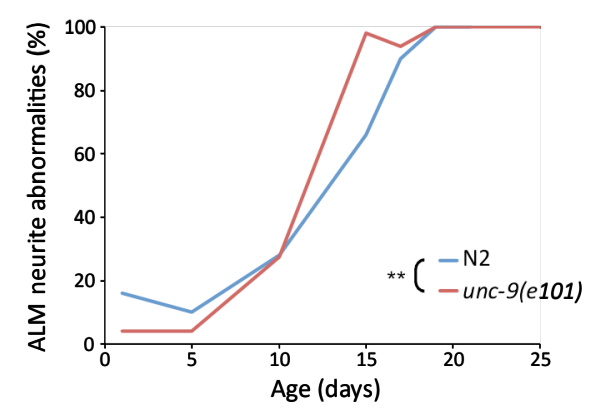

$\mathbf{f}$
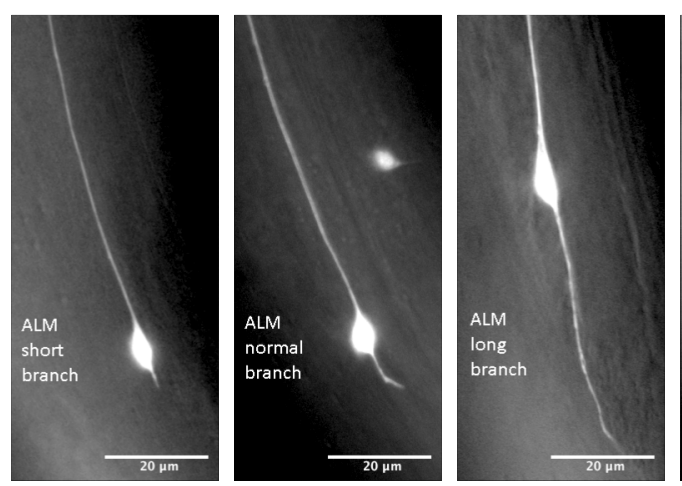

h

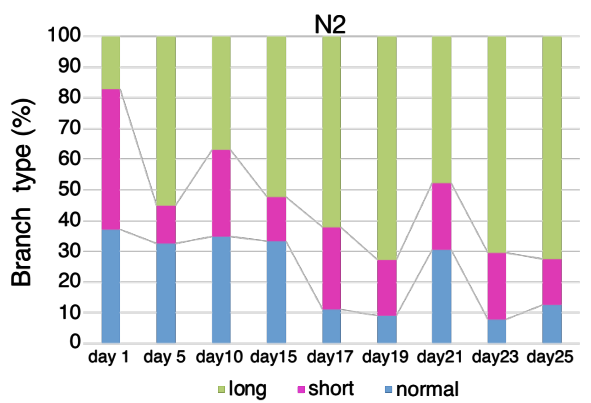

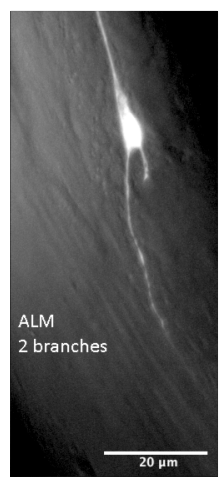
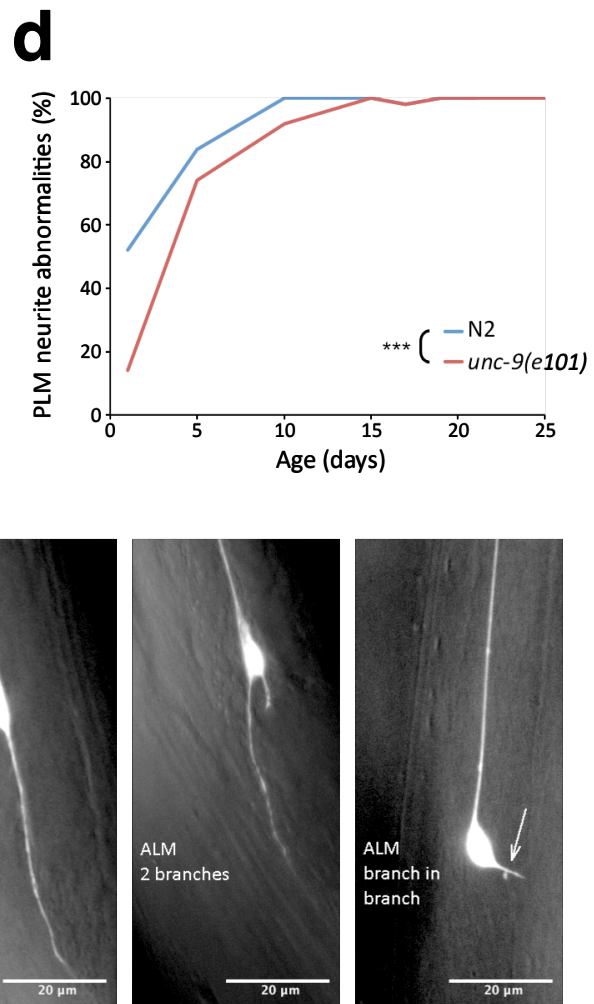

i

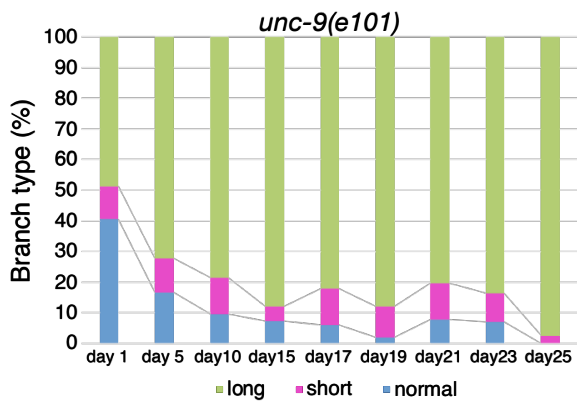

b Day 1

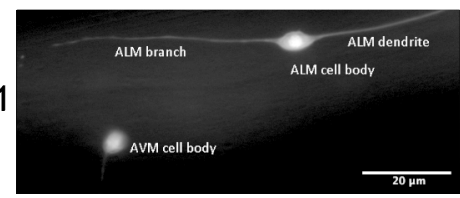

Day 5

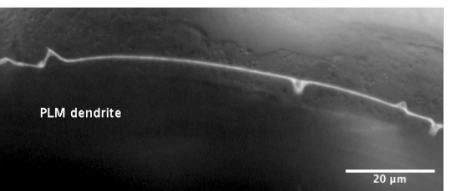

Day 17

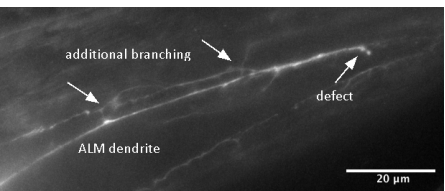

e

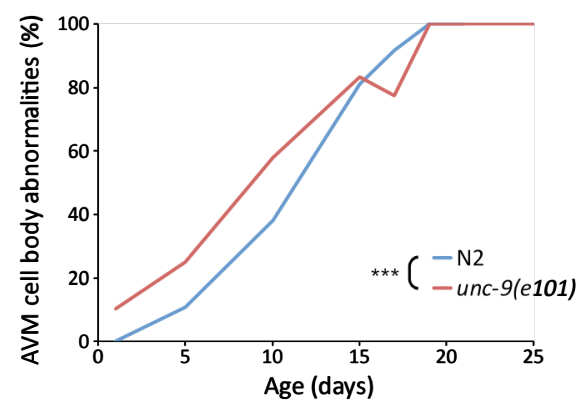

g
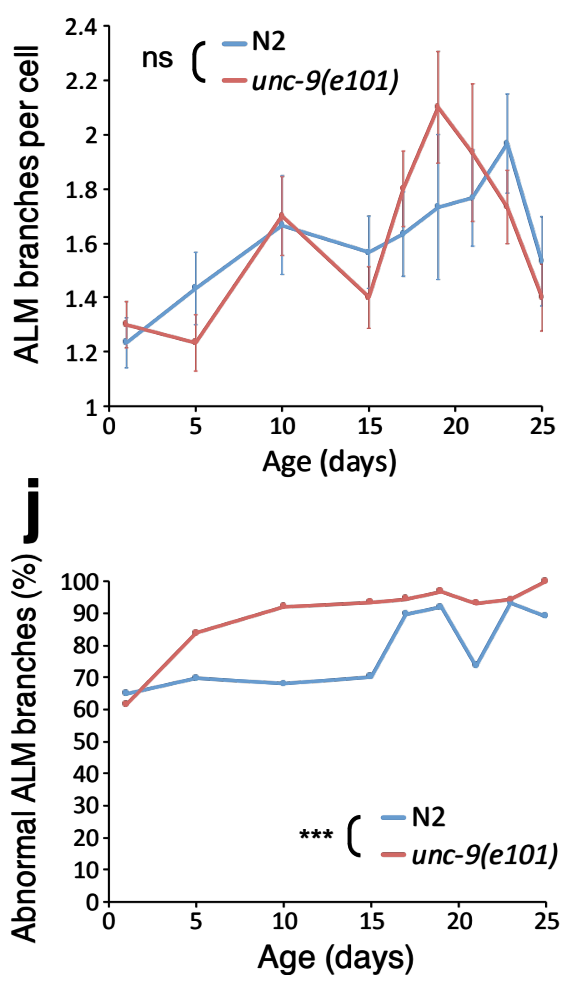
bioRxiv preprint doi: https://doi.org/10.1101/657817; this version posted June 2, 2019. The copyright holder for this preprint (which was

not certified by peer review) is the author/funder, who has granted bioRxiv a license to display the preprint in perpetuity. It is mafe igure 8

a

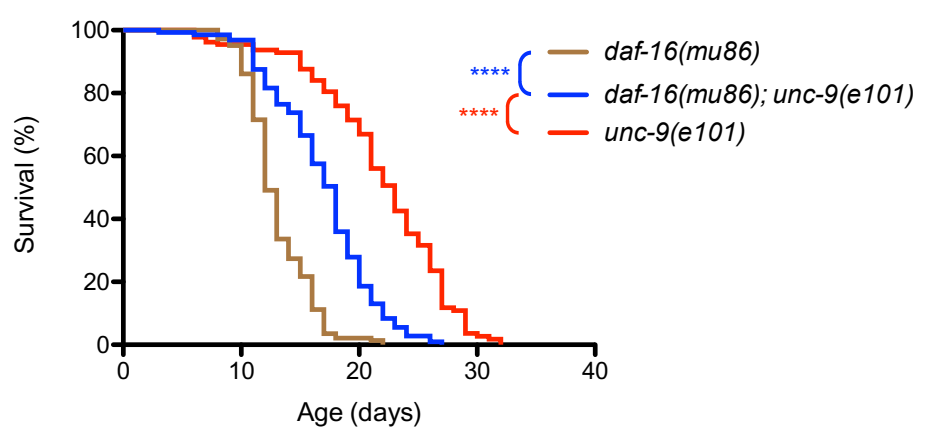

C

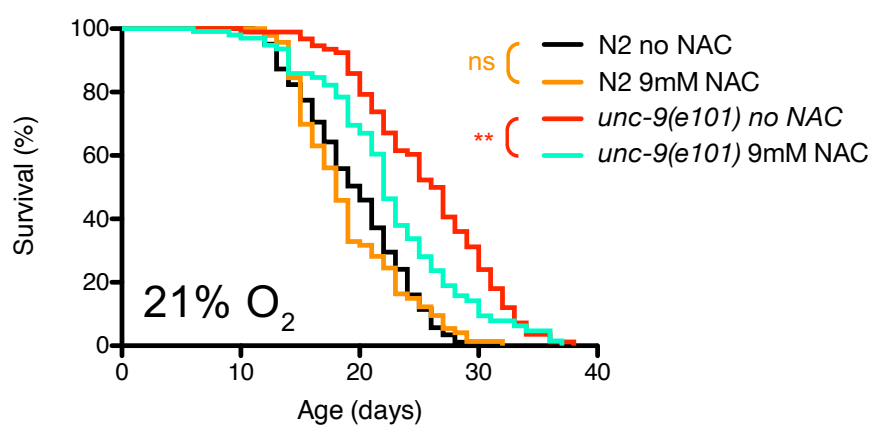

b
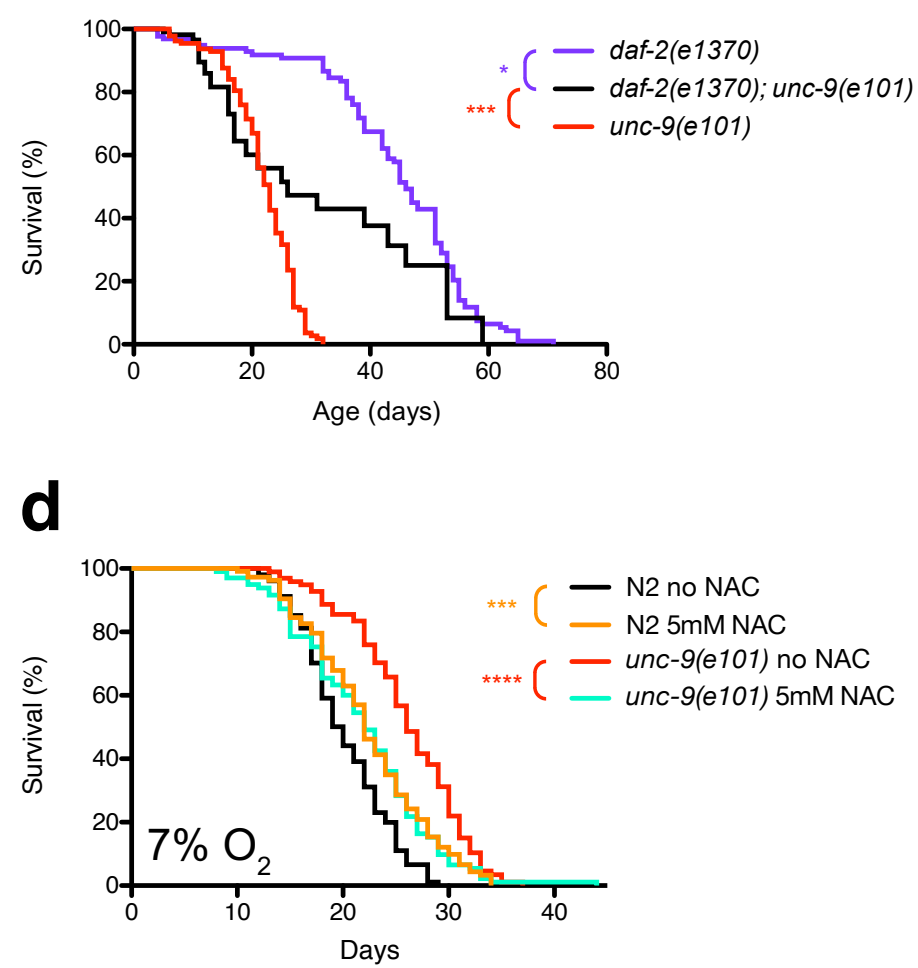


\title{
Supplementary Methods
}

\begin{abstract}
Ablation
Laser ablation of the PVR interneuron to conduct a lifespan assay was performed essentially as described ${ }^{16}$. L1 larvae were immobilized in a $2 \mu \mathrm{l}$ drop of $80 \mathrm{mM} \mathrm{NaN}_{3}$ on a $2 \%$ agarose pad. PVR was ablated in flp-20::GFP worms. PVR was identified based on its position near the PLM neurons and the shape of its processes. Worms were mounted on a Zeiss Axio Imager.M2 using a $63 x$ objective, and cells were ablated with the Andor Micropoint system using a laser microbeam in asynchronous FRAP mode with 60 pulses at $60 \%$ of maximal power. The next day L4 stage worms were checked for proper ablation and selected for the lifespan assay. Mock ablated animals were treated in the same way except that the laser firing was omitted.
\end{abstract}

\section{Tap assay}

Conditions and software were used as outlined for the locomotion assay, with the addition of mechanical stimuli. The tapper component of WormLab (MBF Biosciences) induces a single mechanical stimulus, and consists of a custom built linear solenoid actuator which drives a small plunger into a contact point on the plate holder assembly. The linear solenoid has a $5.5 \mathrm{~mm}$ throw and is operated at 24V DC. Maximum stimulus intensity was used every 60 seconds during the recording. Analysis was performed as described for the locomotion assays. In addition, moving average speed was calculated before and after two taps. The subtracted value between the two time periods, indicating the change in speed, was averaged between the two taps and plotted as relative increase in speed ${ }^{17}$.

\section{Swimming assays}

To verify the rescue effect of unc- 9 expression from a fosmid, the swimming behaviour was compared between N2 Bristol, unc-9(e101) and unc-9(e101); [punc-9::unc-9; pmyo$2:: m$ Cherry] worms. One day prior to the assay L4 larvae were selected. Ten animals per strain were transferred with an eyelash pick to one well of a 96 well plate, filled with NGM and topped up with M9 Buffer. After ten minutes of acclimatisation videos of 1 min length at 30 fps were recorded with a Point Grey Grasshopper3 camera mounted on a Leica stereo microscope. Thrashes, defined as the synchronous left and right movement of head and tail back to start position, were counted for each animal. Average thrash rates of strains were compared. For statistical analysis Student's t-test was used.

\section{Crosses}

unc-9(e101)/daf-2(e1370): Because of temperature sensitivity of daf-2(e1370), crosses were performed at $15^{\circ} \mathrm{C}$. The unc- 9 mutation was verified by locomotion defective phenotype as well as PCR and restriction digest with Bsll; the daf-2 mutation confirmed by PCR with primer pair KEB836/KEB837, restriction digest with Bsll and sequencing.

unc-9(e101)/daf-16(mu86): The unc-9 mutation was verified by locomotion defective phenotype as well as PCR and restriction digest with Bsll; the daf-16(mu86) deletion mutation was confirmed by PCR with primer pairs KEB839/KEB840 and KEB838/KEB840.

unc-9(e101)/mec-6(e1342): The unc-9 mutation was verified by locomotion defective phenotype as well as PCR and restriction digest with Bsll; the mec-6(e1342) substitution mutation preselected by touch response and verified by sequencing of a PCR product generated with primer pair KEB914/KEB915. 
unc-9(e101)/mec-4(u235): The unc-9 mutation was verified by locomotion defective phenotype as well as PCR and restriction digest with Bsll; the mec-4(u235) deletion mutation preselected by touch response and verified by PCR with primer pairs KEB911/KEB913 and KEB912/KEB913.

unc-9(e101)/pmec-3::GFP: The unc-9 mutation was verified by locomotion defective phenotype as well as PCR and restriction digest with Bsll; presence of pmec-3::GFP was confirmed by GFP fluorescence.

unc-1(e1598)/unc9(e101): The unc-9 mutation was verified with locomotion defective phenotype as well as PCR and restriction digest with $\mathrm{BtsCl}$; the unc-1 mutation was verified by sequencing of the PCR product generated with primer pair KEB937/KEB938.

\author{
Primer list \\ KEB836 CTCCTCATCCAGCGATCC \\ KEB837 CCGCACGATTTGTGATGG \\ KEB838 GTCTCTCTATCGGCCACC \\ KEB839 CCAGATGCAAAGCCAGG \\ KEB840 GTGTCGAGTGAAGGGAGC \\ KEB911 CTTGGATGTATGATAATGCTC \\ KEB912 GCACCTTTTCCAGCAATTAC \\ KEB913 CTCTCTGATTGACATTCTTCC \\ KEB914 CACCTATGTTAGAAACACGG \\ KEB915 CCTCTCCGGAGATTACTTG \\ KEB937 ACTGAACGGACTTTCTGCGA \\ KEB938 GGGATCCAAATTTCAAAAGGTGC
}

\title{
Supplementary Table 1:
}

\section{Information about the mutants used in the study}

\begin{tabular}{|c|c|c|c|c|c|}
\hline Gene & Strain & Allele & $\begin{array}{l}\text { Molecular } \\
\text { lesion }\end{array}$ & Comment & Reference \\
\hline $\operatorname{in} x-1$ & - & $\operatorname{tm} 3524$ & $\begin{array}{l}238 \mathrm{bp} \\
\text { deletion }\end{array}$ & likely null, deletes exon 6 & \\
\hline $\operatorname{in} x-2$ & CX13325 & ok376 & $\begin{array}{l}992 \mathrm{bp} \\
\text { deletion }\end{array}$ & $\begin{array}{l}\text { almost certainly null, deletes most of } \\
\text { exon } 2 \text { and all of exons } 3 \text { and } 4\end{array}$ & \\
\hline che-7 & RB1834 & ok2373 & $\begin{array}{l}1496 \mathrm{bp} \\
\text { deletion }\end{array}$ & $\begin{array}{l}\text { almost certainly null, deletes most of } \\
\text { exon } 3 \text { and all of exons } 4 \text { and } 5\end{array}$ & \\
\hline$i n x-5$ & RB1086 & ok1053 & $\begin{array}{l}\text { 1221bp } \\
\text { deletion }\end{array}$ & $\begin{array}{l}\text { putative null - 1221bp deletion in } \\
\text { R09F10: 5058-6278; deletes all amino } \\
\text { acids after pos. 285, takes out part of } \\
\text { exon } 5 \text { and all of exon } 6\end{array}$ & this study \\
\hline $\operatorname{in} x-6$ & MR127 & $r r 5$ & $\begin{array}{l}\text { P353L } \\
\text { missense } \\
\text { mutation }\end{array}$ & $\begin{array}{l}\text { temperature sensitive allele, } 25^{\circ} \mathrm{C} \\
\text { restrictive temperature }\end{array}$ & 18 \\
\hline $\operatorname{in} x-7$ & RB1792 & ok2319 & $\begin{array}{l}1610 \mathrm{bp} \\
\text { deletion }\end{array}$ & $\begin{array}{l}\text { almost certainly null, deleted part of } \\
\text { exon } 1 \text { and all of exons } 2-5 \text { in isoform a } \\
\text { and exons 1-3 in isoform b }\end{array}$ & \\
\hline
\end{tabular}


bioRxiv preprint doi: https://doi.org/10.1101/657817; this version posted June 2, 2019. The copyright holder for this preprint (which was not certified by peer review) is the author/funder, who has granted bioRxiv a license to display the preprint in perpetuity. It is made available under aCC-BY-NC-ND 4.0 International license.

\begin{tabular}{|c|c|c|c|c|c|}
\hline in $x-8$ & VC116 & $g k 42$ & $\begin{array}{l}850 \mathrm{bp} \\
\text { deletion }\end{array}$ & $\begin{array}{l}\text { likely loss-of-function or null allele, } \\
\text { deletes exon } 1 \text {; fertile. }\end{array}$ & \\
\hline $\operatorname{in} x-9$ & CX12726 & ok1502 & $\begin{array}{l}719 \mathrm{bp} \\
\text { deletion }\end{array}$ & $\begin{array}{l}\text { very likely null, deletes most of exons } 2 \\
\text { and 3. Fertile; VC994 is 0x outcrossed }\end{array}$ & \\
\hline $\operatorname{in} x-10$ & RB2051 & ok2714 & $\begin{array}{l}689 \mathrm{bp} \\
\text { deletion }\end{array}$ & $\begin{array}{l}\text { likely null, most of exon } 3 \text { and part of } \\
\text { exon } 4 \text { deleted }\end{array}$ & \\
\hline inx $x-11$ & RB2108 & ok2783 & $\begin{array}{l}752 \mathrm{bp} \\
\text { deletion }\end{array}$ & $\begin{array}{l}\text { likely null, exons 3, 4, } 5 \text { and part of } 6 \\
\text { deleted (in isoform b) }\end{array}$ & \\
\hline inx-14 & AU98 & $\operatorname{ag} 17$ & $\begin{array}{l}\mathrm{R} 326 \mathrm{H} \\
\text { missense } \\
\text { mutation }\end{array}$ & $\begin{array}{l}\text { ag17 is hypomorphic allele; ok3267, } \\
\text { tm2593 and tm2864, which are partial } \\
\text { deletions, all marked as sterile. Arginine- } \\
\text { to-histidine substitution in inx-14 near } \\
\text { the end of the predicted third } \\
\text { transmembrane domain }\end{array}$ & 19 \\
\hline $\operatorname{in} x-15$ & - & $\operatorname{tm} 3394$ & $\begin{array}{l}\text { 458bp } \\
\text { deletion }\end{array}$ & likely null, most of exon 2 deleted & \\
\hline$i n x-16$ & EG144 & ox144 & $\begin{array}{l}\text { nonsense } \\
\text { mutation at } \\
\text { position } 104\end{array}$ & likely null & 20 \\
\hline $\operatorname{in} x-17$ & - & $\operatorname{tm} 3292$ & $\begin{array}{l}309 \mathrm{bp} \\
\text { deletion }\end{array}$ & $\begin{array}{l}\text { likely null - most of exon } 2 \text { and part of } \\
\text { exon } 3 \text { deleted }\end{array}$ & \\
\hline$i n x-18$ & RB1896 & ok2454 & $\begin{array}{l}1704 \mathrm{bp} \\
\text { deletion }\end{array}$ & $\begin{array}{l}\text { putative null; } 1704 \mathrm{bp} \text { deletion, in } \\
\mathrm{C} 18 \mathrm{H} 7 \text { : } 30705-32408 \text {; deletes part of } \\
\text { exon } 4 \text { and all of exon } 5\end{array}$ & this study \\
\hline$i n x-19$ & CX6161 & ky634 & $\begin{array}{l}\text { E54K/E70K } \\
\text { missense } \\
\text { mutation }\end{array}$ & described as loss-of-function allele & 21 \\
\hline in $x-20$ & CX12725 & ok681 & $\begin{array}{l}1483 \mathrm{bp} \\
\text { deletion }\end{array}$ & $\begin{array}{l}\text { likely null, deletes exons } 2-8 \text {; see also } \\
\text { RB683, bearing a different allele }\end{array}$ & 22 \\
\hline inx $x-20$ & RB683 & ok426 & $\begin{array}{l}984 \mathrm{bp} \\
\text { deletion }\end{array}$ & $\begin{array}{l}\text { likely null, deletes part of exon } 5 \text { and 6-9 } \\
\text { completely, part of exon } 10\end{array}$ & \\
\hline in $x-21$ & RB1929 & ok2524 & $\begin{array}{l}\text { 1960bp } \\
\text { deletion }\end{array}$ & $\begin{array}{l}\text { exons } 3 \text { and } 4 \text { deleted but is not a null } \\
\text { allele (which would be sterile) - see }{ }^{23}\end{array}$ & \\
\hline inx $x-22$ & XM1011 & $\operatorname{tm} 1661$ & $\begin{array}{l}\text { 765bp } \\
\text { deletion }\end{array}$ & $\begin{array}{l}\text { likely null, deletes most of exon } 2 \text { and all } \\
\text { of exon 3; viable and fertile }\end{array}$ & 23 \\
\hline eat-5 & DA1402 & ad1402 & $\begin{array}{l}1439 \mathrm{bp} \\
\text { deletion }\end{array}$ & $\begin{array}{l}\text { putative null deletion that removes } \\
\text { exons } 2 \text { through } 4 .\end{array}$ & 24 \\
\hline unc-9 & CB101 & e101 & $\begin{array}{l}\text { splice } \\
\text { acceptor site } \\
\text { mutation at } \\
\text { last exon }\end{array}$ & reference allele, severe or null mutant & 25 \\
\hline unc-9 & CW129 & $f c 16$ & $\begin{array}{l}\text { nonsense } \\
\text { mutation at } \\
\text { position } 157\end{array}$ & $\begin{array}{l}\text { putative null mutant resulting from } \\
\text { premature stop in the intracellular loop } \\
\text { between the second and third } \\
\text { membrane-spanning domain }\end{array}$ & 25 \\
\hline unc-7 & CB5 & $e 5$ & $\begin{array}{l}\text { nonsense } \\
\text { mutation }\end{array}$ & $\begin{array}{l}\text { likely null mutation, premature stop } \\
(\text { Q216*) in the first predicted } \\
\text { extracellular loop of UNC-7 }\end{array}$ & 26 \\
\hline unc-1 & CB719 & e719 & $\begin{array}{l}\text { frameshift at } \\
\text { pos. } 162\end{array}$ & $\begin{array}{l}\text { putative null - a splice junction mutation } \\
\text { causes frameshift and premature } \\
\text { termination }\end{array}$ & 27 \\
\hline unc-1 & CB1598 & e1598 & $\begin{array}{l}\mathrm{A} 216 \mathrm{~V} \\
\text { missense } \\
\text { mutation }\end{array}$ & $\begin{array}{l}\text { canonical dominant gain-of-function } \\
\text { allele }\end{array}$ & 28 \\
\hline & & & & & \\
\hline
\end{tabular}


bioRxiv preprint doi: https://doi.org/10.1101/657817; this version posted June 2, 2019. The copyright holder for this preprint (which was not certified by peer review) is the author/funder, who has granted bioRxiv a license to display the preprint in perpetuity. It is made available under aCC-BY-NC-ND 4.0 International license.

\begin{tabular}{|l|l|l|l|l|l|}
\hline mec-3 & CB1338 & e1338 & $\begin{array}{l}\text { A inserted at } \\
2782\end{array}$ & $\begin{array}{l}\text { frameshift, touch receptors do not } \\
\text { differentiate, PVD nonfunctional }\end{array}$ & 29,30 \\
\hline mec-4 & CB1611 & e1611 & $\begin{array}{l}\text { A713T } \\
\text { substitution }\end{array}$ & $\begin{array}{l}\text { dominant, all gentle-touch sensory } \\
\text { neurons degenerate }\end{array}$ & 31 \\
\hline mec-4 & TU253 & u253 & $\begin{array}{l}\text { deletion in } \\
\text { exon 3 }\end{array}$ & likely null, no mechanoreceptor currents & 32 \\
\hline mec-6 & CB1472 & e1342 & $\begin{array}{l}\text { W303* } \\
\text { nonsense } \\
\text { mutation }\end{array}$ & $\begin{array}{l}\text { reference allele, nonsense mutation and } \\
\text { therefore likely a null }\end{array}$ & 33 \\
\hline
\end{tabular}

\section{Supplementary Table 3: C. elegans strains used}

\begin{tabular}{|c|c|c|}
\hline Strain & Genotype & Reference \\
\hline- & inx-1(tm3524) $x$ & 34 \\
\hline CX13325 & $i n x-2(o k 376) x$ & 22 \\
\hline VC260 & inx-2(ok376) $x$ & 35 \\
\hline RB1834 & che-7/inx-4(ok2373) V. & 35 \\
\hline RB1086 & inx-5(ok1053) $x$ & this study \\
\hline MR127 & inx-6(rr5) IV. & 18 \\
\hline RB1792 & inx-7(ok2319) IV. & 35 \\
\hline VC116 & inx-8(gk42) IV. & 35 \\
\hline CX12726 & inx-9(ok1502) IV. & 22 \\
\hline VC994 & inx-9(ok1502) IV. & 35 \\
\hline RB2051 & $i n x-10(o k 2714) \mathrm{V}$. & 35 \\
\hline RB2108 & inx-11(ok2783) V. & 35 \\
\hline AU98 & inx-14(ag17) I. & 19 \\
\hline- & inx-15(tm3394) I. & 34 \\
\hline EG144 & inx-16(ox144) I. & 20 \\
\hline- & inx-17(tm3292) I. & 34 \\
\hline RB1896 & inx-18(ok2454) IV. & this study \\
\hline CX6161 & inx-19(ky634) I. & 21 \\
\hline CX12725 & inx-20(ok681) I. & 22 \\
\hline$R B 683$ & inx-20(ok426) I. & 35 \\
\hline CX12725 & inx-20(ok426) I. & 22 \\
\hline RB1929 & inx-21(ok2524) I. & 35 \\
\hline XM1011 & inx-22(tm1661) I. & 23 \\
\hline DA1402 & eat-5(ad1402) I. & 24 \\
\hline CB101 & unc-9(e101) $x$ & 25 \\
\hline CW129 & unc-9(fc16) X. & 25 \\
\hline CB5 & unc-7(e5) $x$ & 26 \\
\hline CB1338 & $m e c-3(e 1338) I V$. & 29,30 \\
\hline CB1370 & daf-2(e1370) III. & \\
\hline
\end{tabular}




\begin{tabular}{|c|c|c|}
\hline CB1472 & mec-6(e1342) I. & 33 \\
\hline CB1598 & unc-1(e1598) $x$ & 28 \\
\hline CB1611 & mec-4(e1611)X. & 31 \\
\hline CB719 & unc-1(e719) $X$ & 27,36 \\
\hline CF1038 & daf-16(mu86) I. & \\
\hline KL126 & $\begin{array}{l}\text { unc-9(e101) X; cipEx29(WRM0611aH10 (Fosmid containing unc-9 genomic } \\
\text { DNA); pmyo-2::mCherry) }\end{array}$ & this study \\
\hline KL177 & daf-2(e1370) III.; unc-9(e101)X. & this study \\
\hline KL180 & daf-16(mu86) I.; unc-9(e101)X. & this study \\
\hline KL197 & Is[mec-3::GFP]; unc-9(e101)X. & this study \\
\hline KL230 & $\begin{array}{l}\text { unc-9(e101) X; cipEx29(WRM0611aH10 (Fosmid containing unc-9 genomic } \\
\text { DNA); pmyo-2::mCherry) }\end{array}$ & this study \\
\hline KL240 & mec-6(e1342) I; unc-9(e101)X. & this study \\
\hline KL243 & mec-6(e1342) I; unc-9(e101)X. & this study \\
\hline KL246 & cipEx29[WRM0611aH10(punc-9::unc-9; pmyo-2::mCherry)] & this study \\
\hline KL273 & unc-9(e101) mec-4(u253)X. & this study \\
\hline KL276 & unc-1(e1598) unc9(e101) $X$. & this study \\
\hline KP3948 & eri-1(mg366) IV; lin-15B(n744)X. & 37 \\
\hline NY2054 & ynls54 [flp-20p::GFP] IV. ; him-5(e1490) V. & \\
\hline TU253 & mec-4(u253)X. & 32 \\
\hline- & Is[pmec-3::GFP] & 38 \\
\hline TU3568 & $\begin{array}{l}\text { sid-1(pk3321) him-5(e1490) V; lin-15B(n744) X; uls71[(pCFJ90) myo- } \\
2 p:: m \text { Cherry + mec-18p::sid-1]. }\end{array}$ & 39 \\
\hline XE1375 & $\begin{array}{l}\text { wpls36[unc-47p::mCherry] I; wpSi1[unc-47p::rde-1::SL2::sid-1 + Cbr-unc- } \\
\text { 119(+)] II; eri-1(mg366) IV; rde-1(ne219) V; lin-15B(n744) X. }\end{array}$ & 40 \\
\hline XE1474 & $\begin{array}{l}\text { wpSi6[dat-1p::rde-1::SL2::sid-1 + Cbr-unc-119(+)] II; eri-1(mg366) IV; rde- } \\
\text { 1(ne219) V; lin-15B(n744) X. }\end{array}$ & 40 \\
\hline XE1581 & $\begin{array}{l}\text { wpSi10[unc-17p::rde-1::SL2::sid-1 + Cbr-unc-119(+)] II; eri-1(mg366) IV; rde- } \\
\text { 1(ne219) V; lin-15B(n744) X. }\end{array}$ & 40 \\
\hline XE1582 & $\begin{array}{l}\text { wpSi11[eat-4p::rde-1::SL2::sid-1 + Cbr-unc-119(+)] II; eri-1(mg366) IV; rde- } \\
\text { 1(ne219) V; lin-15B(n744) X. }\end{array}$ & 40 \\
\hline ZM3087 & unc-9(fc16) unc-7(e5) X. & 41 \\
\hline
\end{tabular}

\section{Supplementary References}

1 Hall, D. H. \& Altun, Z. F. C. elegans atlas. (Cold Spring Harbor Laboratory Press, 2008).

2 Bhattacharya, A., Aghayeva, U., Berghoff, E. G. \& Hobert, O. Plasticity of the Electrical Connectome of C. elegans. Cell 176, 1174-1189 e1116, doi:10.1016/j.cell.2018.12.024 (2019).

3 Serrano-Saiz, E. et al. Modular control of glutamatergic neuronal identity in C. elegans by distinct homeodomain proteins. Cell 155, 659-673, doi:10.1016/j.cell.2013.09.052 (2013). 
4 Sulston, J., Dew, M. \& Brenner, S. Dopaminergic neurons in the nematode Caenorhabditis elegans. J Comp Neurol 163, 215-226, doi:10.1002/cne.901630207 (1975).

$5 \quad$ Li, W., Kang, L., Piggott, B. J., Feng, Z. \& Xu, X. Z. The neural circuits and sensory channels mediating harsh touch sensation in Caenorhabditis elegans. Nat Commun 2, 315, doi:10.1038/ncomms1308 (2011).

6 Perkins, L. A., Hedgecock, E. M., Thomson, J. N. \& Culotti, J. G. Mutant sensory cilia in the nematode Caenorhabditis elegans. Developmental biology 117, 456-487 (1986).

7 Ward, S., Thomson, N., White, J. G. \& Brenner, S. Electron microscopical reconstruction of the anterior sensory anatomy of the nematode Caenorhabditis elegans.?2UU. J Comp Neurol 160, 313-337, doi:10.1002/cne.901600305 (1975).

8 Sanders, J. et al. The Caenorhabditis elegans interneuron ALA is (also) a highthreshold mechanosensor. BMC neuroscience 14, 156, doi:10.1186/1471-2202-14156 (2013).

9 Ware, R. W., Clark, D., Crossland, K. \& Russell, R. L. The nerve ring of the nematode Caenorhabditis elegans: Sensory input and motor output. Journal of Comparative Neurology 162, 71-110, doi:10.1002/cne.901620106 (1975).

10 Hart, A. C., Sims, S. \& Kaplan, J. M. Synaptic code for sensory modalities revealed by C. elegans GLR-1 glutamate receptor. Nature 378, 82-85, doi:10.1038/378082a0 (1995).

11 Kindt, K. S. et al. Caenorhabditis elegans TRPA-1 functions in mechanosensation. Nature neuroscience 10, 568-577, doi:10.1038/nn1886 (2007).

12 Zou, W. et al. Polymodal Responses in C. elegans Phasmid Neurons Rely on Multiple Intracellular and Intercellular Signaling Pathways. Sci Rep 7, 42295, doi:10.1038/srep42295 (2017).

13 Goodman, M. B. Mechanosensation. WormBook, 1-14, doi:10.1895/wormbook.1.62.1 (2006).

14 Goodman, M. B. \& Sengupta, P. How Caenorhabditis elegans Senses Mechanical Stress, Temperature, and Other Physical Stimuli. Genetics 212, 25-51, doi:10.1534/genetics.118.300241 (2019).

15 White, J. G., Southgate, E., Thomson, J. N. \& Brenner, S. The structure of the nervous system of the nematode Caenorhabditis elegans. Phil. Transact. R. Soc. Lond. B. 314, 1-340 (1986).

16 Fang-Yen, C., Gabel, C. V., Samuel, A. D., Bargmann, C. I. \& Avery, L. Laser microsurgery in Caenorhabditis elegans. Methods Cell Biol 107, 177-206, doi:10.1016/B978-0-12-394620-1.00006-0 (2012).

17 Podshivalova, K., Kerr, R. A. \& Kenyon, C. How a Mutation that Slows Aging Can Also Disproportionately Extend End-of-Life Decrepitude. Cell Rep 19, 441-450, doi:10.1016/j.celrep.2017.03.062 (2017).

$18 \mathrm{Li}, \mathrm{S}$., Dent, J. A. \& Roy, R. Regulation of intermuscular electrical coupling by the Caenorhabditis elegans innexin inx-6. Mol Biol Cell 14, 2630-2644, doi:10.1091/mbc.e02-11-0716 (2003).

19 Miyata, S., Begun, J., Troemel, E. R. \& Ausubel, F. M. DAF-16-dependent suppression of immunity during reproduction in Caenorhabditis elegans. Genetics 178, 903-918, doi:10.1534/genetics.107.083923 (2008). 
20 Peters, M. A., Teramoto, T., White, J. Q., Iwasaki, K. \& Jorgensen, E. M. A calcium wave mediated by gap junctions coordinates a rhythmic behavior in C. elegans. Curr Biol 17, 1601-1608, doi:10.1016/j.cub.2007.08.031 (2007).

21 Chuang, C. F., Vanhoven, M. K., Fetter, R. D., Verselis, V. K. \& Bargmann, C. I. An innexin-dependent cell network establishes left-right neuronal asymmetry in C. elegans. Cell 129, 787-799, doi:10.1016/j.cell.2007.02.052 (2007).

22 Flavell, S. W. et al. Serotonin and the neuropeptide PDF initiate and extend opposing behavioral states in C. elegans. Cell 154, 1023-1035, doi:10.1016/j.cell.2013.08.001 (2013).

23 Starich, T. A., Hall, D. H. \& Greenstein, D. Two classes of gap junction channels mediate soma-germline interactions essential for germline proliferation and gametogenesis in Caenorhabditis elegans. Genetics 198, 1127-1153, doi:10.1534/genetics.114.168815 (2014).

24 Chiang, J. T., Steciuk, M., Shtonda, B. \& Avery, L. Evolution of pharyngeal behaviors and neuronal functions in free-living soil nematodes. The Journal of experimental biology 209, 1859-1873, doi:209/10/1859 [pii] 10.1242/jeb.02165 (2006).

25 Barnes, T. M. \& Hekimi, S. The Caenorhabditis elegans avermectin resistance and anesthetic response gene unc- 9 encodes a member of a protein family implicated in electrical coupling of excitable cells. Journal of neurochemistry 69, 2251-2260 (1997).

26 Starich, T. A., Xu, J., Skerrett, I. M., Nicholson, B. J. \& Shaw, J. E. Interactions between innexins UNC-7 and UNC-9 mediate electrical synapse specificity in the Caenorhabditis elegans locomotory nervous system. Neural Dev 4, 16, doi:10.1186/1749-8104-4-16 (2009).

27 Rajaram, S., Sedensky, M. M. \& Morgan, P. G. Unc-1: a stomatin homologue controls sensitivity to volatile anesthetics in Caenorhabditis elegans. Proceedings of the National Academy of Sciences of the United States of America 95, 8761-8766, doi:10.1073/pnas.95.15.8761 (1998).

28 Park, E. C. \& Horvitz, H. R. Mutations with dominant effects on the behavior and morphology of the nematode Caenorhabditis elegans. Genetics 113, 821-852 (1986).

29 Xue, D., Tu, Y. \& Chalfie, M. Cooperative Interactions between the CaenorhabditisElegans Homeoproteins Unc-86 and Mec-3. Science 261, 1324-1328, doi:DOI 10.1126/science.8103239 (1993).

30 Way, J. C. \& Chalfie, M. The Mec-3 Gene of Caenorhabditis-Elegans Requires Its Own Product for Maintained Expression and Is Expressed in 3 Neuronal Cell-Types. Genes \& development 3, 1823-1833, doi:DOI 10.1101/gad.3.12a.1823 (1989).

31 Driscoll, M. \& Chalfie, M. The Mec-4 Gene Is a Member of a Family of Caenorhabditis-Elegans Genes That Can Mutate to Induce Neuronal Degeneration. Nature 349, 588-593, doi:DOI 10.1038/349588a0 (1991).

32 Hong, K., Mano, I. \& Driscoll, M. In vivo structure-function analyses of Caenorhabditis elegans MEC-4, a candidate mechanosensory ion channel subunit. Journal of Neuroscience 20, 2575-2588 (2000).

33 Chalfie, M. \& Sulston, J. Developmental genetics of the mechanosensory neurons of Caenorhabditis elegans. Developmental biology 82, 358-370 (1981).

34 Mitani, S. Comprehensive functional genomics using Caenorhabditis elegans as a model organism. Proc Jpn Acad Ser B Phys Biol Sci 93, 561-577, doi:10.2183/pjab.93.036 (2017). 
35 Consortium, C. e. D. M. large-scale screening for targeted knockouts in the Caenorhabditis elegans genome. G3 (Bethesda) 2, 1415-1425, doi:10.1534/g3.112.003830 (2012).

36 Chen, B. J., Liu, Q., Ge, Q., Xie, J. \& Wang, Z. W. UNC-1 regulates gap junctions important to locomotion in C. elegans. Current Biology 17, 1334-1339, doi:10.1016/j.cub.2007.06.060 (2007).

37 Sieburth, D. et al. Systematic analysis of genes required for synapse structure and function. Nature 436, 510-517, doi:10.1038/nature03809 (2005).

38 Zhang, Y. et al. Identification of genes expressed in C. elegans touch receptor neurons. Nature 418, 331-335, doi:10.1038/nature00891 (2002).

39 Calixto, A., Ma, C. \& Chalfie, M. Conditional gene expression and RNAi using MEC-8dependent splicing in C. elegans. Nature methods 7, 407-411, doi:nmeth.1445 [pii] 10.1038/nmeth.1445 (2010).

40 Firnhaber, C. \& Hammarlund, M. Neuron-Specific Feeding RNAi in C. elegans and Its Use in a Screen for Essential Genes Required for GABA Neuron Function. Plos Genetics 9, doi:ARTN e1003921 10.1371/journal.pgen.1003921 (2013).

41 Yeh, E. et al. Caenorhabditis elegans innexins regulate active zone differentiation. $J$ Neurosci 29, 5207-5217, doi:10.1523/JNEUROSCI.0637-09.2009 (2009).

\section{Supplementary Figure Legends}

S1: Violin plots representing the probability density of the lifespan data for all tested mutant and treatment conditions. The white dots represent the median, the thick black bars in the centre represent the interquartile range, and the thin black lines represent the rest of the distribution except for points that are determined to be outliers. Wider sections of the violin plot represent a higher probability that members of the population will take on the given value.

S2: Lateral swimming movements (thrashes) per minute in N2 animals, unc-9(e101) mutants and unc-9(e101) mutants bearing a fosmid containing the unc- 9 genomic locus. ${ }^{* * *} P<0.001$; ns not significant, using Student's t-test.

S3: Changes in locomotory responses to a tap stimulus with age in unc-9(e101) and N2 animals. $\mathrm{N}=120$ animals per group.

S4: Lifespan of unc-9(e101) and N2 worms maintained at either $21 \%$ or $7 \%$ ambient $\mathrm{O}_{2}$. $\mathrm{N}=120$ animals per group. ns not significant, using Log-rank test.

S5: List of neuron classes in C. elegans, with neuron types indicated as classified in ${ }^{1}$. Classes with unc-9 expression in non-dauer hermaphrodites are highlighted orange in the third column, based on ${ }^{2}$. The glutamatergic neurons (green) are based on eat-4 expression ${ }^{3}$. Overlap of unc- 9 expression with glutamatergic and mechanosensory neurons is highlighted in blue and grey, respectively. The number of classes belonging to each category is given 
above the table. Information about the mechanosensory neurons is based on ${ }^{4-14}$ and excludes stretch receptors.

S6: Chemical and electrical coupling of selected mechanosensory neurons, interneurons and command interneurons in C. elegans, based on the synaptic wiring described $\mathrm{in}^{15}$. The number of synapses between connected neurons is displayed.

S7: a Responses to touch with an eyelash pick in N2 and unc-9(e101) animals compared to mec-6(e1342) and mec-6(e1342); unc-9(e101); and (b) mec-4(u253) and mec-4(u253); unc-

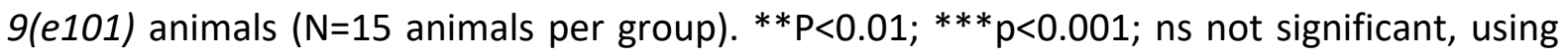
Student's t-test.

S8: a Lifespan of controls and animals with unc- 9 knockdown by cell-specific RNA interference in touch receptor neurons; ns not significant, using Log-rank test. $\mathrm{N}=130$ animals per group. b Lifespan of NY2054 animals where the PVR interneuron was laser ablated, versus controls that were mock ablated. ns not significant, using Log-rank test. $\mathrm{N}=79$ animals per group.

S9: a Age-dependent decline of of ALM or (b) PLM cell body integrity is not significantly affected by genotype. $\mathrm{N}=50$ animals per group. ns not significant, using a binomial regression model.

S10: Propensity for internal egg hatching in daf-16, daf-16; unc-9, unc-9, daf-2 and daf-2; unc9 mutants; $\mathrm{N}=120$ animals per group.

S11: a Effect on lifespan of $9 \mathrm{mM} \mathrm{N}$-Acetyl-Cysteine (NAC) treatment versus untreated controls in $\mathrm{N} 2$ and (b) unc-9(e101) mutant animals, both maintained at $7 \% \mathrm{O}_{2} . \mathrm{N}=120$ animals per group. ${ }^{*} \mathrm{P}<0.05$; ns not significant, using Log-rank test. 


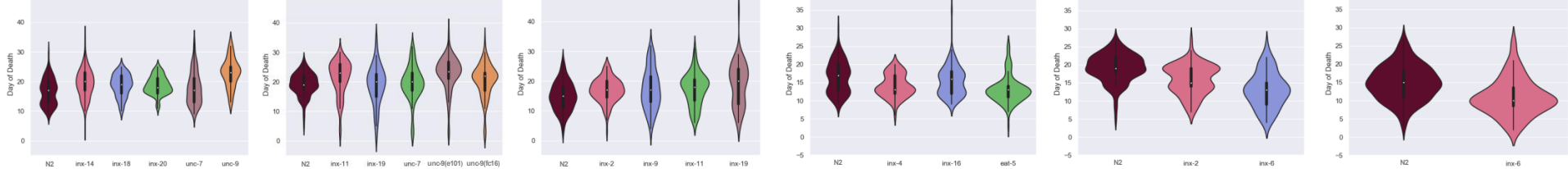

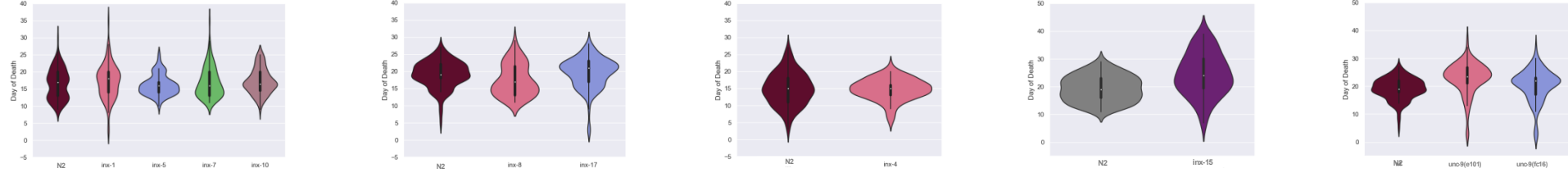

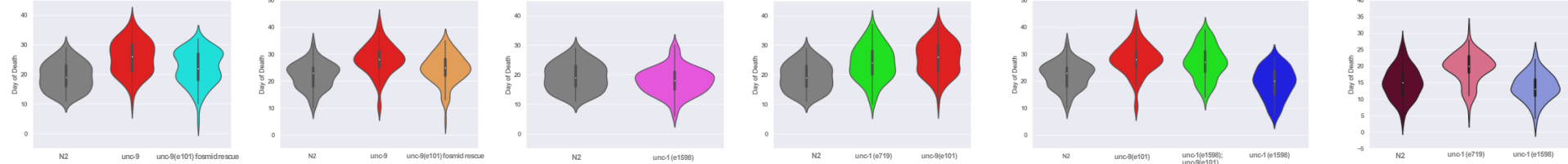
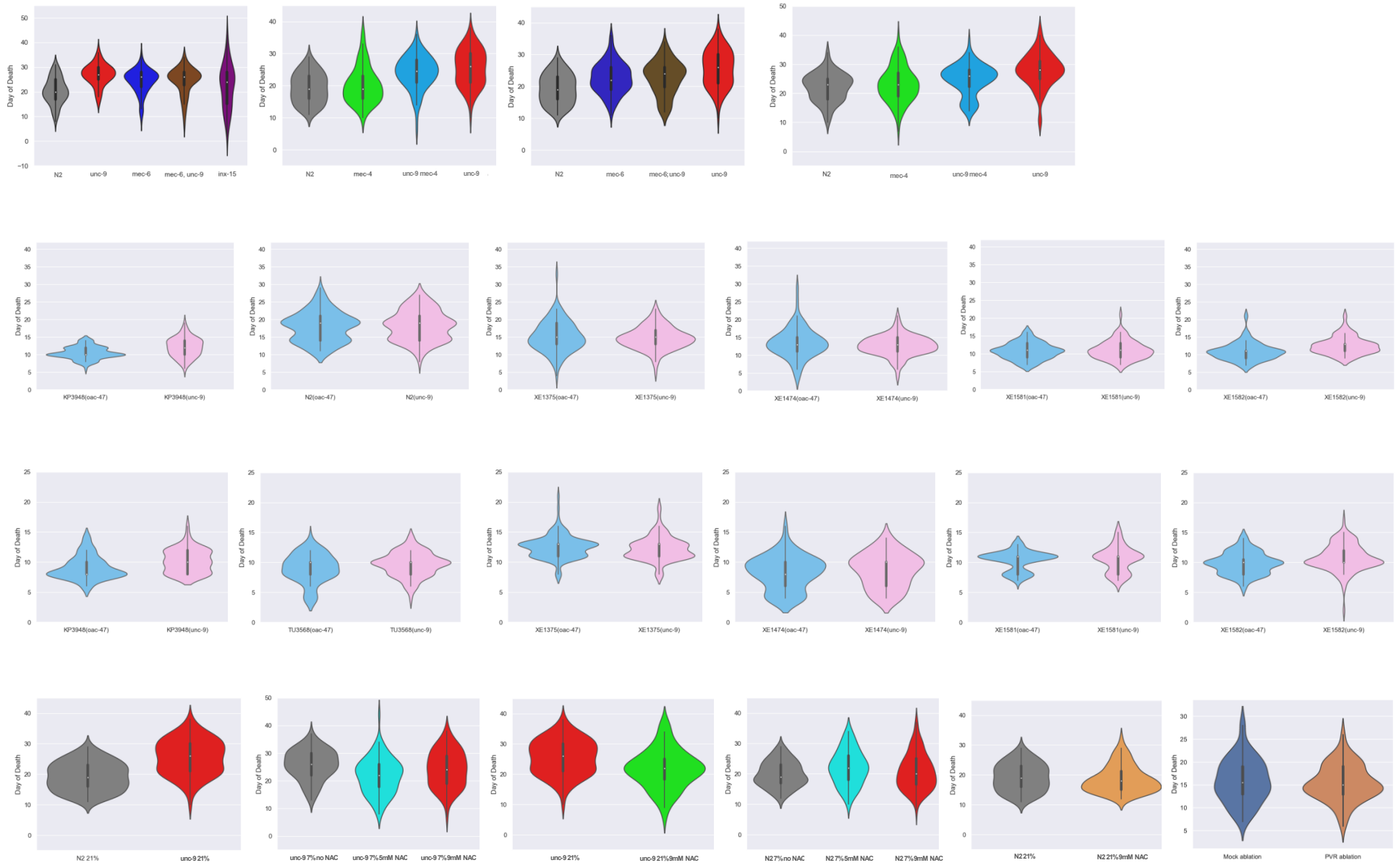
bioRxiv preprint doi: https://doi.org/10.1101/657817; this version posted June 2, 2019. The copyright holder for this preprint (which was

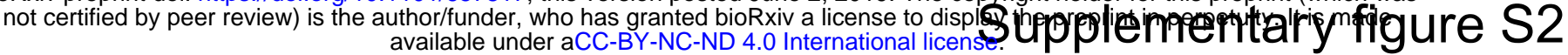

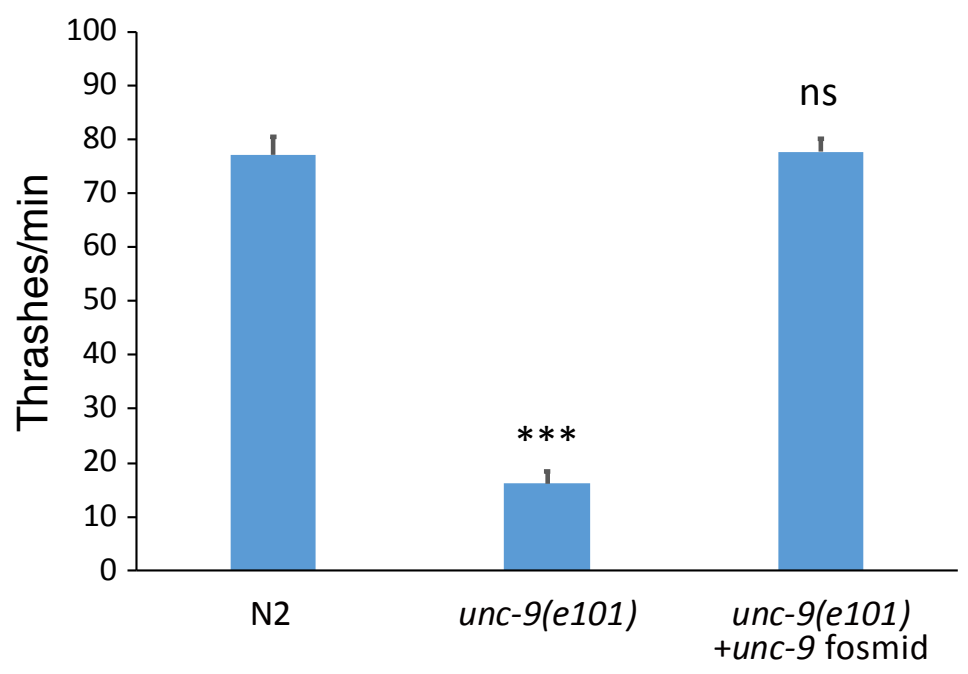




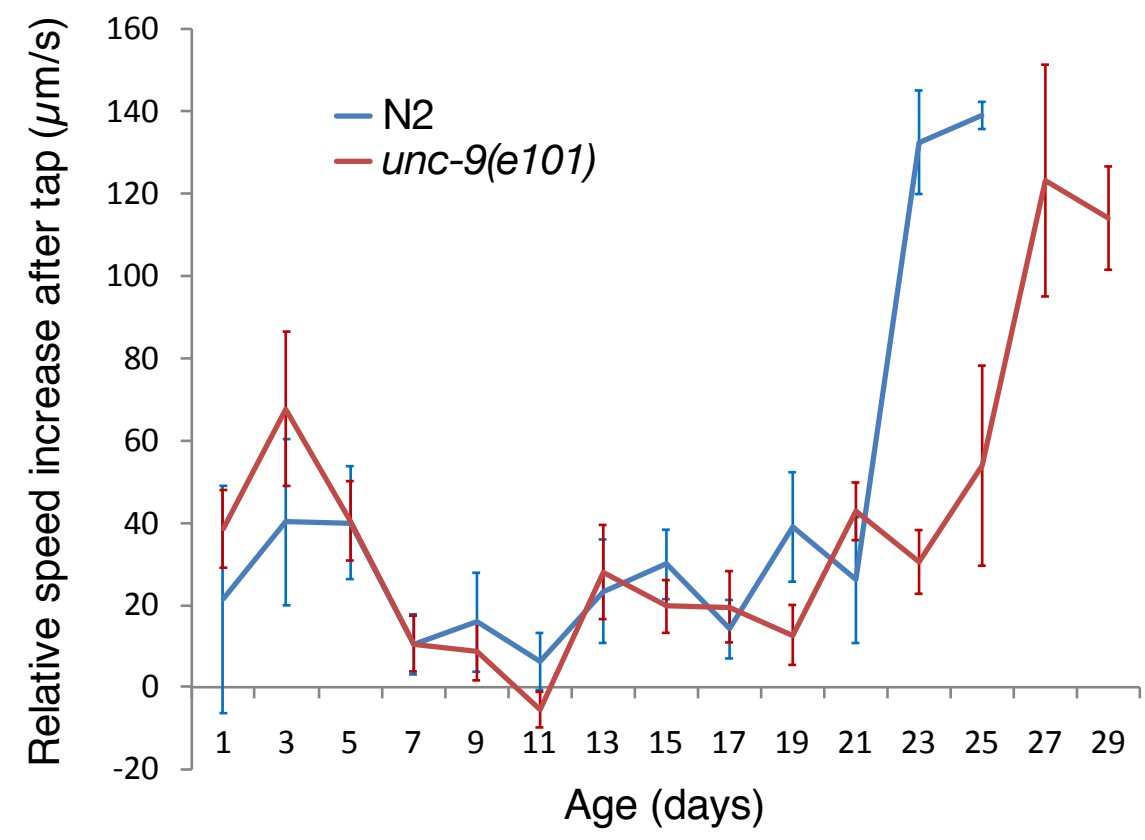




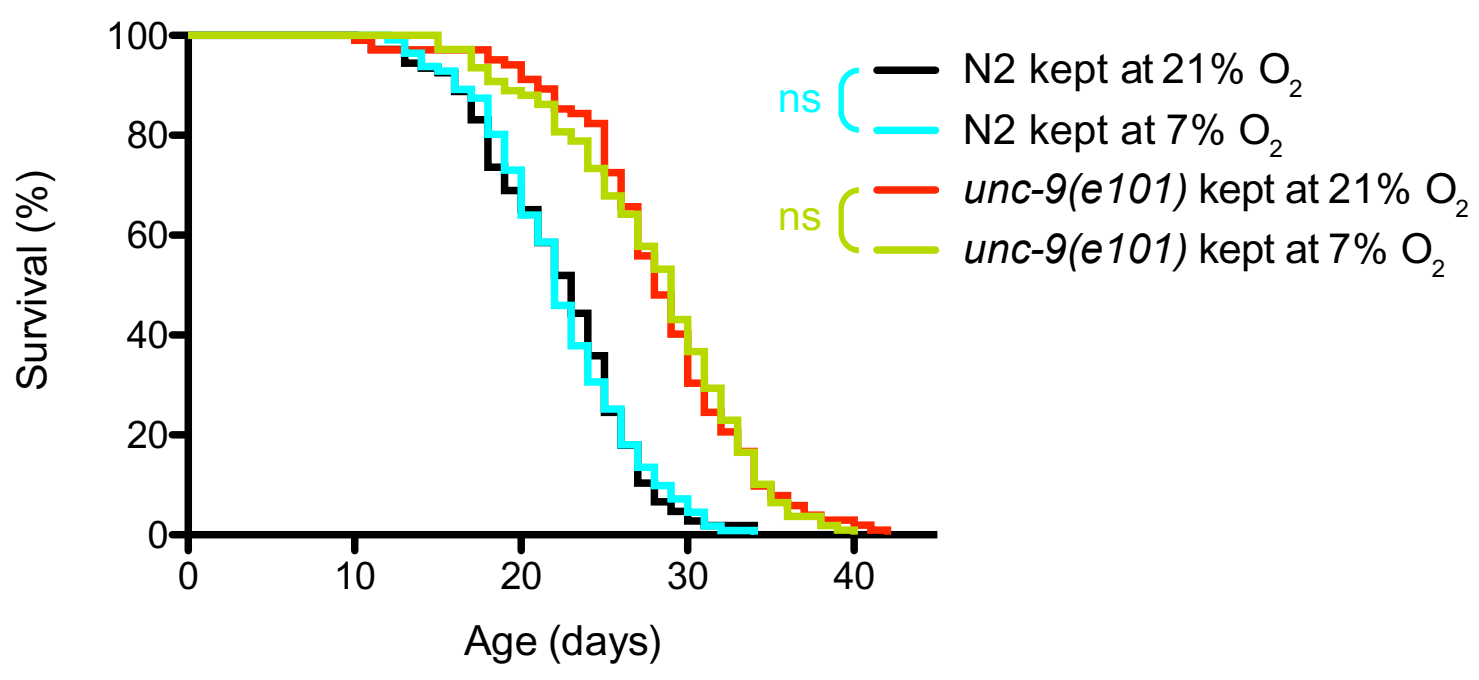


bioRxiv preprint doi: https://doi.org/10.1101/657817; this version posted June 2, 2019. The copyright holder for this preprint (which was not certified by peer review) is the authorftunder, who has granted bioRxiv a license to dispos
available under aCC-BY-NC-ND 4.0 International licens?

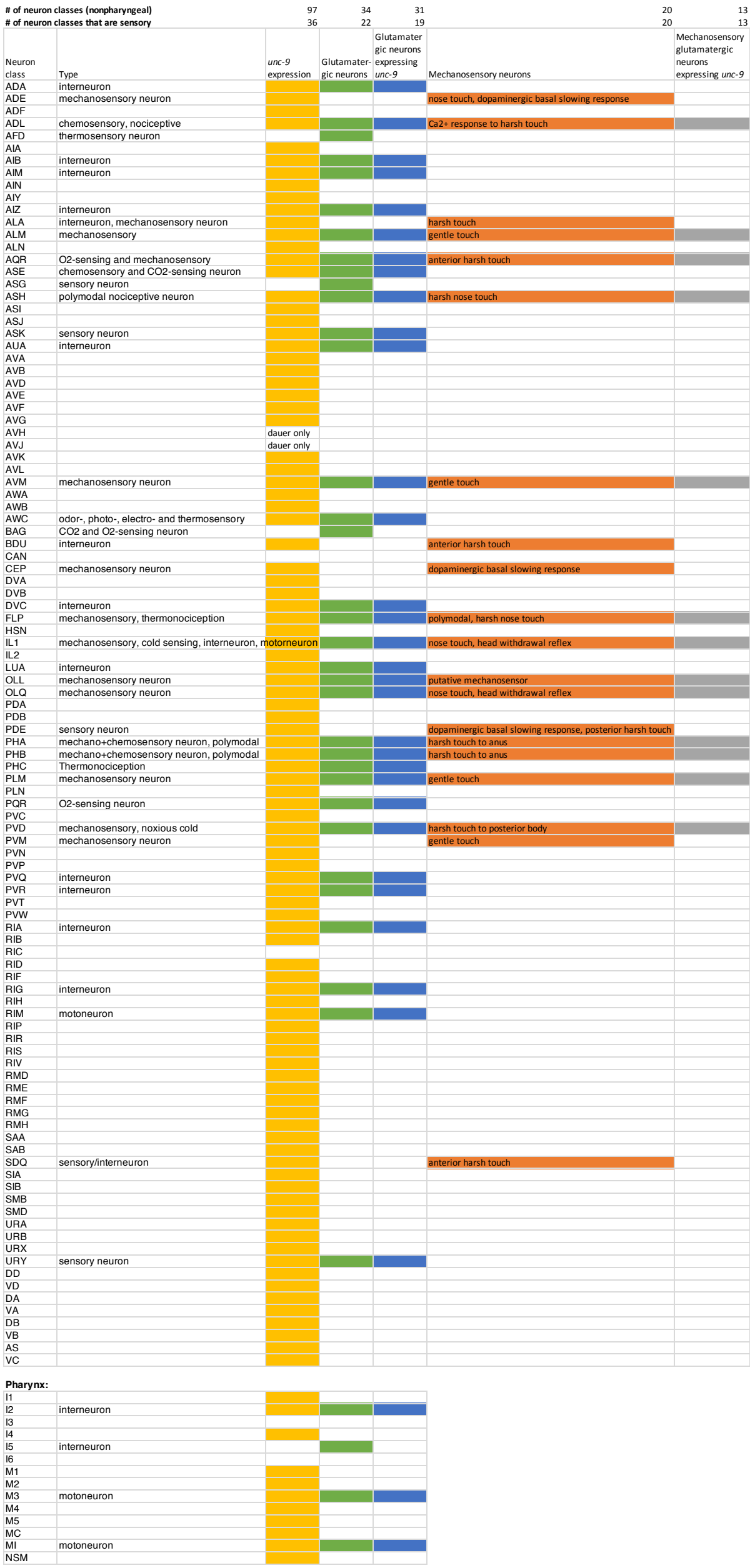




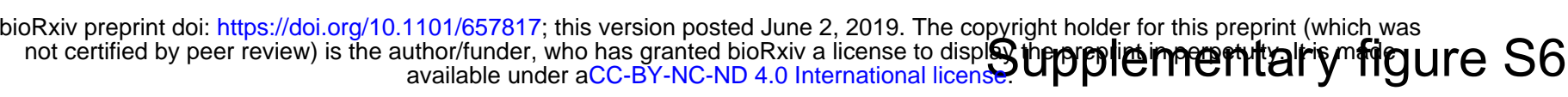

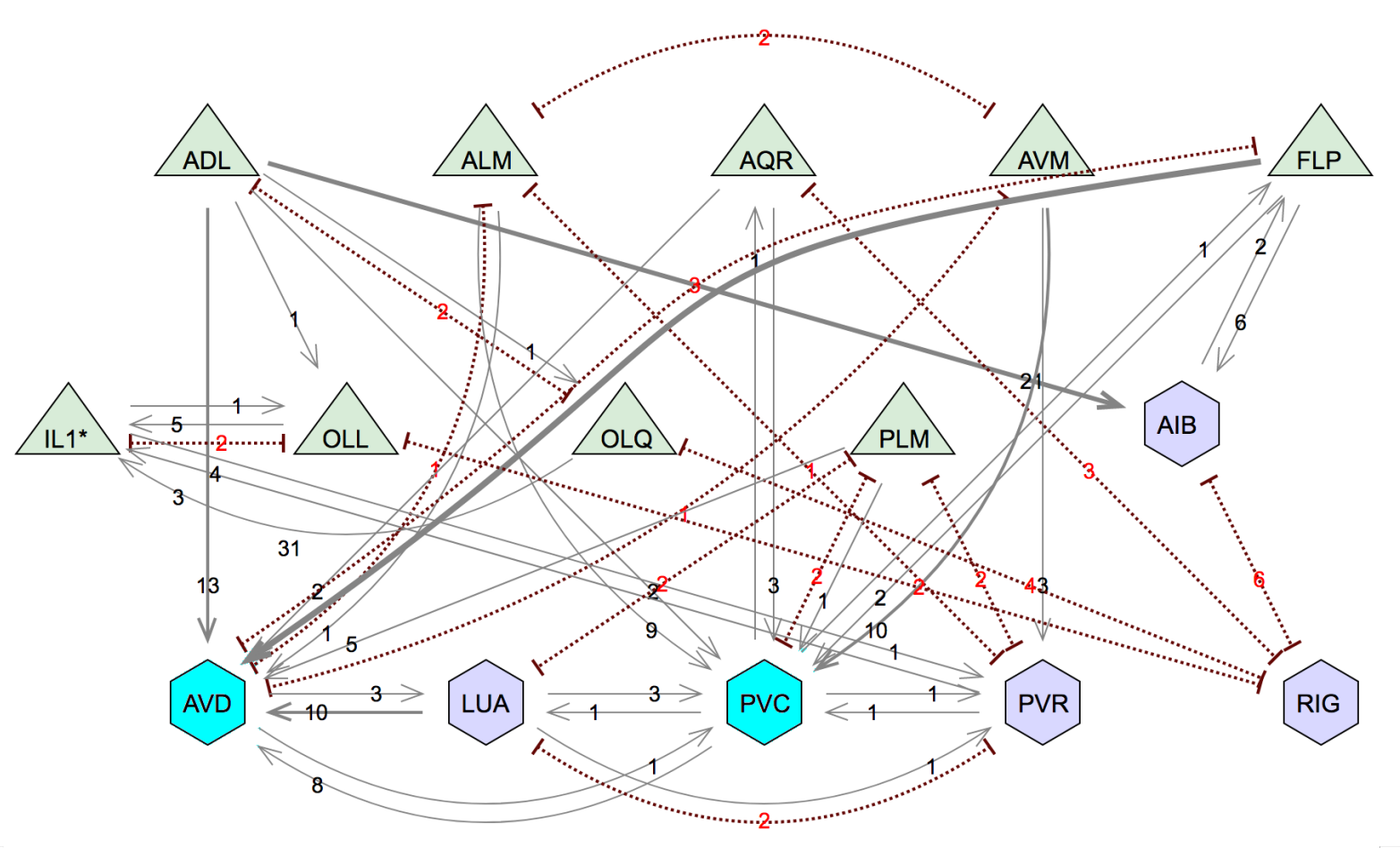

$$
{ }^{*} \text { ) Polymodal neuron: } \mathrm{IL} 1 \text { (se/mo). }
$$


bioRxiv preprint doi: https://doi.org/10.1101/657817; this version posted June 2, 2019. The copyright holder for this preprint (which was

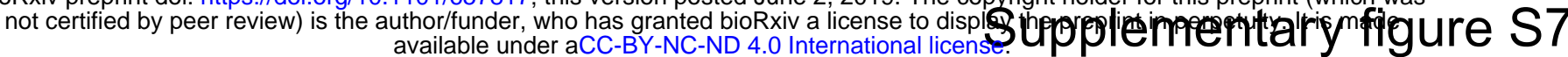

a

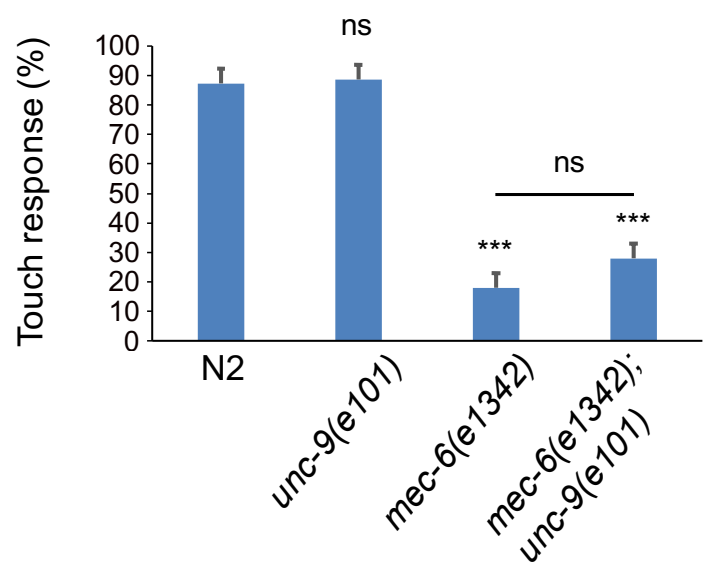

b

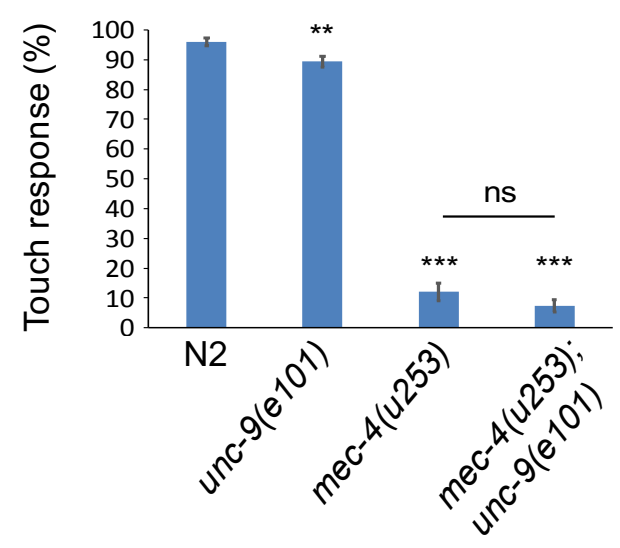


bioRxiv preprint doi: https://doi.org/10.1101/657817; this version posted June 2, 2019. The copyright holder for this preprint (which was

not certified by peer review) is the author/funder, who has granted bioRxiv a license to displQ 2 available under aCC-BY-NC-ND 4.0 International licens?

a

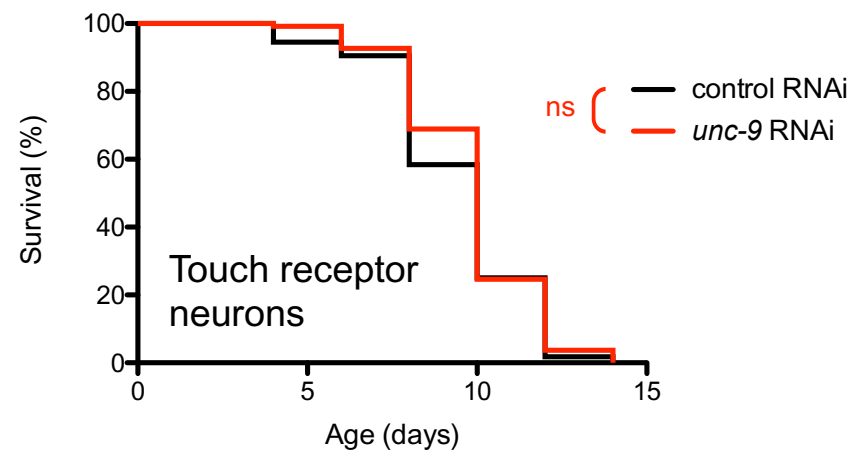

b

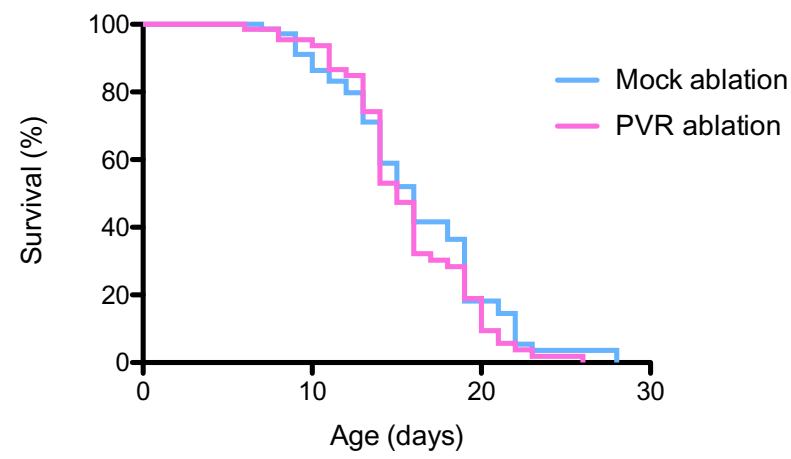


a

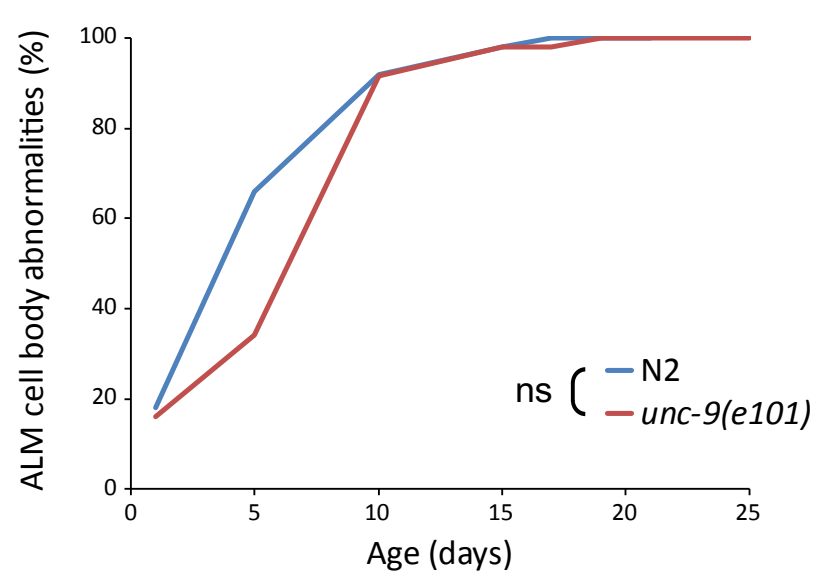

b

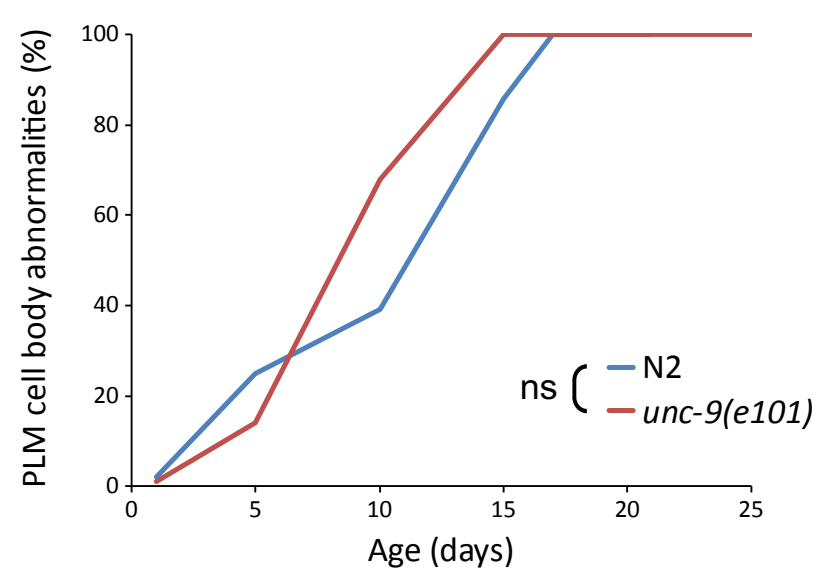




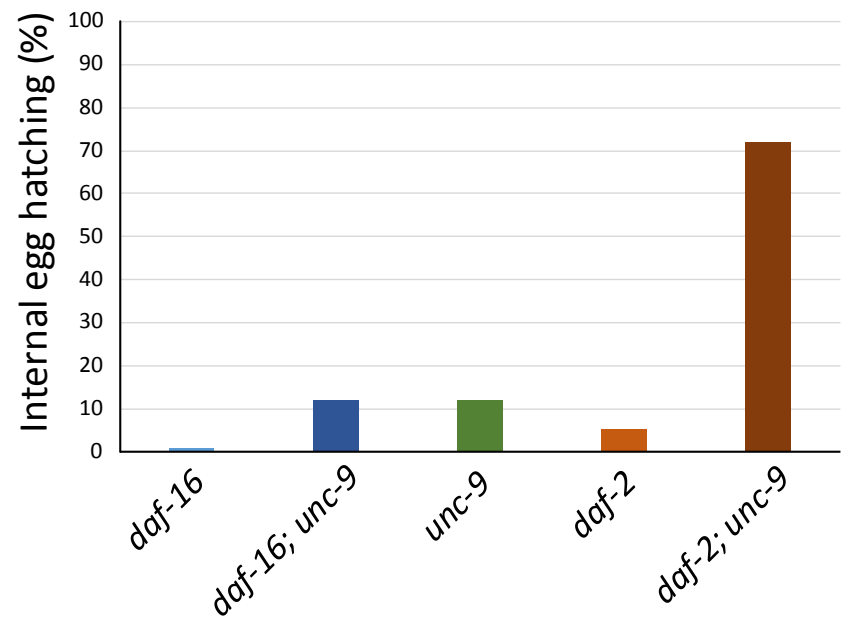


bioRxiv preprint doi: https://doi.org/10.1101/657817; this version posted June 2, 2019. The copyright holder for this preprint (which was

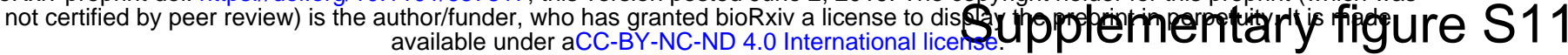

a

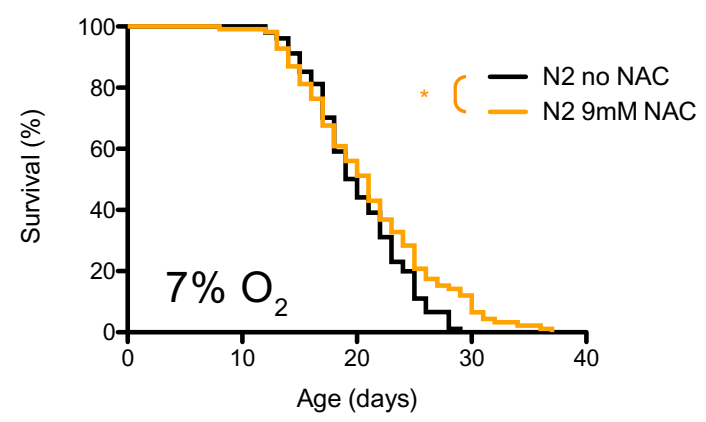

b

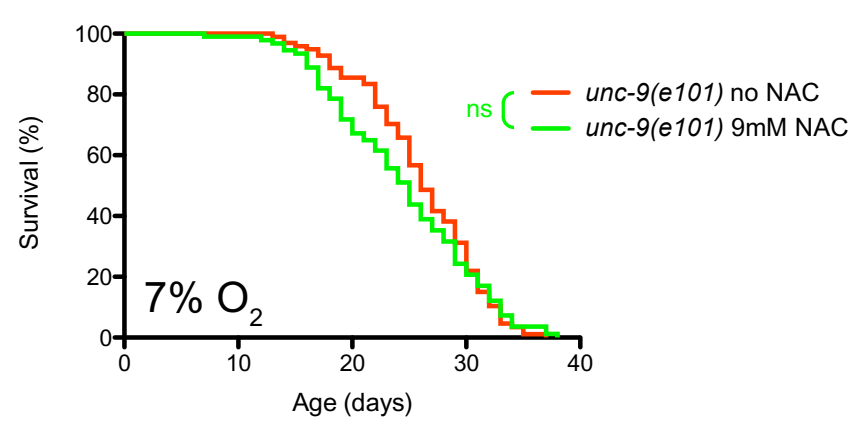

